\title{
GUÍA PRÁCTICA DEL VÉRTIGO POSICIONAL PAROXÍSTICO BENIGNO
}

\section{Practical guideline for Benign Paroxysmal Positional Vertigo}

José Ignacio BENITO-OREJAS ${ }^{1}$; María PONCELA-BLANCO²; Laura DÍEZ-GONZÁLEZ²; Rafael ÁLVAREZ-OTERO2; Gabriel AGUILERA-AGUILERA3; Jean Franco INTRAPRENDENTEMARTINI'; Erwin RACINES-ALAVA ${ }^{3}$; Ramón MARTíNEZ3; María MARCO-CARMONA ${ }^{3}$; Hortensia SÁNCHEZ-GÓMEZ3; Raquel YÁÑEZ-GONZÁLEZ4; Rocío GONZÁLEZ-AGUADO5; Virginia FRANCO-GUTIÉRREZ ${ }^{5}$; Gloria GUERRA-JIMÉNEZ6; Ángel MAZÓN-GUTIÉRREZ ${ }^{5}$; Silvia GANCEDO ${ }^{7}$; Rafael PÉREZ7; Pablo SANTOS-GORJÓN" ${ }^{8}$ Carmen SÁNCHEZ-BLANCO ${ }^{8}$; Francisco José GARCÍA-PURRIÑOS ${ }^{9}$; Cristina GASCÓN-RUBIO ${ }^{10}$; Fernando SALAZAR ${ }^{11}$; Michael BAUER ${ }^{1}$; José VALDA-RODRIGO12; Eduardo MENA-DOMÍNGUEZ13; Gabriel TRINIDAD-RUIZ14; Ángel BATUECAS-CALETRÍO ${ }^{3}$

Comisión de Otoneurología de la Sociedad Otorrinolaringológica de Castilla y León, Cantabria y La Rioja. España.

${ }^{1}$ Hospital Clínico Universitario de Valladolid Valladolid; ${ }^{2}$ Complejo Asistencial Universitario de Palencia. Hospital Río Carrión. Palencia; ${ }^{3}$ Complejo Asistencial Universitario de Salamanca. IBSAL. Salamanca; ${ }^{4}$ Complejo Asistencial de Zamora. Hospital Virgen de la Concha. Zamora; ${ }^{5}$ Hospital Universitario Marqués de Valdecilla. Santander; ${ }^{6} \mathrm{CHU}$ Insular Materno-infantil. Las Palmas de Gran Canaria; ${ }^{7}$ Complejo Asistencial universitario de León. León; ${ }^{8}$ Complejo Asistencial de Ávila. Hospital Nuestra Señora de Sonsoles. Ávila; ${ }^{9}$ Hospital Universitario Los Arcos Del Mar Menor. San Javier. Murcia; ${ }^{10}$ Hospital Reina Sofía. Tudela. Navarra; ${ }^{11} \mathrm{Hospital}$ de San Pedro. Logroño. La Rioja; ${ }^{12}$ Complejo Asistencial universitario de Burgos. Burgos, ${ }^{13}$ Hospital de Santa Bárbara. Puertollano. Ciudad Real; ${ }^{14}$ Complejo Hospitalario Universitario de Badajoz. Badajoz

Correspondencia: abatuc@yahoo.es

Fecha de recepción: 17 de enero de 2017

Fecha de aceptación: 14 de febrero de 2017

Fecha de publicación: 18 de febrero de 2017

Fecha de publicación del fascículo: 1 de septiembre de 2017

Conflicto de intereses: Los autores declaran no tener conflictos de intereses

Imágenes: Los autores declaran haber obtenido las imágenes con el permiso de los pacientes

Política de derechos y autoarchivo: se permite el autoarchivo de la versión post-print (SHERPA/RoMEO)

Licencia CC BY-NC-ND. Licencia Creative Commons Atribución-NoComercial-SinDerivar 4.0 Internacional

Universidad de Salamanca. Su comercialización está sujeta al permiso del editor

RESUMEN

Introducción y Objetivo: El vértigo periférico más frecuente es el Vértigo Posicional Paroxístico Benigno (VPPB), caracterizado por bruscos ataques de sensación rotatoria, que aparecen como consecuencia de determinados cambios en la posición de la cabeza con relación a la gravedad. La observación del nistagmo posicional es fundamental para el diagnóstico de VPPB. El tratamiento consiste en aplicar maniobras de reposición, para intentar trasladar los restos otoconiales libres, desde el conducto semicircular (CS) afectado hasta el utrículo. Esta guía, está orientada para quienes tratan el VPPB, con la intención práctica de ayudarles en el 
diagnóstico y tratamiento de esta enfermedad. Método: La experiencia y el análisis de diferentes acuerdos nacionales e internacionales sobre el VPPB, han permitido a un amplio grupo de especialistas ORL llevar a cabo esta guía. Resultados: Se revisan las diferentes entidades clínicas. VPPB del conducto semicircular posterior (CSP), horizontal (CSA) y anterior (CSA), incluyéndose también el VPPB multicanal, VPPB atípico y central, VPPB subjetivo y las características de este proceso en el anciano. Las maniobras de reposición se han ilustrado con dibujos explicativos. Discusión y conclusiones: Aunque la fisiopatología del VPPB se explica por la presencia de restos otoconiales libres en la endolinfa de uno o varios conductos semicirculares (canalitiasis) y en algunos casos por su adherencia a la cúpula del CS (cupulolitiasis), aún quedan muchas cuestiones por resolver. Pero creemos que la mejor manera de encontrar respuestas parte de utilizar una metodología común en el diagnóstico y tratamiento de estos pacientes.

PALABRAS CLAVE Vértigo posicional paroxístico benigno; vértigo; nistagmo; diagnóstico; tratamiento; mareo

SUMMARY

Introduction and objective: Benign paroxysmal positional vertigo (BPPV) is the most common peripheral vertigo, characterized by brief attacks of rotatory vertigo associated with nystagmus, which are elicited by specific changes in head position relative to gravity. The observation of positional nystagmus is essential for the diagnosis of BPPV. The treatment consists in maneuvers of canalith repositioning procedure to move otoconial debris from the affected semicircular canal to the utricle. These guidelines are intended for all who treat the BPPV in their work, with an intention to assist in the diagnosis and application of an appropriate therapeutic method. Method: The experience and analysis of different national and international consensus on BPPV, has allowed to a large group of ENT specialists carry out this guide. Results: The different clinical entities are reviewed. BPPV of the posterior semicircular canal, horizontal canal and anterior canal, BPPV affecting several canals, atypical and central BPPV, subjective BPPV and the characteristics of this process in the elderly. Canalith repositioning procedures have been illustrated with explanatory drawings. Discussion and conclusions: Although the pathophysiology of BPPV is canalolithiasis comprising free-floating otoconial debris within the endolymph of a semicircular canal, or cupulolithiasis comprising otoconial debris adherent to the cupula, there are still many issues to be resolved. We think that the best way to find answers is part of using a common methodology in the diagnosis and treatment of these patients.

\section{INTRODUCCIÓN [1-9]}

El vértigo posicional paroxístico benigno (VPPB) es el trastorno vestibular más frecuente. Probablemente, la enfermedad se origina por la acumulación de un material litiásico procedente de la membrana otolítica del utrículo. Aunque a veces se relaciona con un traumatismo craneal o tras adoptar de forma prolongada una posición recostada (dentista, peluquero) y con algunas alteraciones del oído interno, generalmente es de causa desconocida. Los pacientes sufren múltiples crisis de vértigo, que duran segundos, sobre todo al acostarse o darse la vuelta en la cama.

Existen varias formas clínicas que pueden afectar al conducto semicircular posterior (CSP), horizontal/lateral (CSH) o anterior/superior (CSA) e incluso en algunos casos, a varios conductos simultáneamente, del mismo o de ambos lados (bilateral). Se asocian a un nistagmo característico, que se desencadena con determinados procedimientos. Para cada variante clínica hay maniobras terapéuticas específicas con elevada efectividad a corto plazo. El porcentaje de recurrencia anual es de al menos el $15 \%$.

\section{EPIDEMIOLOGÍA}

Se estima que la prevalencia a lo largo de la vida en la población adulta es del $2,4 \%$, mientras que la incidencia anual es del 0,6\%. La edad de inicio se sitúa en torno a los 50 años y la incidencia aumenta con la edad, alcanzando el $10 \%$ a los 80 años. También predomina en las mujeres. El VPPB no reconocido podría alcanzar una prevalencia del $9 \%$.

La duración media de cada suceso es de unas 2 semanas, aunque un tercio de los pacientes refiere que el vértigo continuó más de 1 mes.

La enfermedad se limita a un episodio aislado en el $44 \%$ de los casos, mientras que en el 56 $\%$ las crisis de vértigo son recurrentes.

\section{FISIOPATOLOGÍA}

La hipótesis que intenta explicar la fisiopatología del VPPB está basada en una combinación de observaciones clínicas, histopatológicas y en la experimentación fisiológica. La microscopia electrónica ha confirmado que los canalitos están formados por otoconias.

Inicialmente se postuló, que las otoconias desprendidas de la mácula del utrículo, entrarían en los conductos semicirculares (CS) y se 
agregarían alrededor de la cúpula; situación que se denominó cupulolitiasis. Actualmente se considera más probable que los restos de otoconias se desplacen hacia el brazo largo del conducto, lo que se conoce como canalitiasis. Estos residuos pueden aglomerarse y adquirir una masa crítica donde la gravedad desencadena el que se muevan con los cambios de posición de la cabeza, en el plano del conducto afectado. Este flujo inapropiado de endolinfa ocasiona un desplazamiento de la cúpula, responsable de los ataques de vértigo posicional y del nistagmo. Se ha demostrado mediante análisis vectorial del eje de rotación del nistagmo posicional que se pueden afectar cualquiera de los tres CS, e incluso como hemos dicho, participar simultáneamente varios. El nistagmo posicional consecuente a esta situación viene caracterizado por la dirección, la latencia (tiempo que transcurre desde que la cabeza se sitúa en la posición de provocación y se inicia el nistagmo), su duración o fatiga (que se evidencia cuando la velocidad del nistagmo disminuye y el intervalo entre sacudidas nistágmicas aumenta) y la habituación o adaptación de la respuesta con la repetición de la prueba.

Finalmente, algunos estudios demuestran que el VPPB puede asociarse a una disfunción utricular y en ocasiones a una paresia vestibular tanto de los canales horizontales como de los verticales.

Aviso

- EI VPPB podría también desencadenarse si las otoconias se disponen en el brazo corto del CS (lado utricular de la cúpula).

- Cabe la posibilidad de que se produzca simultáneamente en el mismo CS, una cupulolitiasis y una canalitiasis.

- A veces se observa un nistagmo espontáneo que bate en la dirección que corresponde a la estimulación de un CS, con independencia de la posición de la cabeza, en pacientes que, por otra parte, cumplen los criterios diagnósticos de cupulolitiasis o canalitiasis. Suele ser un hallazgo de breve duración, después de una maniobra terapéutica, aunque también se ha visto espontáneamente y se supone que podría ser causado por un bloqueo de la cúpula.

- Finalmente, se han descrito casos de nistagmo posicional geotrópico de dirección cambiante y persistente, que una vez des- cartada la alteración neurológica, se especula que pudieran deberse a cambios en la densidad de la cúpula o la endolinfa o a déficit de vitamina $D$.

\section{DIAGNÓSTICO CLÍNICO}

Los pacientes relatan el VPPB como un ataque de vértigo rotatorio de unos segundos de duración, precipitado por ciertos movimientos o cambios de posición de la cabeza. Los más comúnmente referidos son el giro en la cama, la extensión del cuello o la inclinación de la cabeza hacia delante. En ocasiones se identifica el lado afecto (por ejemplo, aparece vértigo cuando se gira en la cama a la derecha, pero no a la izquierda, lo que indica que el oído derecho está involucrado).

La crisis de vértigo suele ser de 10 a 30 s, aunque algunos la perciben durante más tiempo, probablemente porque sobrevaloren esta duración. A veces padecen varios episodios separados entre sí, que pueden referir como uno solo y otras, se centran en describir las náuseas, el mareo o el desequilibrio que persiste horas después de una crisis, lo que dificulta el diagnóstico. Aunque el $80 \%$ cuenta una sensación rotatoria, hasta el $47 \%$ refiere sensación de flotación. Los episodios de vértigo pueden manifestarse durante varias semanas $(23 \%)$ o resolverse en el curso de un día (52\%). Los pacientes afectados tienen mayor riesgo de caídas.

EI VPPB también se puede manifestar con la neuritis vestibular, la migraña o a la enfermedad de Ménière, asociándose en un $25 \%$ con hipofunción vestibular calórica. En estos casos se solicitan otras pruebas vestibulares y/o audiológicas.

El diagnóstico completo incluye especificar el CS afecto y la fisiopatología (cupulolitiasis o canalitiasis), lo que en teoría podría generar 6 combinaciones por cada oído, además de la afectación múltiple. Sin embargo, no se ha descrito la cupulolitiasis del CSA. La maniobra de provocación en el plano del CS afecto evoca un nistagmo posicional que puede observarse directamente o con la ayuda de las gafas de Frenzel o en casos complejos, de la video-oculografía. EI CSP es el más frecuentemente afectado (80-90\%), seguido del horizontal (5-30\%), siendo muy raro el vértigo posicional del CSA (1-2\%).

La exploración debe responder a las siguientes preguntas: ¿cuál es el oído afecto?, ¿en 
qué CS está el problema?, ¿cuál es el mecanismo fisiopatológico que explica el VPPB?, para finalmente, poder aplicar la maniobra de reposición más adecuada.

\section{EXPLORACIÓN Y ACTITUD}

La exploración otoneurológica del paciente con VPPB no debe diferenciarse de la del resto de pacientes que acuden a una consulta de otoneurología. Aunque la anamnesis suele ponernos en la pista ante la presencia de un VPPB, no deben excluirse las pruebas de provocación en la exploración del enfermo que no cuenta una clínica de VPPB. Esto se da de forma frecuente en los ancianos, que suelen referir inestabilidad en lugar de giro de objetos con los cambios de posición.

En el VPPB se debe explorar la presencia de nistagmo espontáneo, tanto con fijación visual como sin ella, con el paciente en sedestación. Un $10 \%$ de los pacientes con neuritis vestibular desarrollan un VPPB y en muchos de ellos, cuando aparece el VPPB aún no se ha producido el proceso de compensación vestibular y pueden presentar un nistagmo espontáneo. Es muy importante conocer la existencia de un nistagmo espontáneo en sedestación antes de realizar la maniobra de provocación, ya que la presencia de ese nistagmo puede confundirnos a la hora de identificar el canal responsable del VPPB.

La motilidad ocular, el seguimiento y las sacadas son otras exploraciones que también deben realizarse en estos enfermos.

Desde el punto de vista oculomotor, la maniobra más importante es la maniobra de impulso oculocefálico. Es necesario recordar que hasta un $25 \%$ de los pacientes con VPPB tienen un déficit vestibular homolateral mantenido. Un resultado positivo de esta maniobra indica la presencia de un gran déficit vestibular en el lado correspondiente.

Son obligatorias las pruebas de los índices, Romberg y marcha, en el estudio del reflejo vestíbulo espinal.
No se aconseja, ante la sospecha de un VPPB, la realización de la maniobra de agitación cefálica o la vibración mastoidea, ya que estímulos de este tipo pueden alterar la exploración del nistagmo correspondiente al VPPB.

La metodología más académica para la exploración (Figura 1) de un paciente con la sospecha de VPPB sugiere iniciarla por el canal semicircular superior/anterior (CSA), realizando una maniobra de hiperextensión cefálica. Esto es así porque, en ocasiones, el nistagmo que genera un VPPB del CSA es muy tenue, y se agota ante la repetición de las maniobras, con lo que, si se llega al CSA después de haber examinado el CSP y el CSH, la exploración puede haberse negativizado.

Si tras hiperextender la cabeza no se objetiva nistagmo, procederemos con la exploración del $\mathrm{CSH}$, mediante la maniobra de McClure. Al estar el paciente en decúbito supino, no es necesario incorporarle para realizar dicha maniobra, economizando movimientos que pueden facilitarnos la exploración. Si también resultara negativa, incorporaremos al enfermo para realizar el Dix-Hallpike. EI CSP debería ser el último en explorarse.

Hay autores que defienden que como el VPPB de CSP es el más frecuente (casi $90 \%$ de los casos), la exploración debe comenzar por ahí, pero en el caso de que el canal afecto fuera otro, la exploración puede estar condicionada. ¿Debemos detenernos cuando encontramos una exploración positiva para un canal? Evidentemente no. Lo correcto es explorar todos los canales, aunque en el sentido del comentario anterior, hay autores que abogan por, una vez hallado el canal afecto, realizar directamente la maniobra de reposición de partículas. Este hecho puede hacer que obviemos otros canales o incluso que dejemos de diagnosticar VPPB atípicos, o centrales.

A todos los pacientes con VPPB se les debe realizar una audiometría. 
Guía PRÁctica del VÉRTIgo Posicional PAROXístico BENIGNO BENITO-OREJAS JI ET AL.

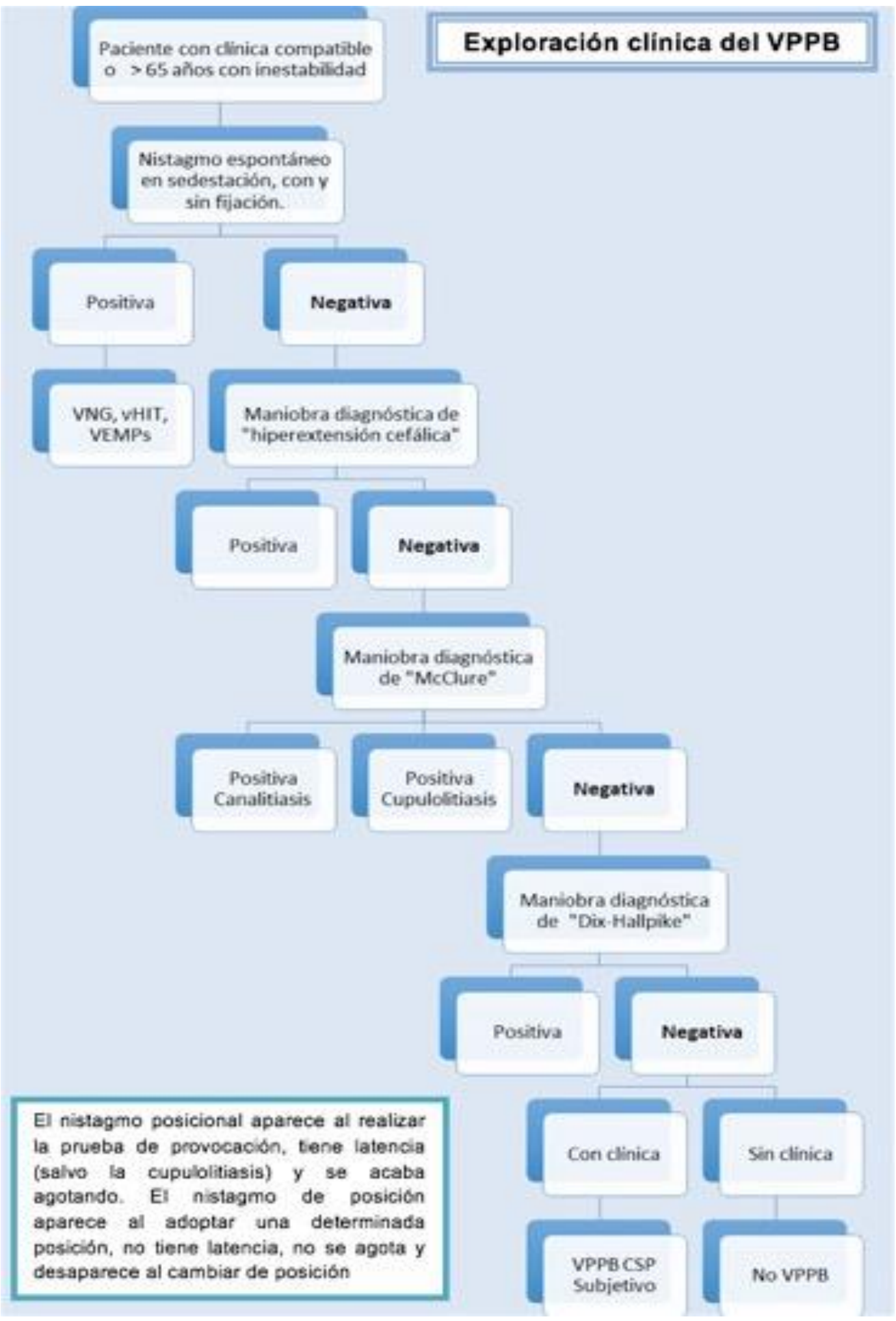

Figura 1. Toma de decisiones ante un enfermo con cínica sugerente de vértigo posicional paroxístico benigno. 


\section{ABORDAJE PRÁCTICO DEL VPPB APARTADOS}

1. VPPB del conducto semicircular posterior (CSP)

2. VPPB del conducto semicircular horizontal/lateral (CSH)

3. VPPB del conducto semicircular anterior/superior (CSA)

4. VPPB multicanal.

5. VPPB atípico y central.

6. VPPB subjetivo.

7. VPPB en el anciano.

8. Seguimiento y recurrencia del paciente con VPPB.

\section{VPPB DEL CONDUCTO SEMICIRCULAR POSTERIOR (CSP) [3-9]}

\section{CARACTERÍSTICAS GENERALES}

El VPPB del CSP es el más frecuente (60$90 \%$ ), quizá por ser el más dependiente de la gravedad.

\section{DIAGNÓSTICO}

La maniobra de Dix-Hallpike se considera la prueba gold standard para el diagnóstico de VPPB del CSP. Su sensibilidad y especificidad son del $82 \%$ y $71 \%$ respectivamente, pero debido al bajo valor predictivo (52\%) la maniobra negativa no descarta un VPPB del CSP, sugiriéndose su repetición siempre que persista la sospecha clínica de VPPB.

La maniobra de Dix-Hallpike se inicia explorando el lado que se supone sano. Se coloca al paciente sentado sobre la camilla con la cabeza girada $45^{\circ}$ hacia el oído a explorar. En esta posición el CSP se dispone alineado con el eje vertical de la gravedad. A continuación, se tumba al paciente colocando la cabeza por debajo del plano horizontal (cabeza colgando). Durante la maniobra, el plano del CSP contralateral se sitúa perpendicular a la gravedad, por lo que no se estimula. Una vez que el movimiento de la cabeza se ha completado, tras unos pocos segundos (2 a 5 s.), aparece el vértigo rotatorio y el nistagmo, que se incrementan y disminuyen hasta desaparecer en unos 30 segundos. Figuras 2, 3 y 4 .

\section{Aviso}

- La maniobra de Dix-Hallpike se debe evitar en caso de obesidad mórbida, patología cervical severa, síndrome de Down y sospecha de insuficiencia vertebrobasilar. En estos casos se realiza la maniobra de Semont, que consiste en colocar al paciente sentado en el lateral de la camilla, con la cabeza girada $45^{\circ}$ hacia el lado no explorado, y desde esta posición moverle rápidamente colocándole tumbado con el oído contrario en la posición más baja. En esta postura se produciría la misma corriente endolinfática utriculífuga que en la maniobra de Dix-Hallpike.

- Cupulolitiasis del CSP. En algunos casos se puede sospechar una cupulolitiasis del CSP, donde las otoconias están adheridas a la cúpula. Sospecharemos este caso cuando al realizar la maniobra de Dix-Hallpike aparezca un nistagmo sin latencia, con clínica acompañante, que dura >1 minuto. En muchos casos pueden combinarse tanto la canalitiasis como la cupulolitiasis del CSP.

\section{HALLAZGOS NISTÁGMICOS}

El nistagmo que aparece al realizar la maniobra de Dix-Hallpike es debido a la corriente ampulífuga producida hacia la parte más inferior del CSP (hacia la cruz común con el CSA), que conlleva al desplazamiento de la cúpula en esa misma dirección, resultando una corriente excitatoria. En la vía disináptica excitoinhibitoria que conecta el CSP con los músculos oculares, se produce una estimulación del músculo oblicuo superior ipsilateral y del recto inferior contralateral, y una inhibición del músculo oblicuo inferior ipsilateral y del recto superior contralateral.

El resultado neto es una rotación lenta y antihoraria, si la estimulación es de la cresta ampular del CSP izquierdo, y horaria si la estimulación es derecha, con un componente vertical 
inferior. El nistagmo resultante es horario al estimular el CSP izquierdo y antihorario, al esti- mular el CSP derecho (por tanto, siempre geotrópico) con un componente vertical superior.

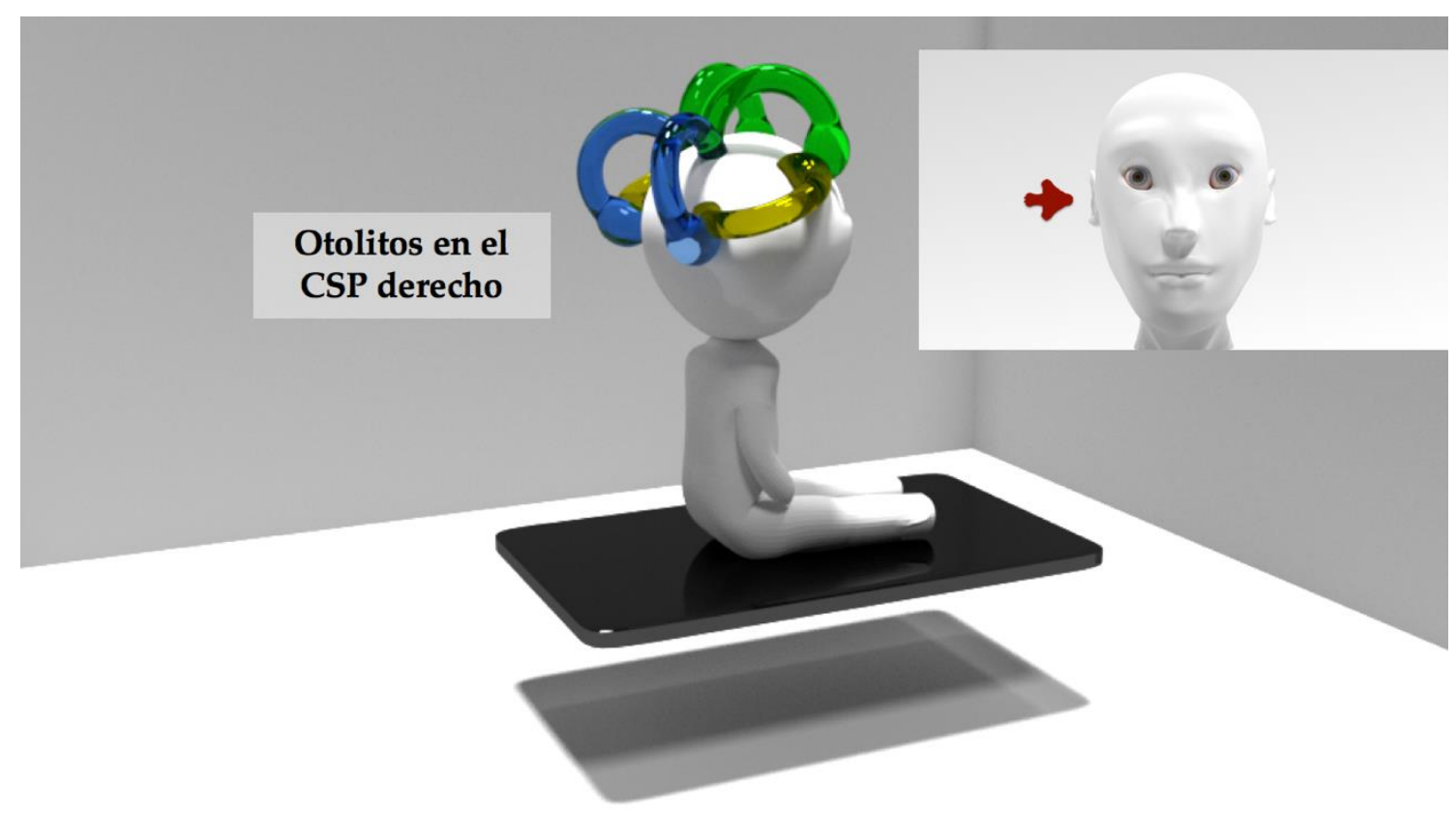

Figura 2. Posición inicial del paciente en la realización de la maniobra de Dix-Hallpike. El paciente permanece sentado sobre la camilla en la que se va a realizar la maniobra y se le gira la cabeza $45^{\circ}$ hacia el lado que se vaya a estudiar.

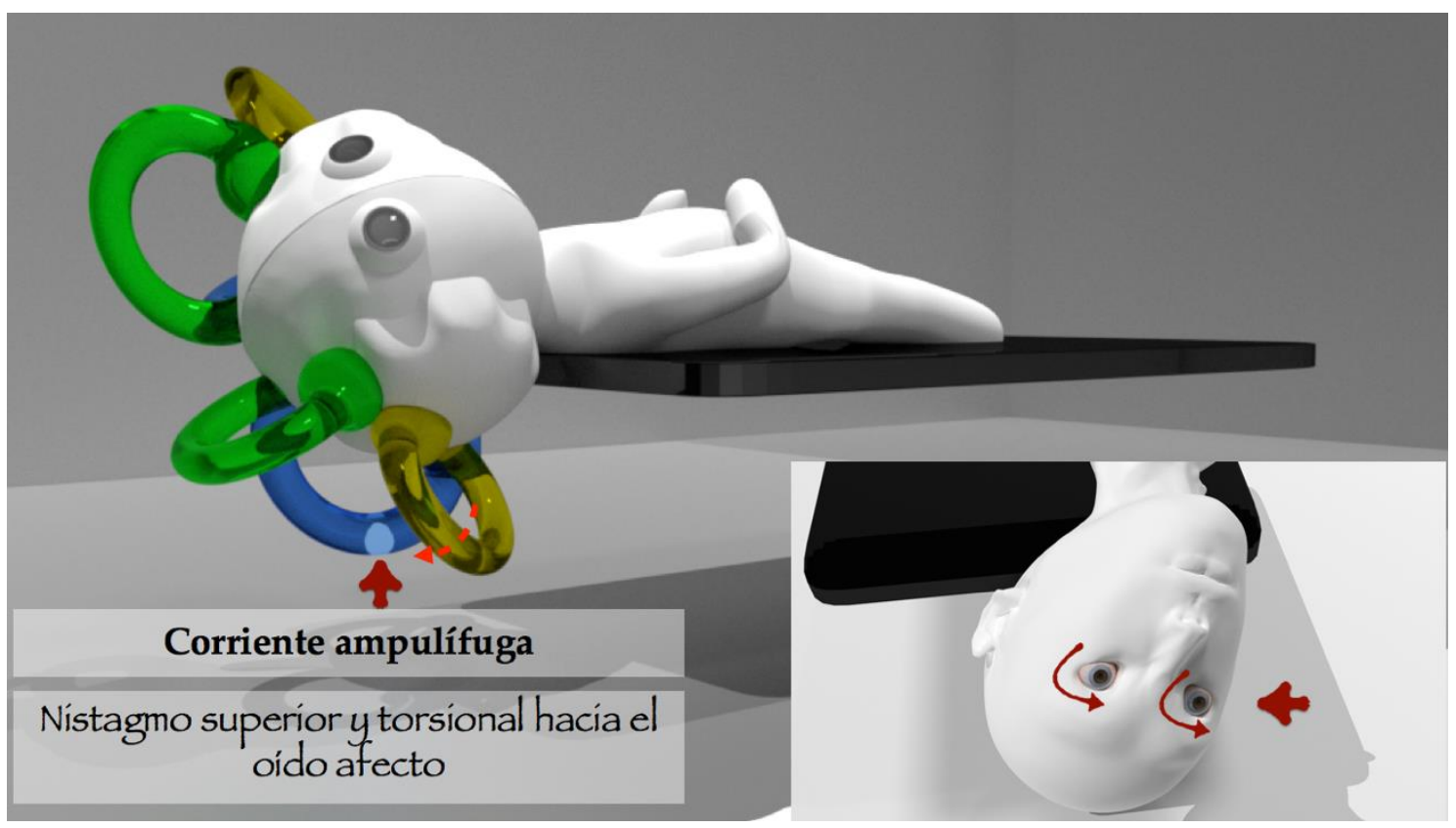

Figura 3. Con la cabeza girada 45ำ hacia el lado que se vaya a estudiar se desplaza al enfermo hacia atrás, pasando a la posición de decúbito supino. La posición ideal de la cabeza es $30^{\circ}$ por debajo de la horizontal. En esa posición se explora el nistagmo del enfermo. En el caso de presentar un VPPB de canal semicircular posterior, que es el que se explora, el paciente presentará una nistagmo rotatorio con un componente vertical superior de características antihorarias cuando se explore el lado derecho y horarias cuando se explore el lado izquierdo. 


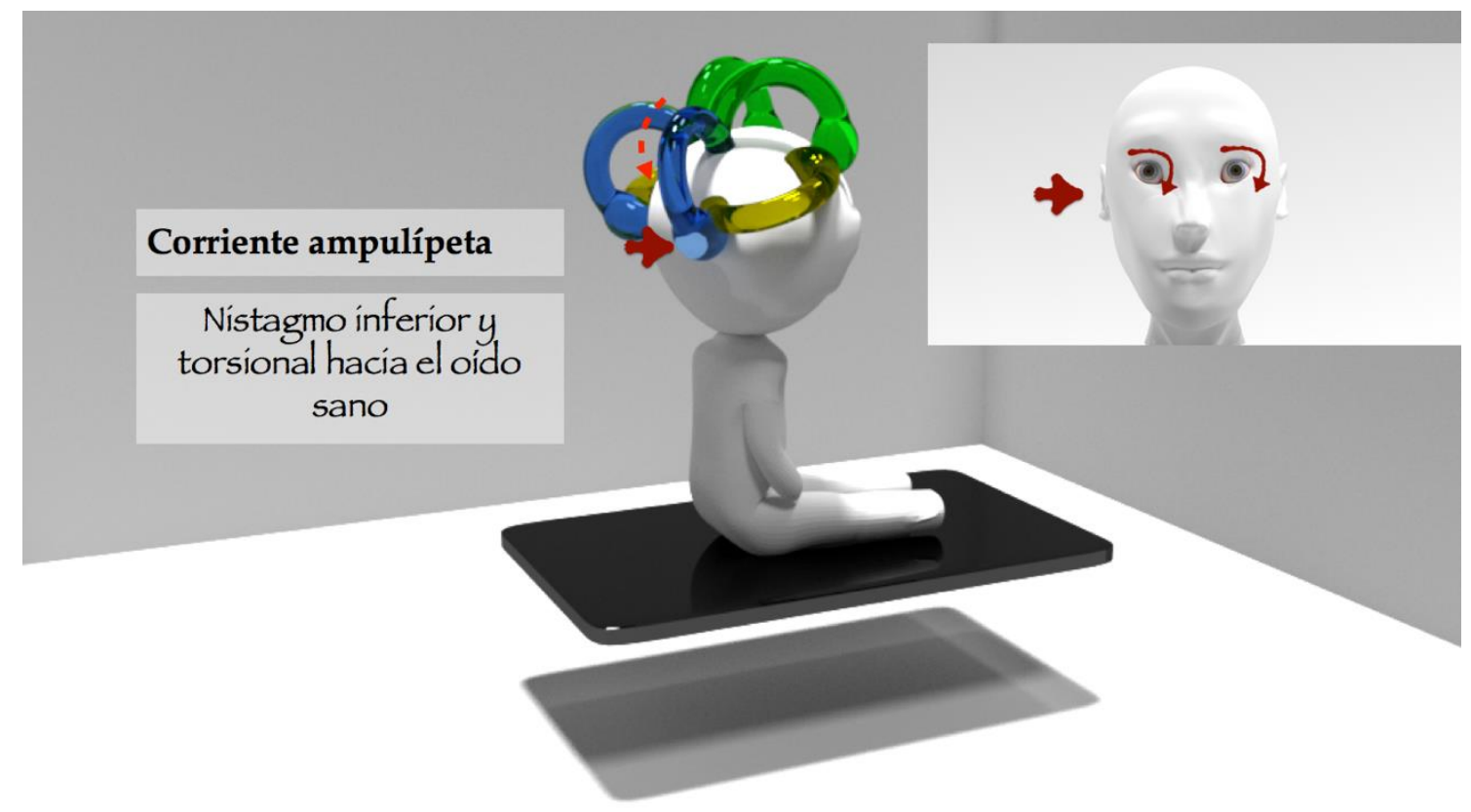

Figura 4. Tras agotarse el nistagmo, se devuelve al paciente a la posición inicial sentado. En esa posición se debe observar un nistagmo de características opuestas (Inverso) a las que se observaron cuando se realizó la posición anterior.

MANIOBRAS DE REPOSICIÓN DE PARTÍCULAS Las maniobras para recolocar las partículas del CSP son las descritas por Semont y Epley. Ambas están basadas en la misma idea de mover los otolitos a través del brazo largo del CSP y recolocarlas en el utrículo, utilizando la fuerza de la gravedad.

MANIOBRA DE EPLEY. Es la más utilizada. Se realiza sobre el oído afecto desde la posición de la cabeza colgando al realizar la prueba de Dix-Hallpike, manteniéndola durante unos 30 segundos tras la desaparición del nistagmo. A partir de esta posición, se gira la cabeza 90 grados hacia el otro lado, manteniéndola durante 1 minuto con independencia de que aparezca nistagmo. El tercer paso consiste en girar al paciente sobre el lado sano, en decúbito lateral, quedando con la cara mirando al suelo, durante otros 30 segundos. Después el paciente se sienta lentamente, con la cabeza flexionada $30^{\circ}$ hacia adelante. Es frecuente que durante la maniobra de reposición y las primeras 24 horas postratamiento, se experimente una sensación nauseosa 0 de inestabilidad (12\% de los pacientes). En un $7 \%$ de casos el VPPB del CSP puede convertirse en VPPB del $\mathrm{CSH}$. Figuras 5, 6, 7, 8 y 9. 


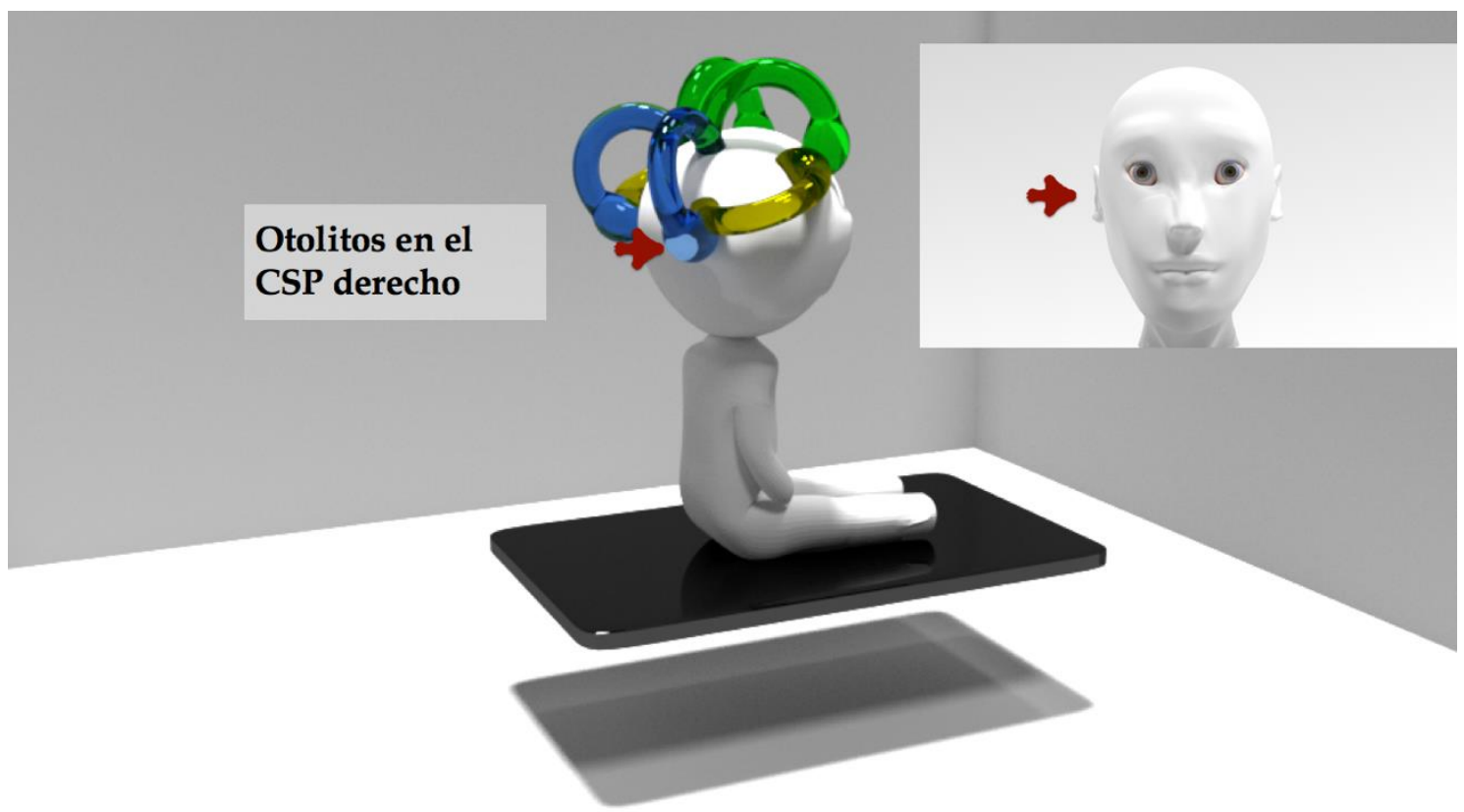

Figura 5. Primera posición de la maniobra de Epley. El paciente permanece sentado sobre la camilla.

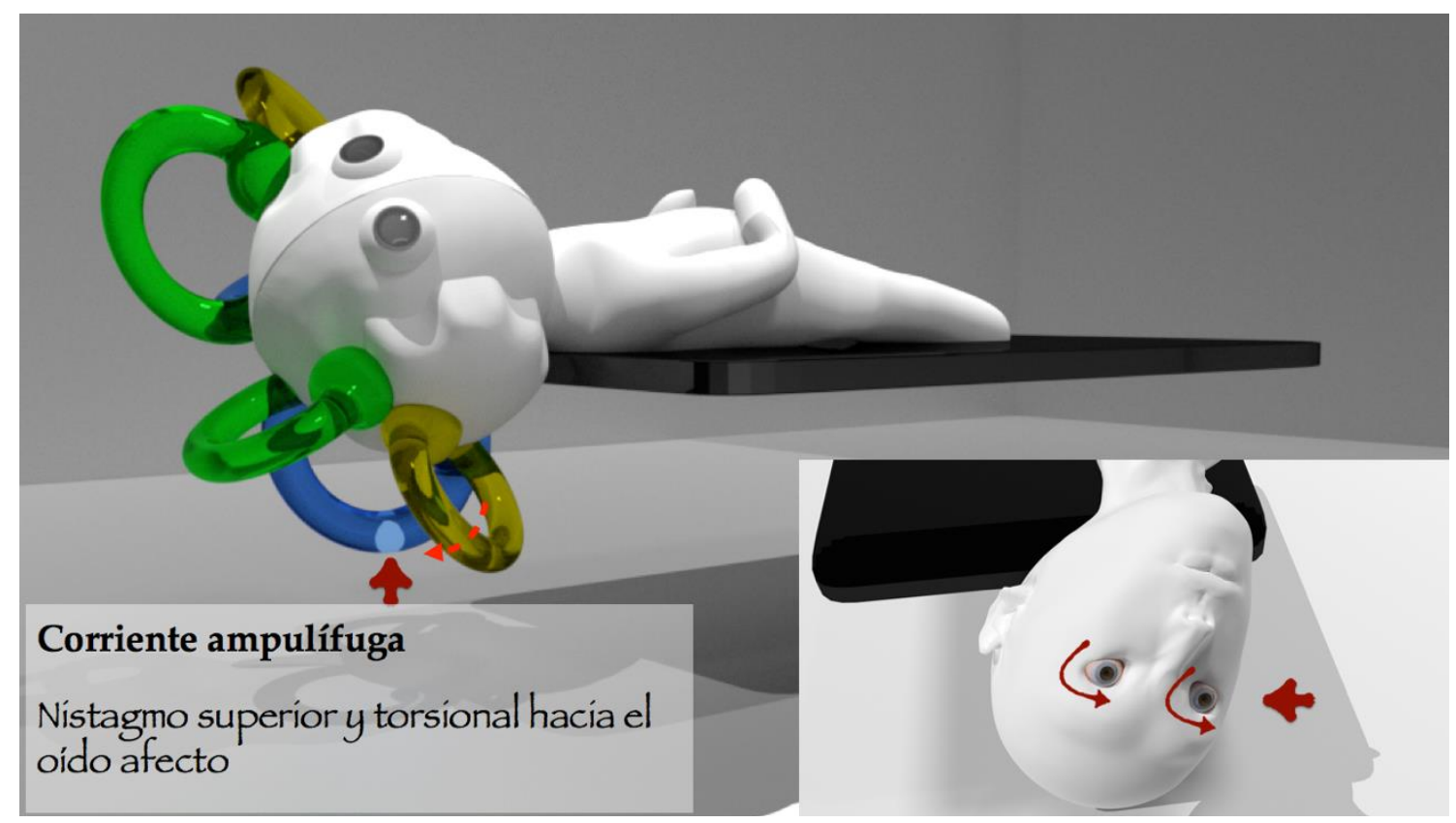

Figura 6. Esta posición coincide con la primera posición de la maniobra de exploración de Dix-Hallpike. Con la cabeza girada $45^{\circ}$ hacia el lado afecto en la posición de sentado, el paciente se desplaza hacia atrás, pasando a estar en decúbito supino, preferiblemente con la cabeza $30^{\circ}$ por debajo de la horizontal. El paciente debe permanecer en esa posición, al menos, hasta que desaparezca el nistagmo. Se recomienda que el paciente permanezca al menos 30 segundos en esa posición desde la finalización del nistagmo. 


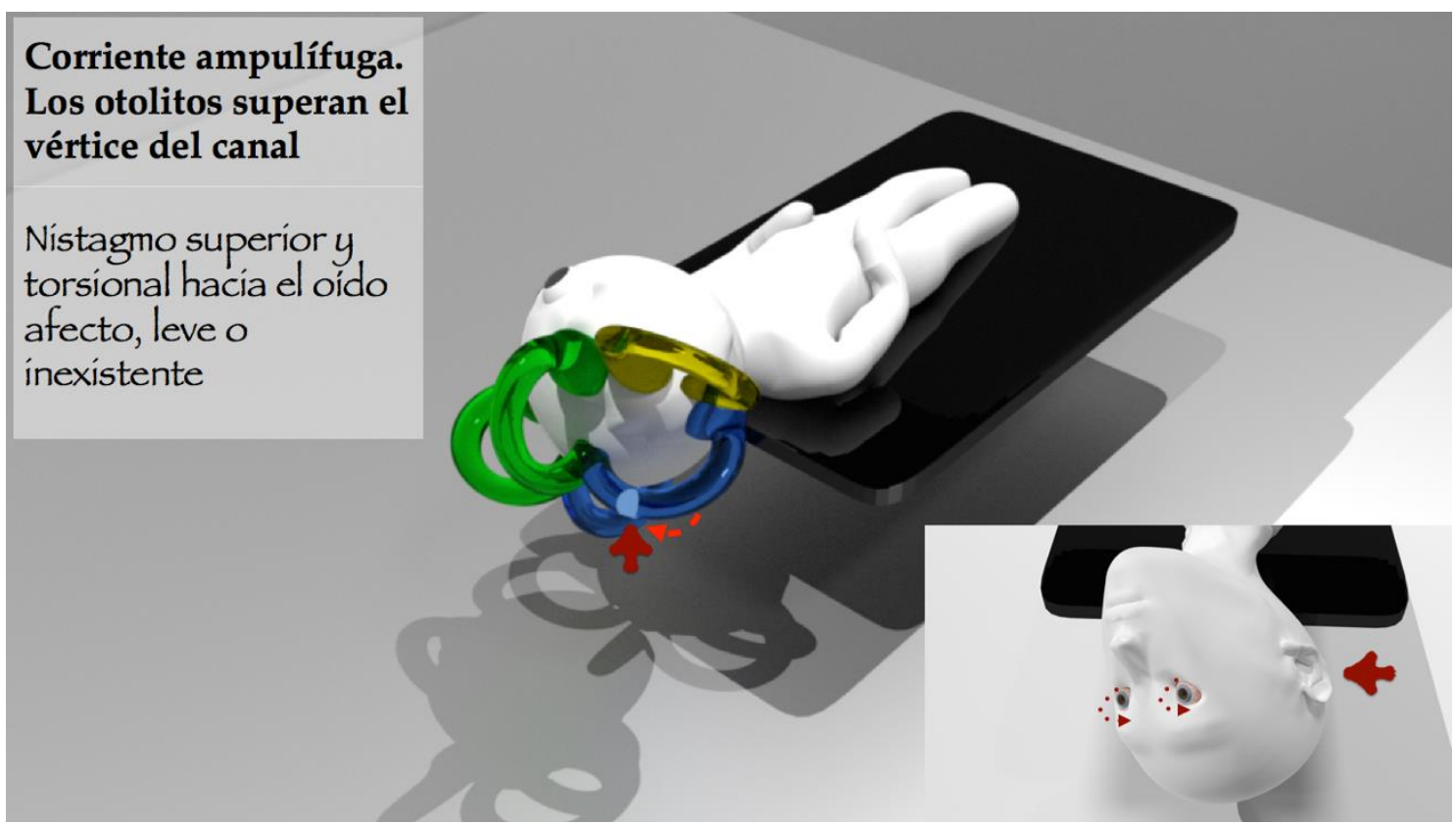

Figura 7. A continuación, se gira la cabeza del paciente hacia el lado opuesto, dentro de la posición de decúbito supino. En ocasiones se observa un nistagmo en esta segunda posición. Se denomina nistagmo ortotrópico y es semejante al observado en la primera posición. Según la mayoría de los autores se trata de un signo de buen pronóstico.

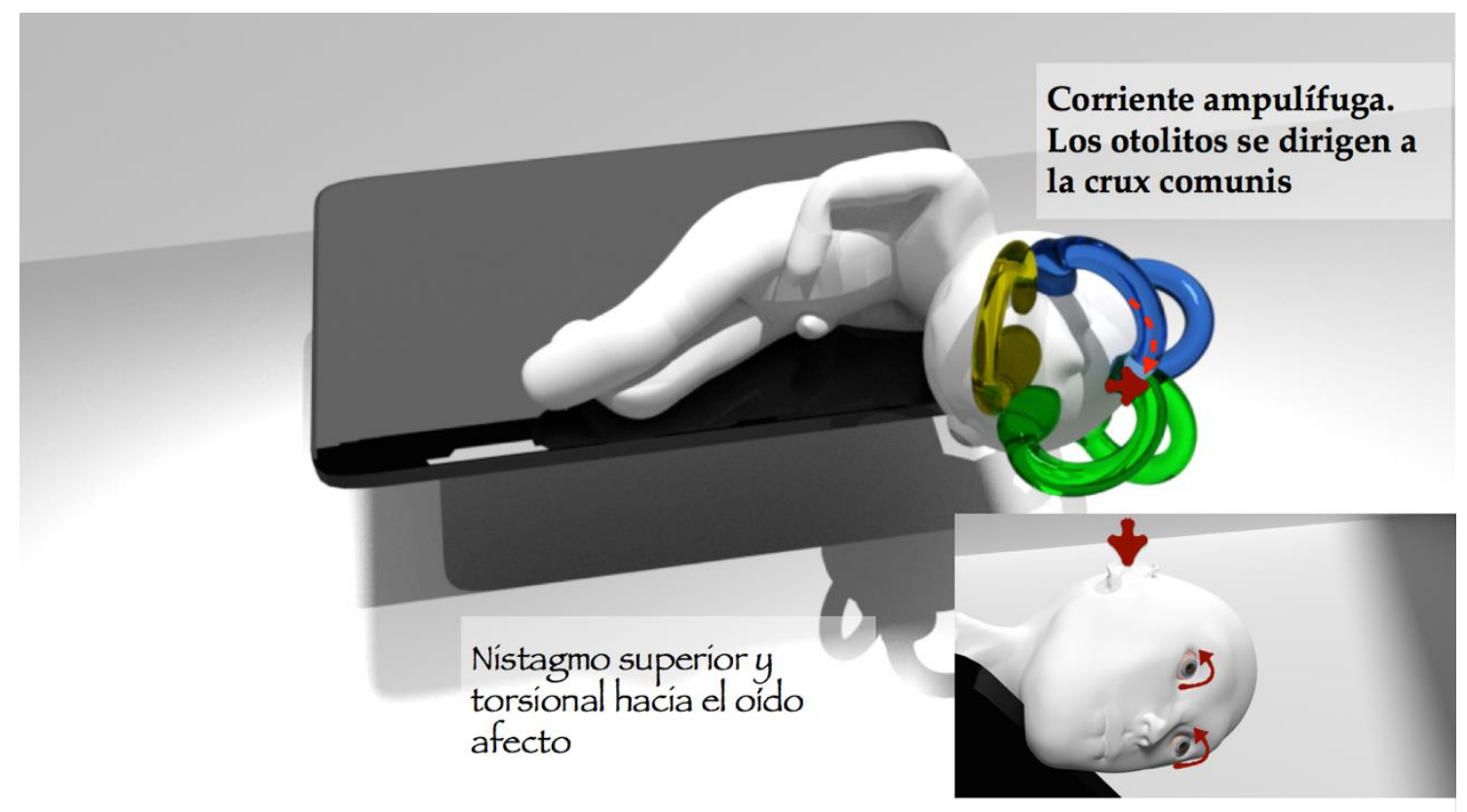

Figura 8. En la tercera posición, el paciente se gira otros $45^{\circ}$ siguiendo el sentido previo. En esta posición, el paciente gira todo el cuerpo hacia el lado sano y se queda mirando hacia el suelo. Muchos pacientes refieren una gran sensación vértigo en esta posición, pues es la posición en la que las otoconias realizan un desplazamiento mayor. Conviene advertírselo al enfermo antes de realizar el movimiento. 


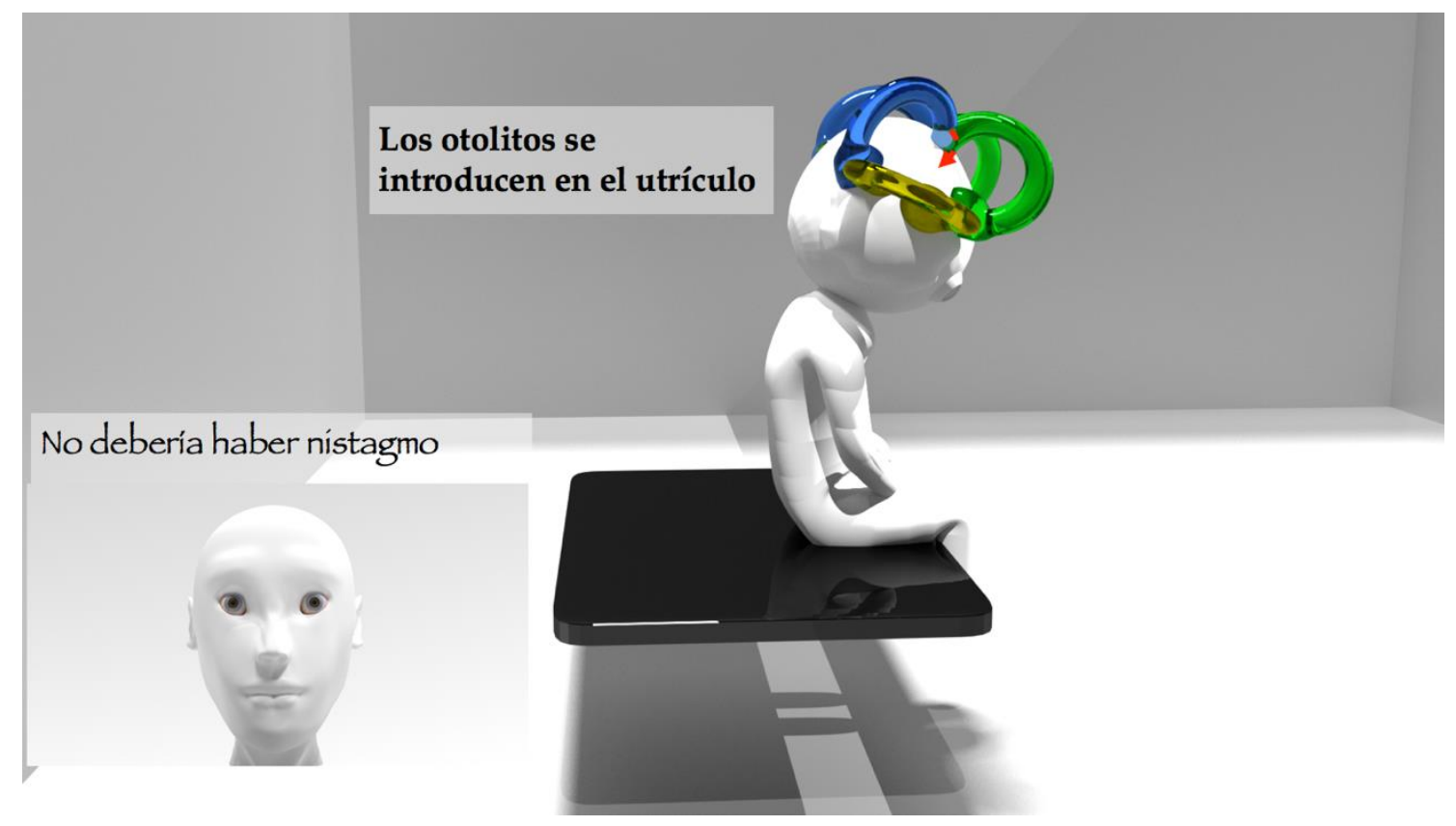

Figura 9. El paciente se incorpora pasando a una posición de sentado con la cabeza ligeramente inclinada hacia abajo. En esta posición es raro que el paciente refiera vértigo, sin embargo, es frecuente que noten un intenso mareo.

\section{COMENTARIOS}

- Recomendaciones tRas la maniobra de EPLEY. No existen estudios que demuestren mayor efectividad de la maniobra si se aplica vibración mastoidea durante la misma, si se duerme sentado 48 horas post-reposición, si se limitan los movimientos cervicales (uso de collarín cervical) o se evita dormir sobre el lado afecto durante 5-7 días. En nuestra práctica habitual aconsejamos no acostarse del lado patológico en las primeras 48 horas postratamiento.

- La efectividad de una única maniobra de Epley a los 7 días de realizarla es del $82 \%$.

MANIOBRA LIBERAdORA DE SEMONT. Consiste en realizar la maniobra diagnóstica de Semont y si aparece el nistagmo típico con la clínica de vértigo acompañante, desde la posición de tumbado del lado afecto (con la cabeza girada 45 grados hacia el lado sano), se le mueve rápidamente al paciente hacia el otro lado sin parar en la posición de sentado y sin cambiar la posición de la cabeza, terminando por tanto, con la nariz apoyada contra la camilla, manteniendo esta posición 30 segundos, para pasar posteriormente a sentarse despacio.
Esta maniobra terapéutica se aplica en los casos donde esté contraindicada la de Dix-Hallpike y en una supuesta cupulolitiasis del CSP. La efectividad a los 7 días parece ser igual que si se realiza la maniobra liberadora de Epley. Sin embargo, según algunos estudios, a los 3 meses de seguimiento los pacientes tratados con Epley refieren mejores resultados que con Semont. (Figuras 10, 11, 12 y 13).

EJERCICIOS DE HABITUACIÓN DE BRANDT Y DAROFF. En los pacientes ancianos o con movimientos cervicales limitados, donde las maniobras liberadoras no se hacen correctamente y por ello no se obtienen tan buenos resultados, en los que rechazan estas maniobras por temor al vértigo (aún con tratamiento sedante previo) y en los que no mejoran, se proponen los ejercicios de habituación vestibular, que se basan en reproducir la sintomatología vertiginosa, dispersar los otolitos e inducir en el sistema nervioso central una tolerancia a la sensación de mareo. Se efectúan 2 veces al día durante 4 semanas. Su realización consiste en, estando sentado en el lateral de la cama, acostarse lateralmente sobre un oído y esperar 30 segundos, volver a sentarse y repetir hacia el lado contrario. La eficacia es menor que la maniobra de Semont. 


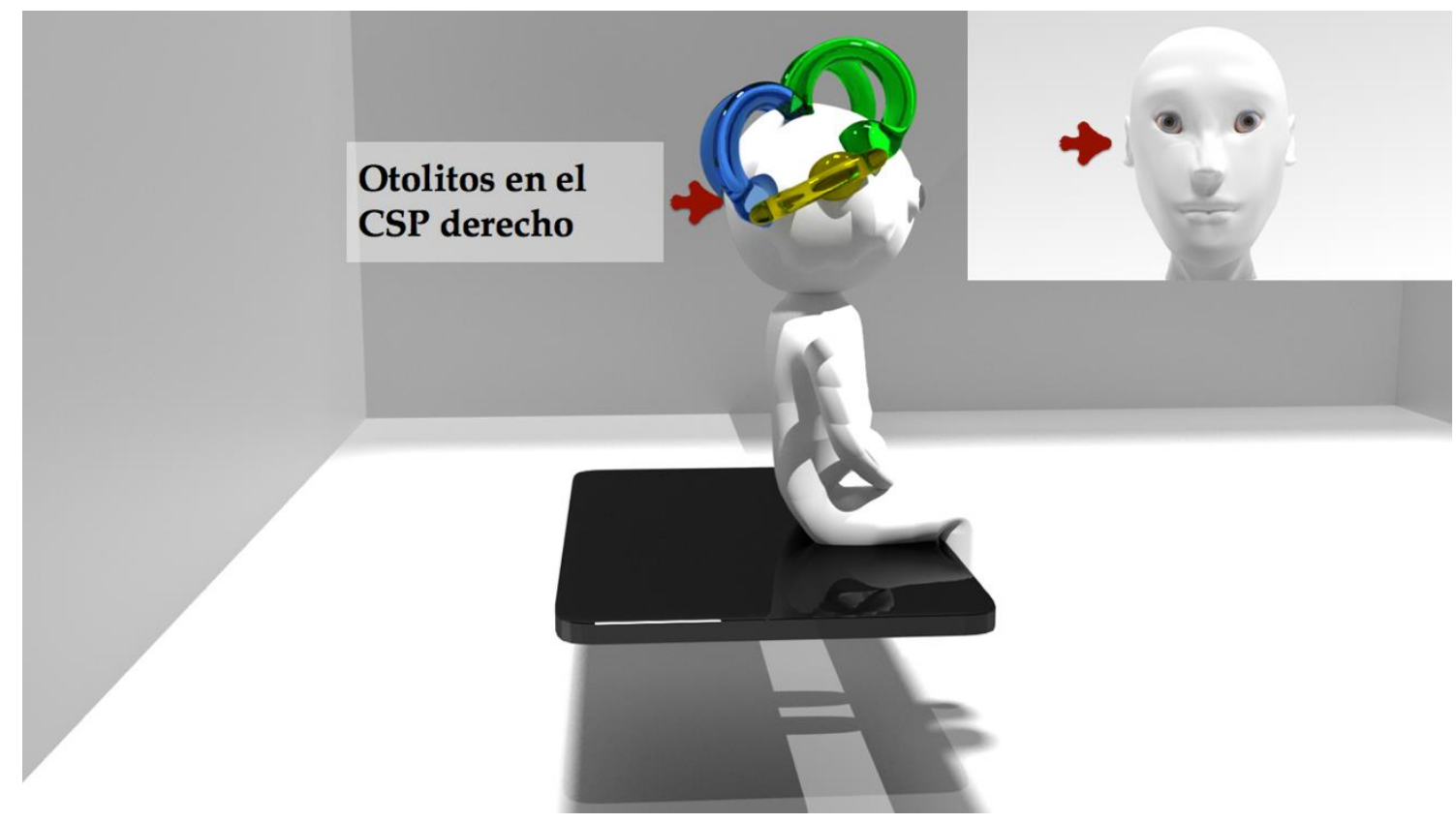

Figura 10. La maniobra de Semont tiene prácticamente la misma efectividad que la maniobra de Epley. Además, se puede utilizar como maniobra diagnóstica en enfermos con problemas de movilidad ya que puede resultarle más cómoda al paciente. En la posición inicial el paciente permanece sentado en el borde de la camilla y se gira la cabeza $45^{\circ}$ hacia el lado sano.

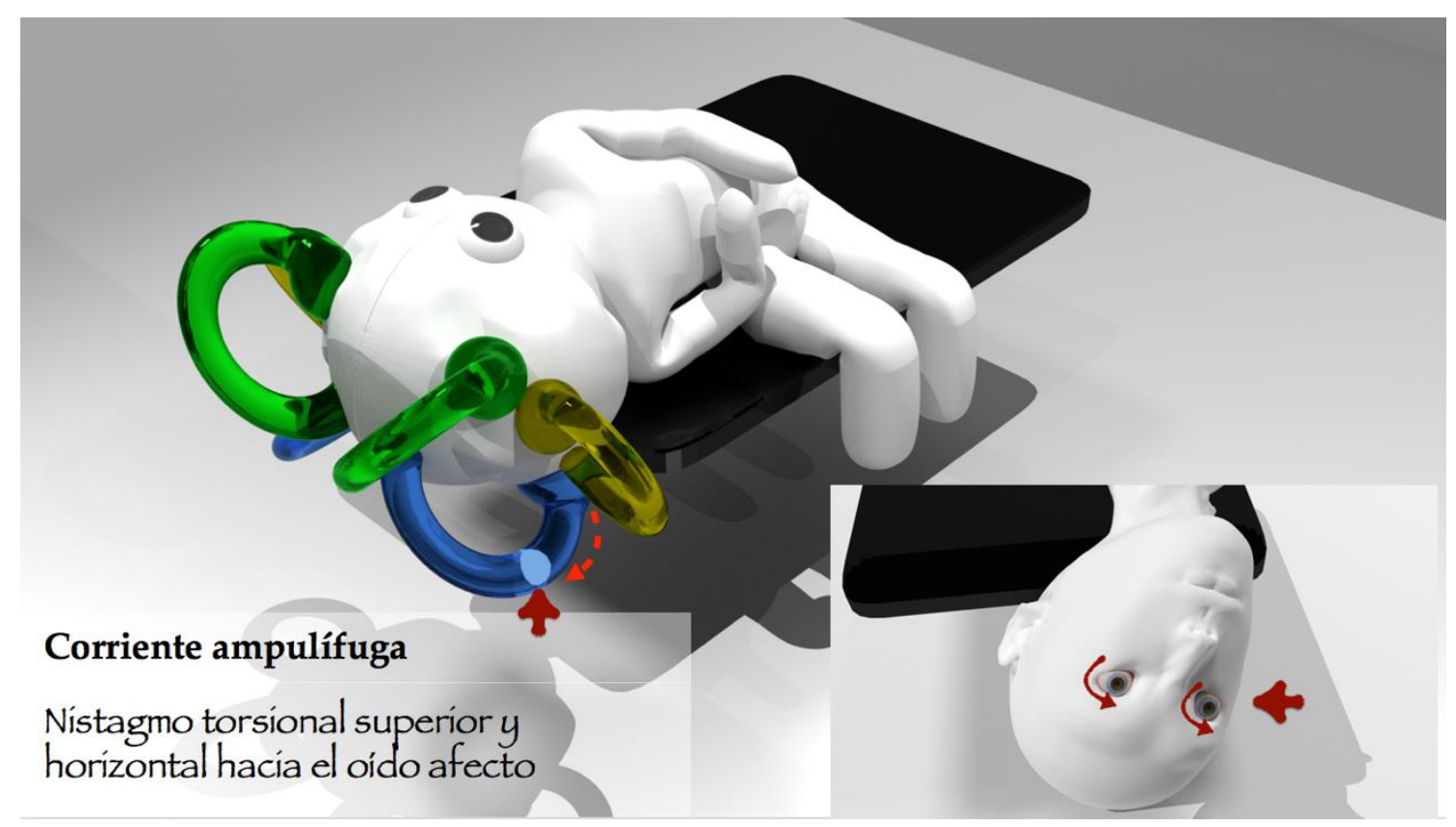

Figura 11. Con la cabeza girada $45^{\circ}$ hacia el lado sano, se tiende al paciente hacia el lado enfermo. El paciente quedará mirando hacia arriba. En esa posición se objetivará un nistagmo similar al descrito en la maniobra de Epley. 


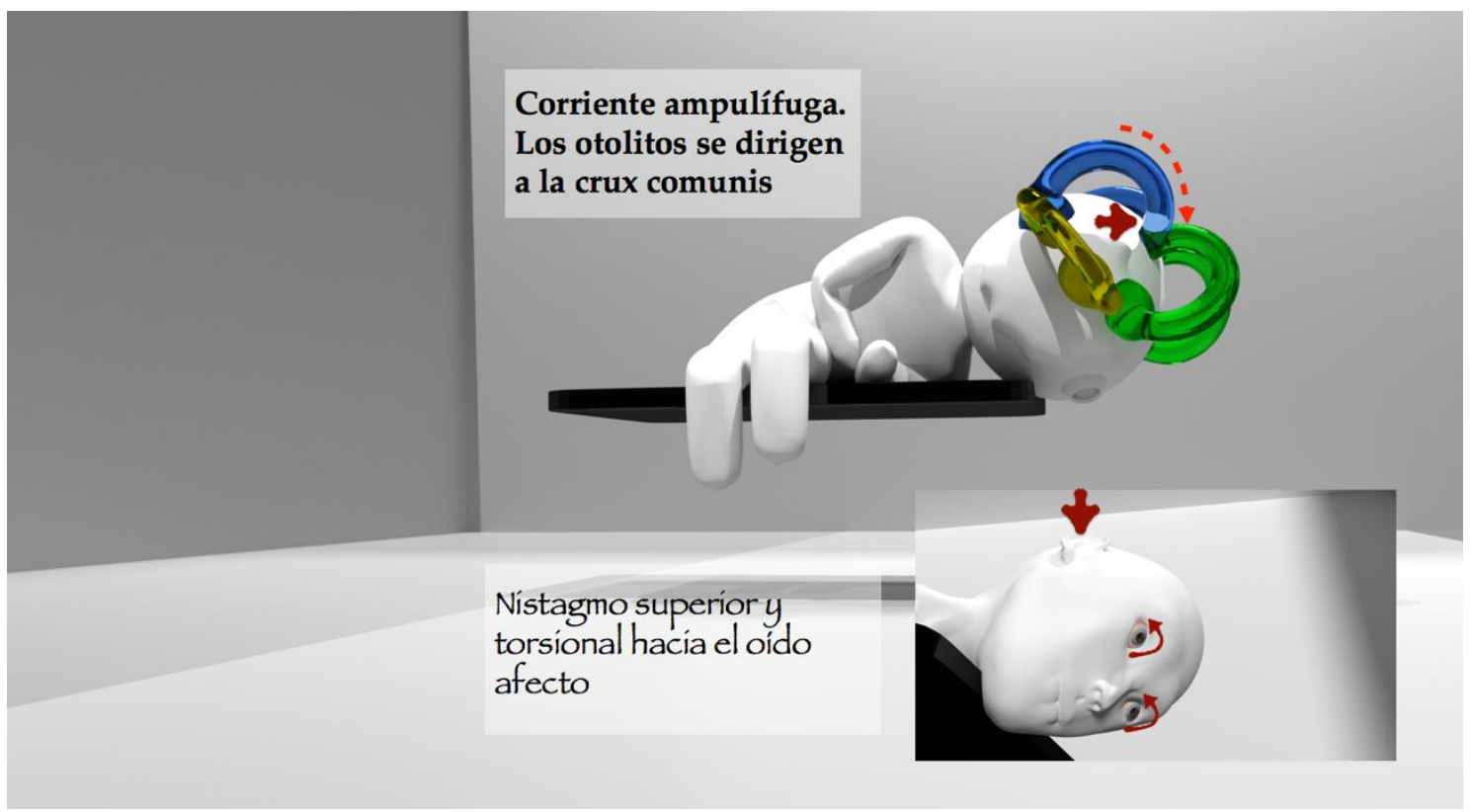

Figura 12. Desde la posición anterior, y sin mover la cabeza con respecto a los hombros, se gira al paciente $180^{\circ}$ hasta el otro lado de la camilla, en un movimiento lo más rápido posible. El paciente queda mirando hacia el suelo, con la cara pegada a la camilla.

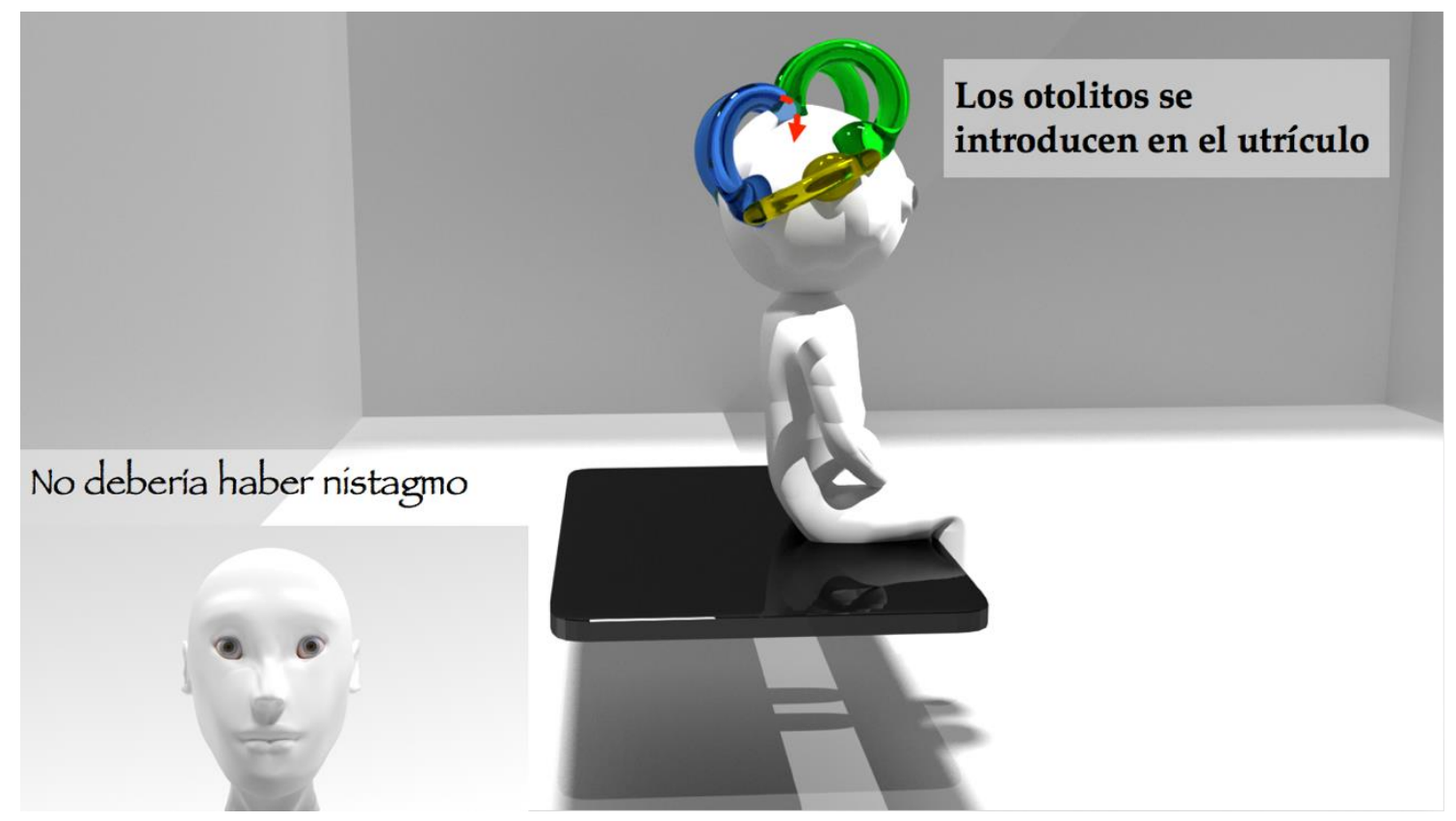

Figura 13. Desde la posición anterior, el paciente pasa a la posición de sentado. 


\section{VPPB DEL CONDUCTO SEMICIRCULAR HORIZONTAL/LATERAL (CSH) [3-16]}

\section{CARACTERÍSTICAS GENERALES}

Se estima que entre un 5-30\% de los VPPB se producen por el CSH, siendo el segundo en frecuencia tras el del CSP. De ellos, aproximadamente un $25 \%$ se podrían etiquetar como ageotrópicos y un $75 \%$ como geotrópicos. La etiología es común con el resto de VPPB.

Cuando el vértigo producido por del canal semicircular horizontal (CSH) se acompaña de un nistagmo que bate «hacia el suelo» (nistagmo geotrópico) se supone una canalitiasis y cuando se «aleja del suelo» (nistagmo ageotrópico o apogeotrópico) se cree que está causado por las partículas de otoconias adheridas a la cúpula (cupulolitiasis) o atrapadas en la parte anterior del canal horizontal.

Los criterios diagnósticos son (según el Consensus Document of the Committee for the Classification of Vestibular Disorders of the Bárány Society, 2015):

A. Ataques recurrentes de vértigo posicional o mareo con los cambios de posición provocados al tumbarse o al girar desde la posición de decúbito.

B. Canalitiasis: nistagmo posicional generado con poca o nula latencia mediante la maniobra de McClure-Pagnini, que bate horizontalmente hacia el oído más cercano al suelo cuando giramos la cabeza del paciente hacia uno u otro lado (nistagmo de dirección cambiante geotrópico), con duración $<1$ minuto.

Cupulolitiasis: nistagmo posicional generado con poca o nula latencia mediante la maniobra de McClure-Pagnini, que bate horizontalmente hacia el oído más alejado del suelo cuando giramos la cabeza del paciente hacia uno u otro lado (nistagmo de dirección cambiante ageotrópico), con duración $>1$ minuto.

C. No se puede atribuir a otras entidades nosológicas.

\section{FISIOPATOLOGÍA}

- Canalitiasis: La presencia de partículas otoconiales flotando libremente en el brazo largo del CSH modifica la sensibilidad de la cúpula a las aceleraciones. Cuando el paciente rota la cabeza de forma brusca hacia el lado afectado, situándose el oído involucrado en la parte más baja, se produce una corriente endolinfática utriculípeta. Ello provocará un nistagmo excitatorio en sentido geotrópico que se manifiesta por un mareo intenso con nistagmo horizontal puro de pocos segundos de latencia, y con menos tendencia a la fatigabilidad que los de otros canales (duración < 1 minuto). Si el giro de la cabeza es hacia el lado sano, se generará una corriente utriculífuga en el oído contrario que provocará un nistagmo inhibitorio geotrópico, de menor intensidad.

- Cupulolitiasis: Cuando giramos la cabeza hacia el lado sano, los detritus otoconiales adheridos a la cúpula del canal horizontal del oído afecto, producen una deflexión ampulípeta excitatoria, cuyo resultado es un nistagmo ageotrópico. Si giramos la cabeza hacia el lado afecto, habría una deflexión ampulífuga e inhibitoria, generando un nistagmo ageotrópico de menor intensidad.

AvISO

Hay autores que ponen en duda la teoría de la cupulolitiasis como causa de vértigo intenso. También sería posible que una lesión de la cúpula, por inflamación o isquemia, causara un aumento de densidad, comportándose como una cupulolitiasis. Finalmente, no debemos olvidar que algunas lesiones del sistema nervioso central podrían simular un nistagmo del canal horizontal, al igual que la migraña vestibular, el hídrops endolinfático e incluso el neurinoma del acústico.

\section{DIAGNÓSTICO}

En el VPPB del CSH la sensación vertiginosa es larga y prolongada y se ve más influenciada por los movimientos de la cabeza que en el caso del VPPB del canal posterior. Son pacientes inestables con síntomas vegetativos ocasionales, acompañados de sensación de movimiento de duración imprecisa.

La maniobra de McClure-Pagnini (o supine roll test) nos permite explorar este conducto. Se realiza con el paciente en decúbito supino y girando rápidamente su cabeza $90^{\circ}$ hacia la derecha y luego $90^{\circ}$ hacia la izquierda. Entre un giro y otro tendremos que esperar a que desaparezca completamente el nistagmo producido. La cabeza puede estar elevada unos $30^{\circ}$ sobre la horizontal para que los conductos horizontales estén en un plano perpendicular al suelo. 
- Canalitiasis: la rotación rápida de la cabeza del paciente hacia uno y otro lado provoca un nistagmo geotrópico de dirección cambiante, es decir que, en ambas posiciones de giro de la cabeza, el nistagmo bate hacia el oído situado más bajo. Aunque es bilateral, suele tener mayor intensidad en el del oído afecto, lo que se explicaría por la segunda ley de Ewald según la cual en los canales horizontales las corrientes endolinfáticas ampulípetas son más excitatorias que las ampulífugas (Figuras 14, 15, 16 y 17).

- Cupulolitiasis: provocaremos un nistagmo ageotrópico de dirección cambiante. Este nistagmo horizontal, con un leve componente torsional, sin componente vertical es de latencia corta (0-3 seg), de gran intensidad y la adaptación de la respuesta o fatiga es menor que la observada en el nistagmo posicional del conducto posterior. Su intensidad se va incrementado lentamente durante unos 30 segundos y posteriormente disminuye de forma variable (duración $>1$ minuto). En este caso, la mayor intensidad aparecería cuando el oído sano estuviera más bajo (corriente ampulípeta en el contralateral, afectado). En ocasiones, si repetimos la maniobra el nistagmo ageotrópico se transforma en geotrópico. La continua aparición de un nistagmo ageotrópico horizontal tras varias maniobras de giro cefálico apoyaría el diagnóstico de cupulolitiasis. (Figuras 18, 19, 20 y 21).

\section{AvISO}

Conviene explorar la presencia de un nistagmo pseudoespontáneo colocando la cabeza del paciente en posición vertical (sentado). Cuando aparezca, nos orientará en el diagnóstico, puesto que el nistagmo batirá hacia el lado sano en caso de canalitiasis y hacia el afecto si cupulolitiasis, debiendo desaparecer al flexionar la cabeza $30^{\circ}$ hacia el suelo (pues al horizontalizar los $\mathrm{CSH}$, se pierde el efecto de la gravedad sobre las otoconias). Cuando la cabeza se inclina $60^{\circ}$ hacia delante (en reverencia, bow), cambiaría la dirección de los respectivos nistagmos. $Y$ finalmente si el paciente extiende la cabeza o se tumba (test de sentado a supino), se incrementaría el encontrado en posición vertical, al aproximarse el canal horizontal a la vertical, influyendo plenamente la fuerza de gravedad. Este test que se denomina test de Bow-Lean, nos permite conocer el lado afecto en aquellos casos en los que tenemos dudas, ya que, para el caso de las canalitiasis, al inclinar la cabeza hacia delante, el nistagmo se dirige al lado afecto y al inclinar la cabeza hacia atrás el nistagmo se dirige al lado sano (Figuras 22, 23 y 24).

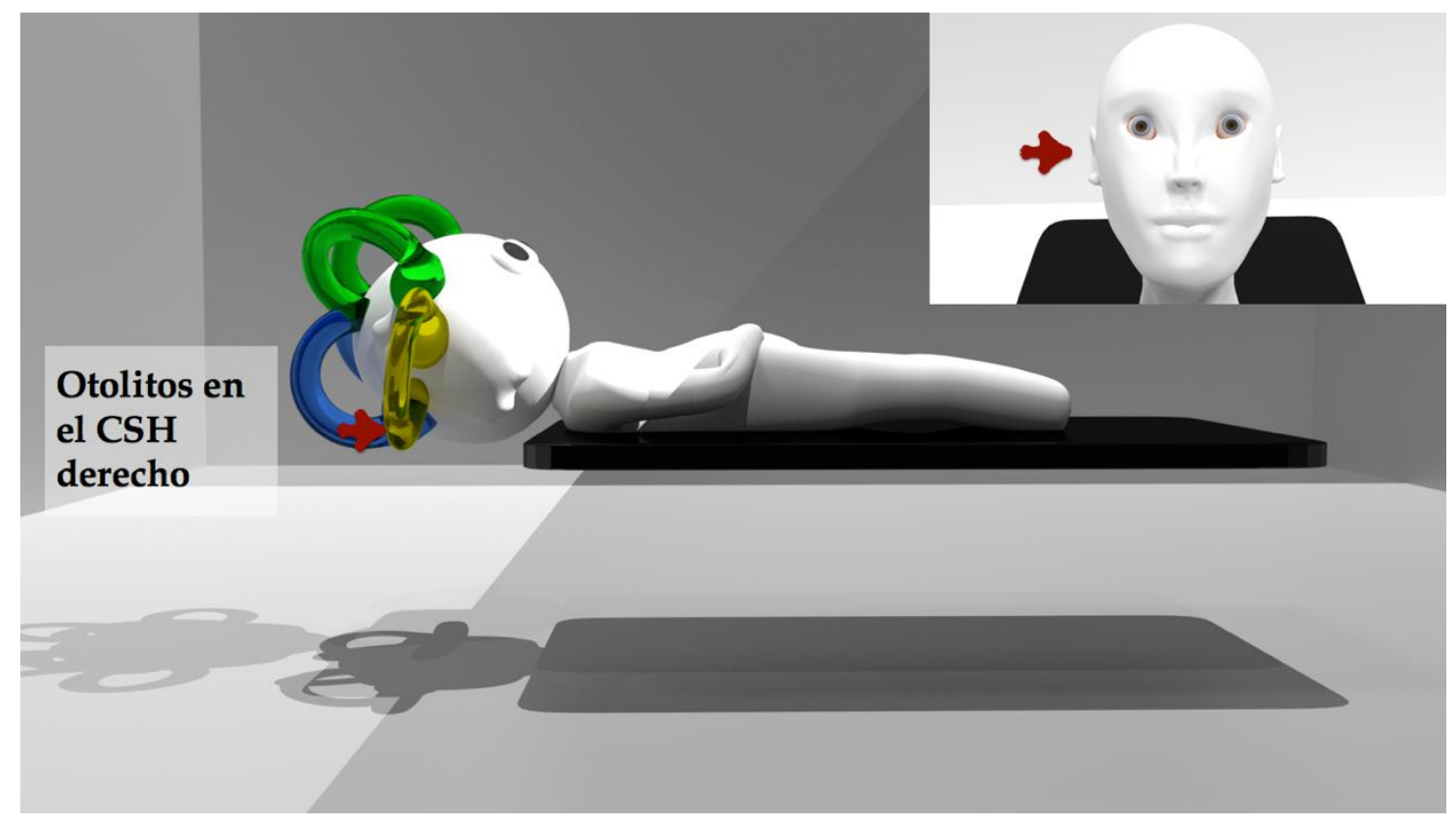

Figura 14. Maniobra de McClure. Posición incial: Paciente en decúbito supino. 


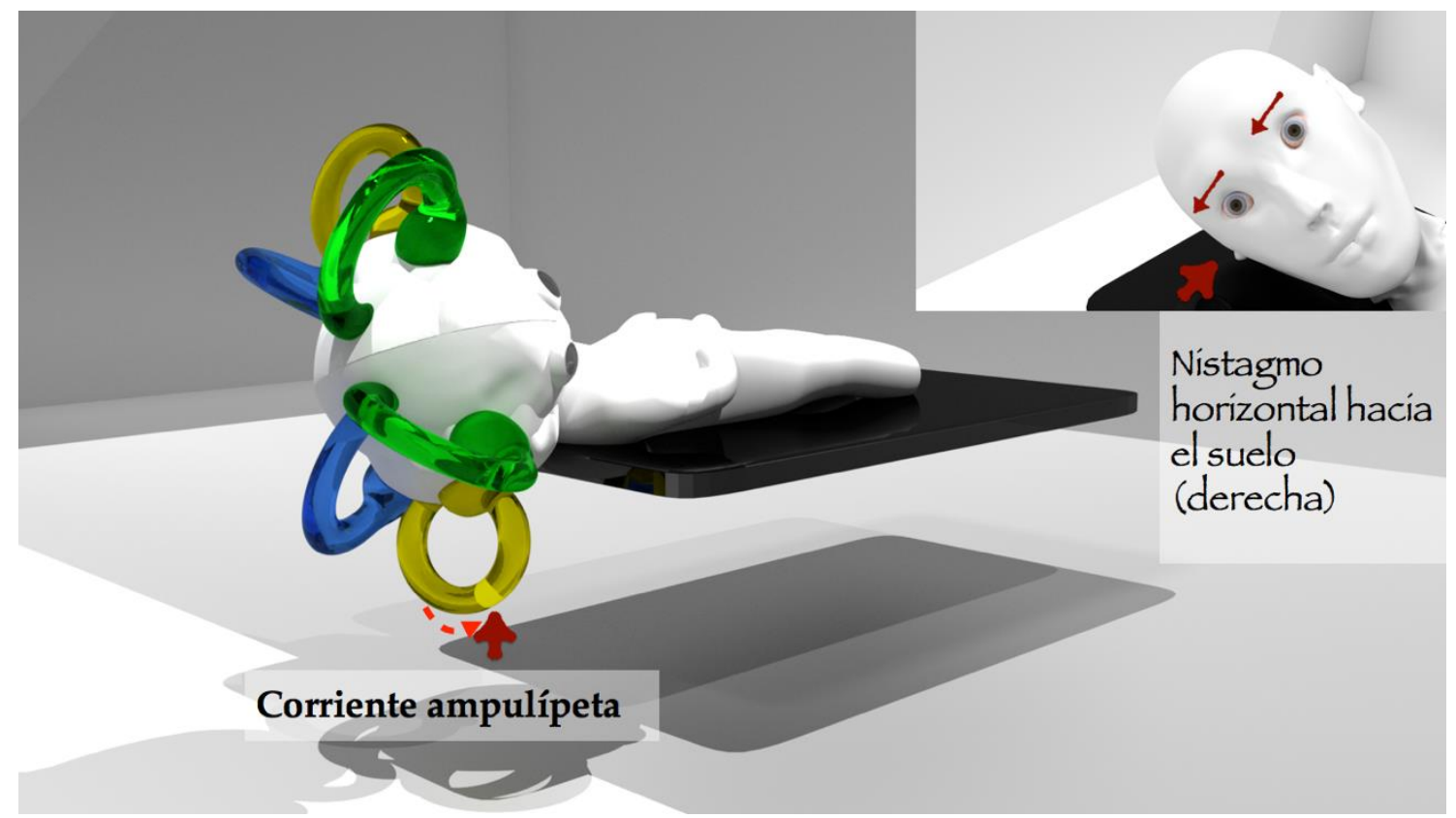

Figura 15. La segunda posición consiste en girar $45^{\circ}$ la cabeza a la derecha o a la izquierda. En el caso de esta figura a la derecha. Dado que se trata de una canalitiasis del Canal semicircular horizontal derecho, se objetiva un nistagmo horizontal puro que bate hacia el suelo (geotrópico).

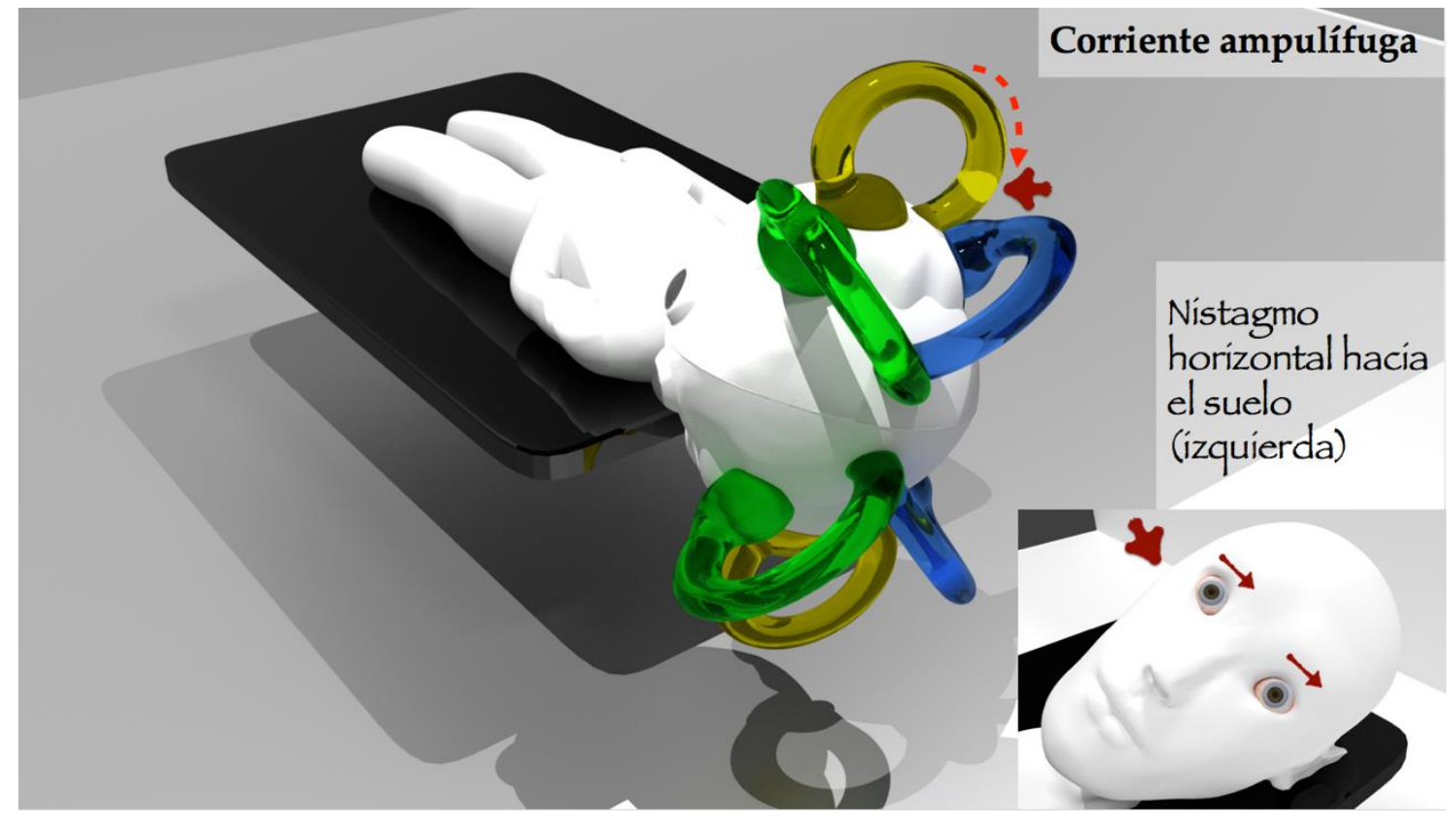

Figura 16. La siguiente posición de la mniobra de McClure consiste en girar la cabeza hacia el lado contrario del anteriormente explorado. En este caso hacia el lado izquierdo. Dado que el ejemplo se trata de una canalitiasis del Canal horizontal derecho, objetivaremos un nistagmo horizontal puro que bate también hacia el suelo (Geotrópico), pero con una intensidad menor que hacia el lado afecto. 


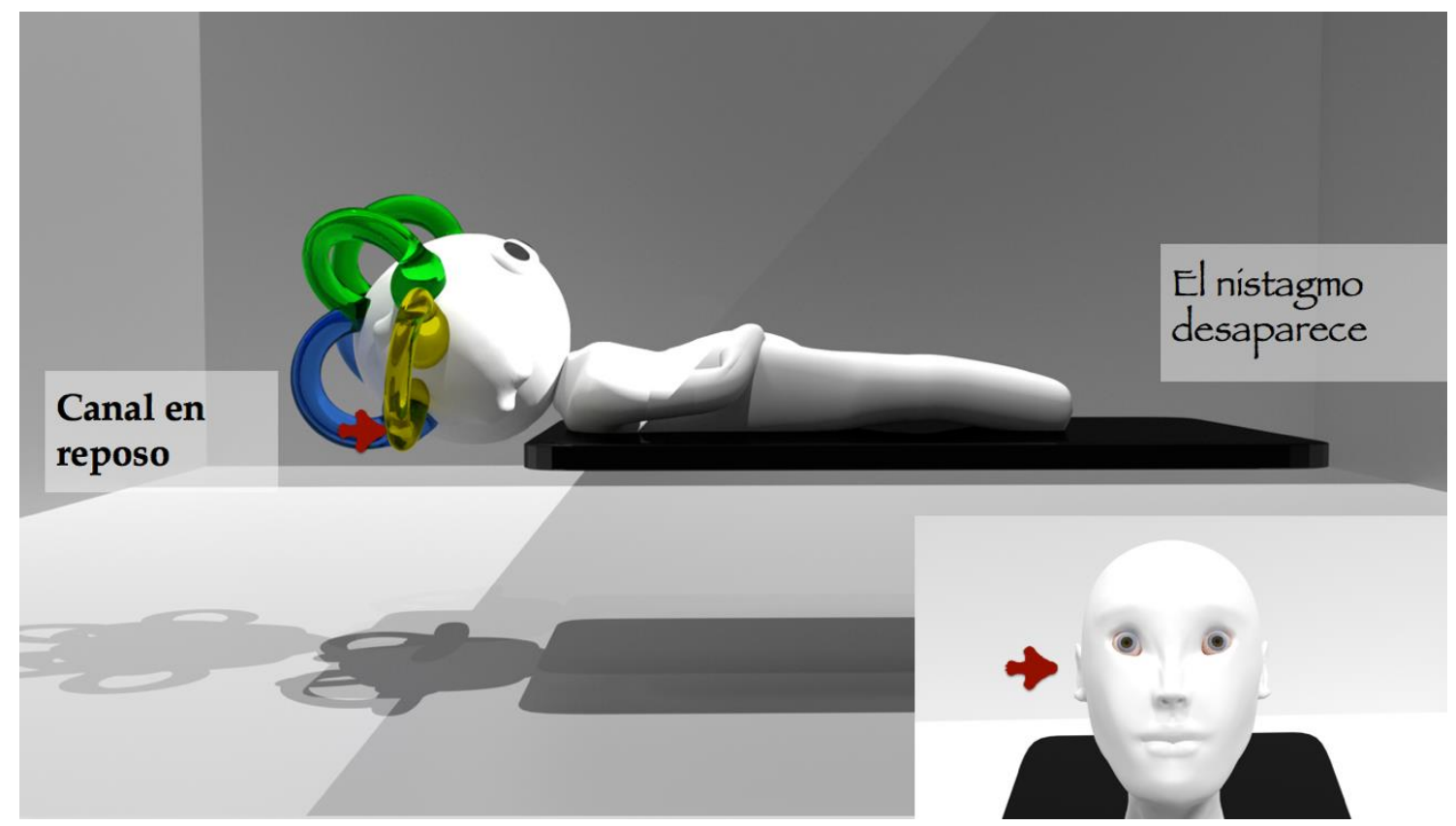

Figura 17. La última posición de la maniobra exploratoria de McClure para el canal horizontal consiste en devolver la cabeza del paciente a la posición inicial, esto es, al decúbito supino, donde debe desaparecer el nistagmo.

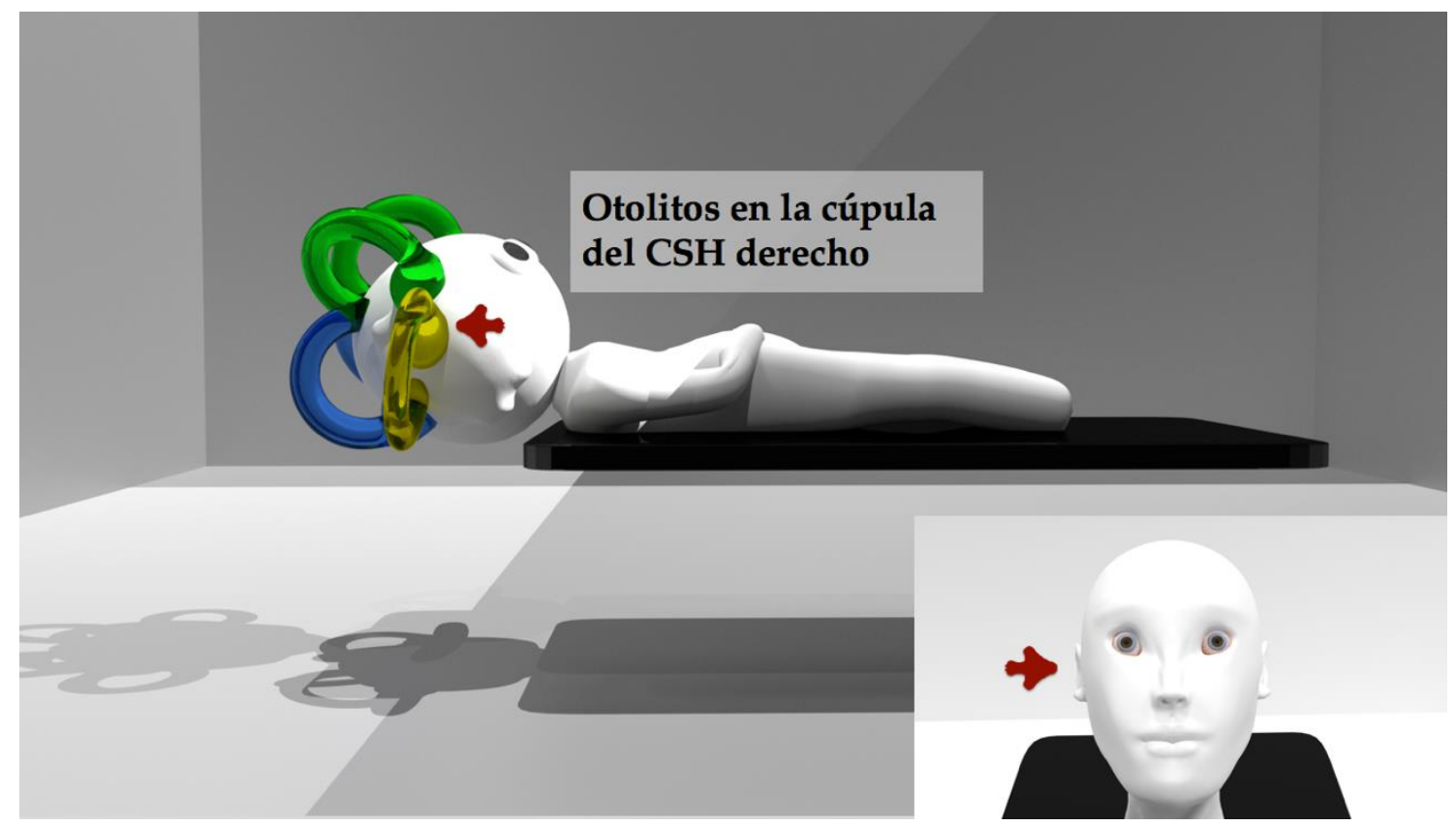

Figura 18. La maniobra es exactamente igual cuando nos encontramos ante un paciente con una cupulolitiasis del canal horizontal. En este caso el ejemplo se refiere a una cupulolitiasis del canal horizontal derecho. 


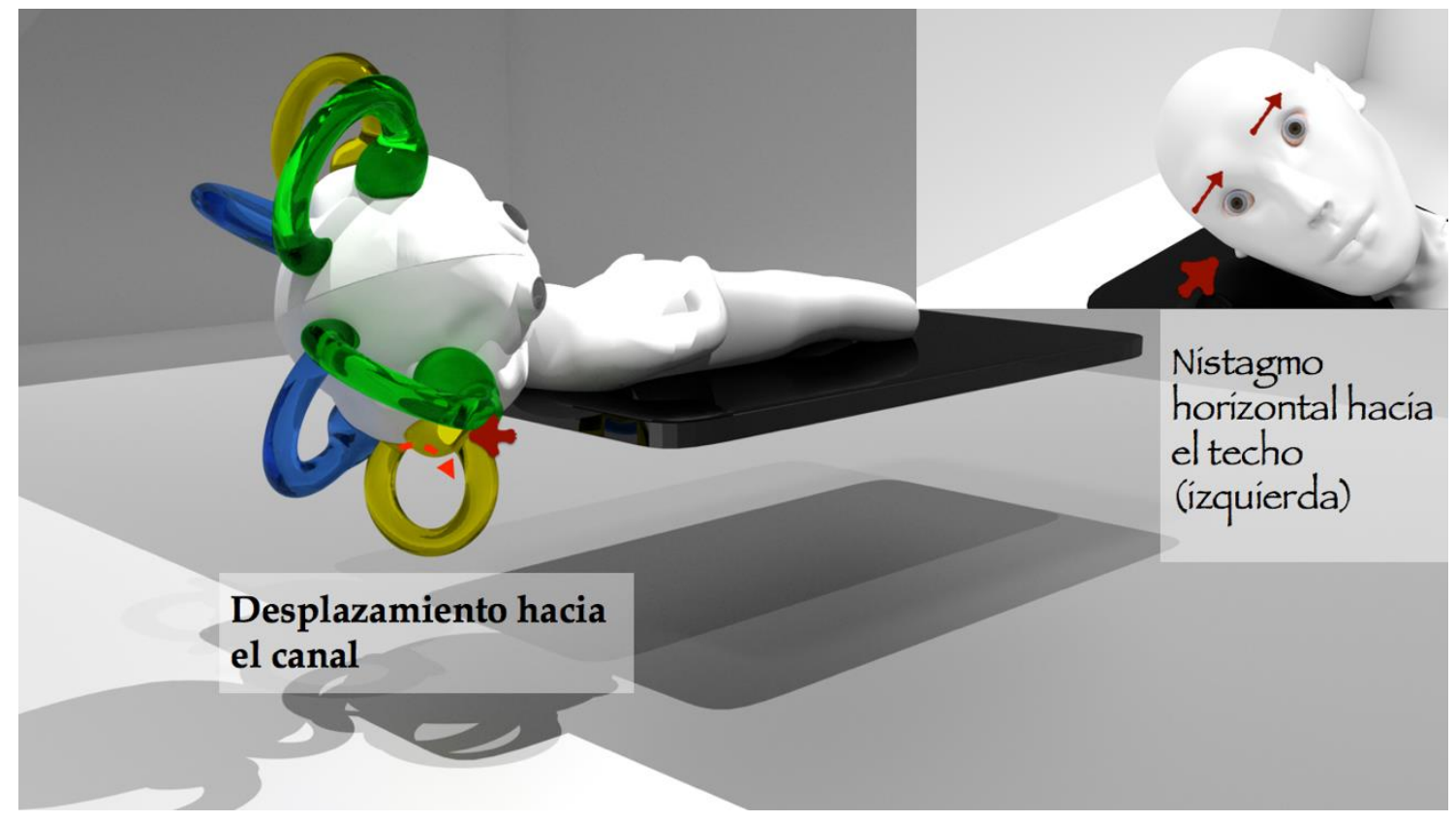

Figura 19. En este caso, al girar la cabeza hacia el lado derecho objetivaremos un nistagmo horizontal puro, que bate hacia el techo (ageotrópico)

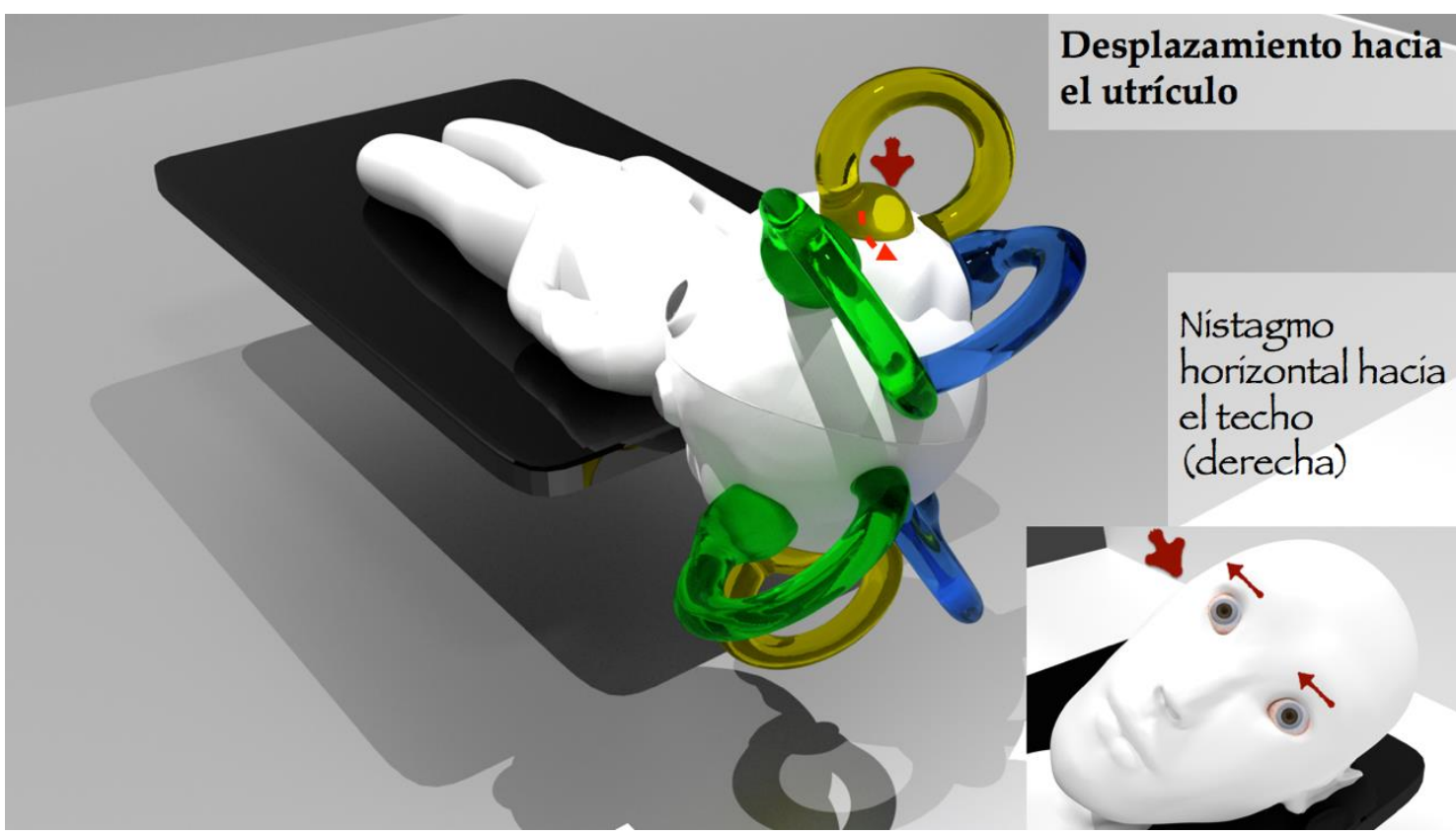

Figura 20. Al girar la cabeza hacia el lado contrario, hacia el izquierdo, objetivaremos un nistagmo igualmente ageotrópico, pero en este caso de mayor intensidad que hacia el lado afecto. El nistagmo provocado por una cupulolitiasis del canal horizontal es de menor intensidad hacia el lado afecto. 
Guía PRÁctica del VÉRTIGo Posicional PaROXístico BENIGNO BENITO-OREJAS JI ET AL.

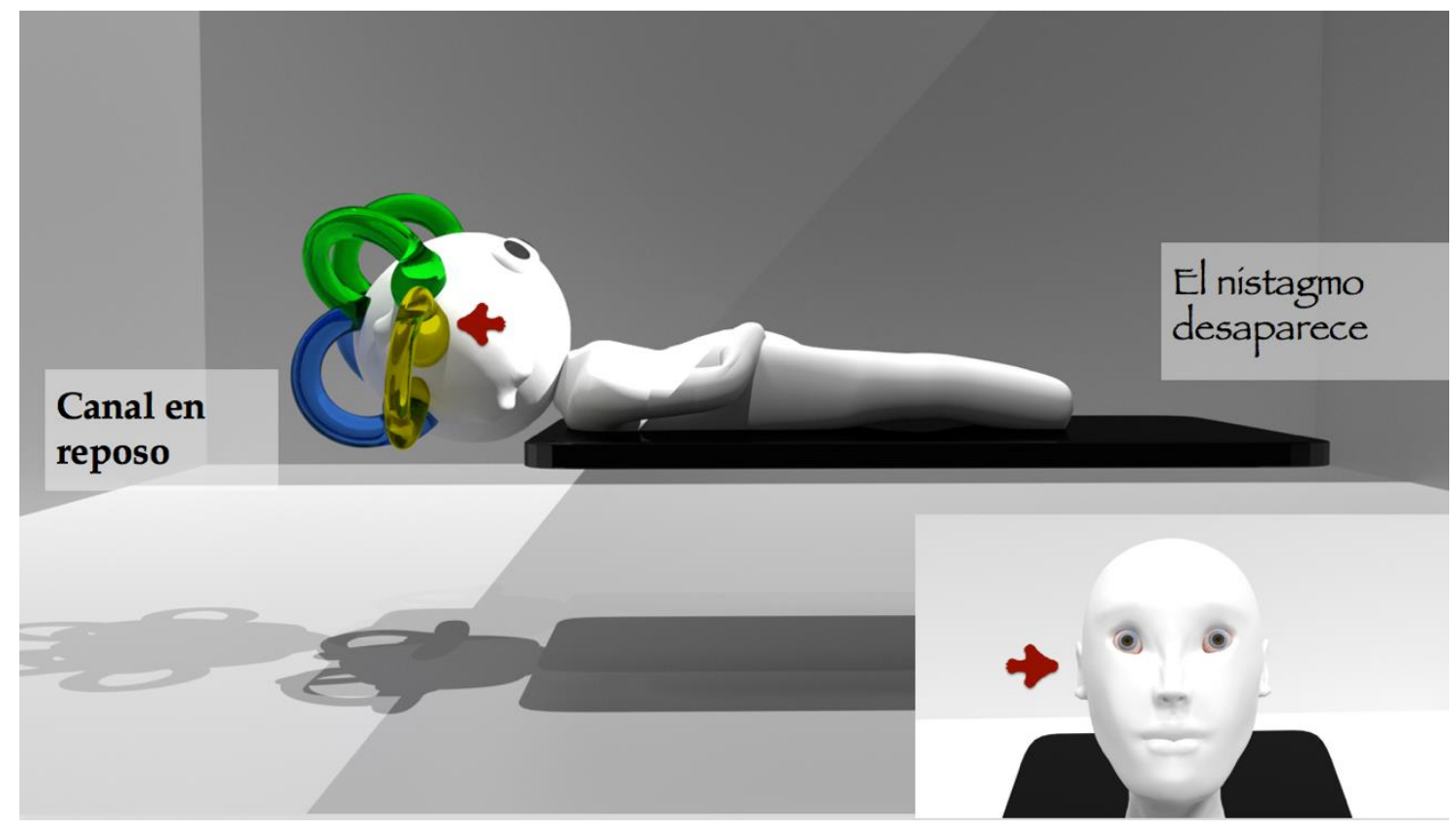

Figura 21. La posición final de la maniobra de McClure es el decúbito supino.

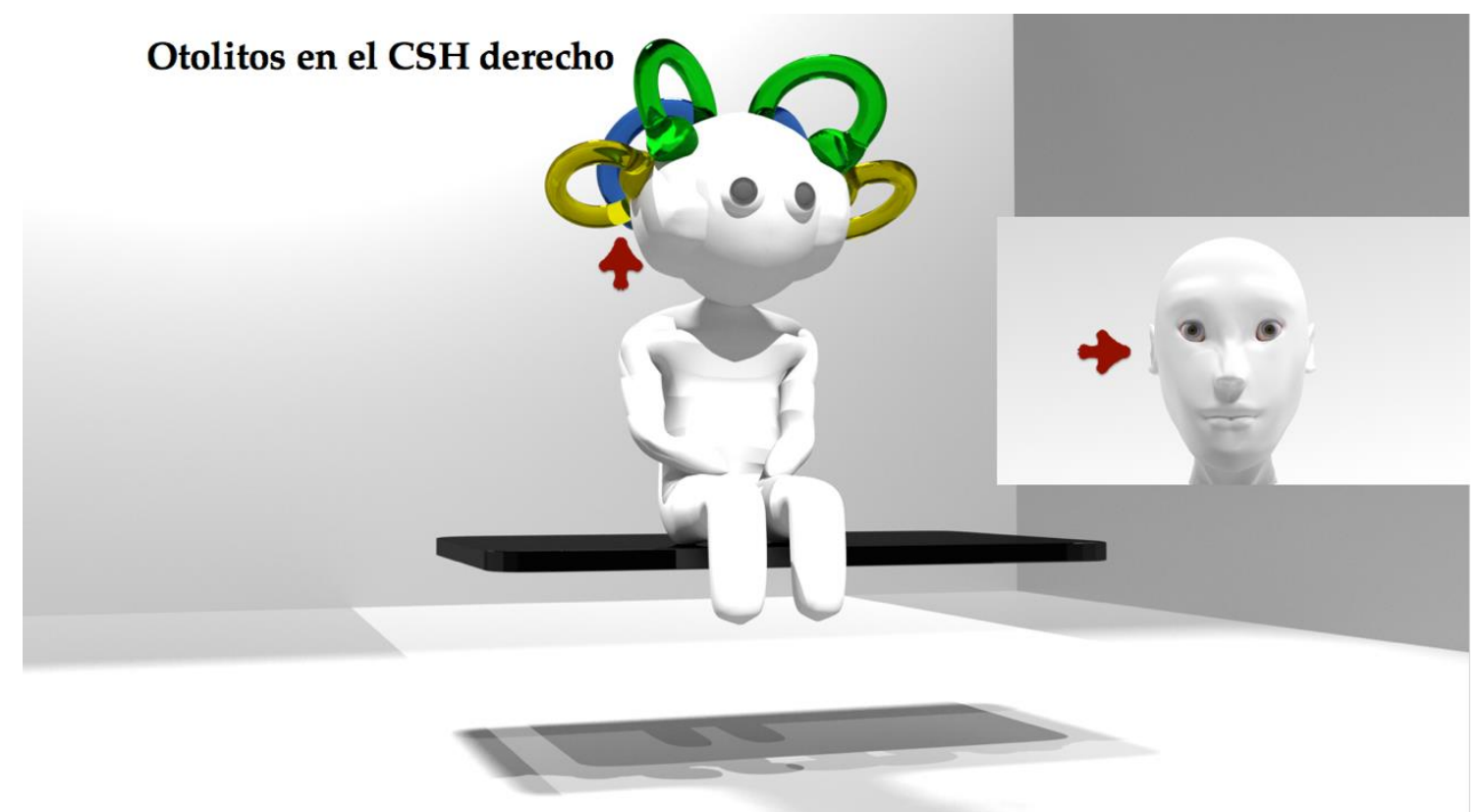

Figura 22. Maniobra de Bow and Lean para la canalitiasis del canal horizontal. Se realiza cuando existen dudas sobre cuál es el lado afecto. Se inicia con el paciente en posición sentada mirando al frente. 


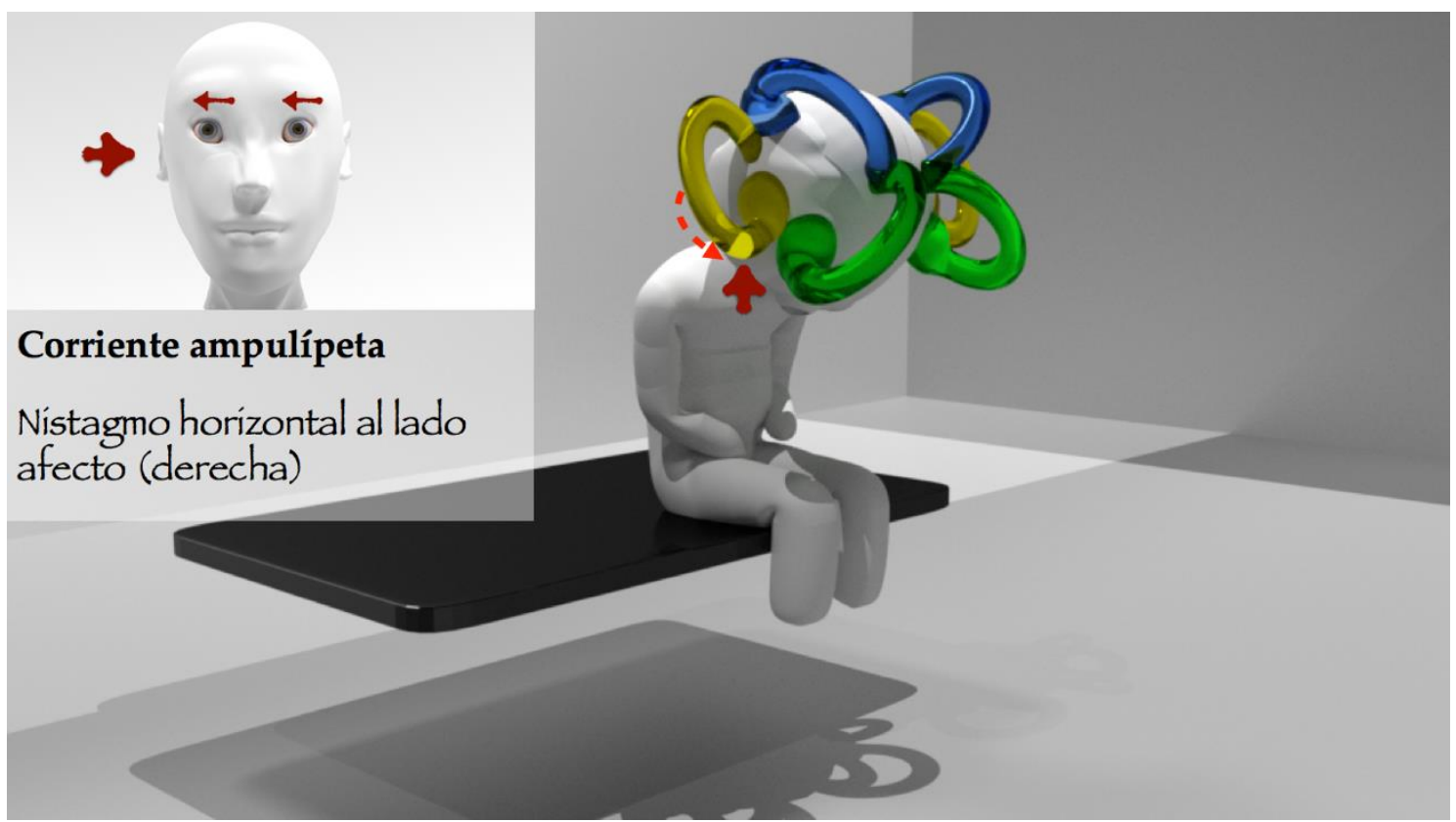

Figura 23. Maniobra de Bow and Lean para la canalitiasis del canal horizontal. Al inclinar la cabeza hacia delante, hiperflexionando, en un paciente con una canalitiasis del canal horizontal derecho objetivaremos un nistagmo que bate hacia el lado afecto.

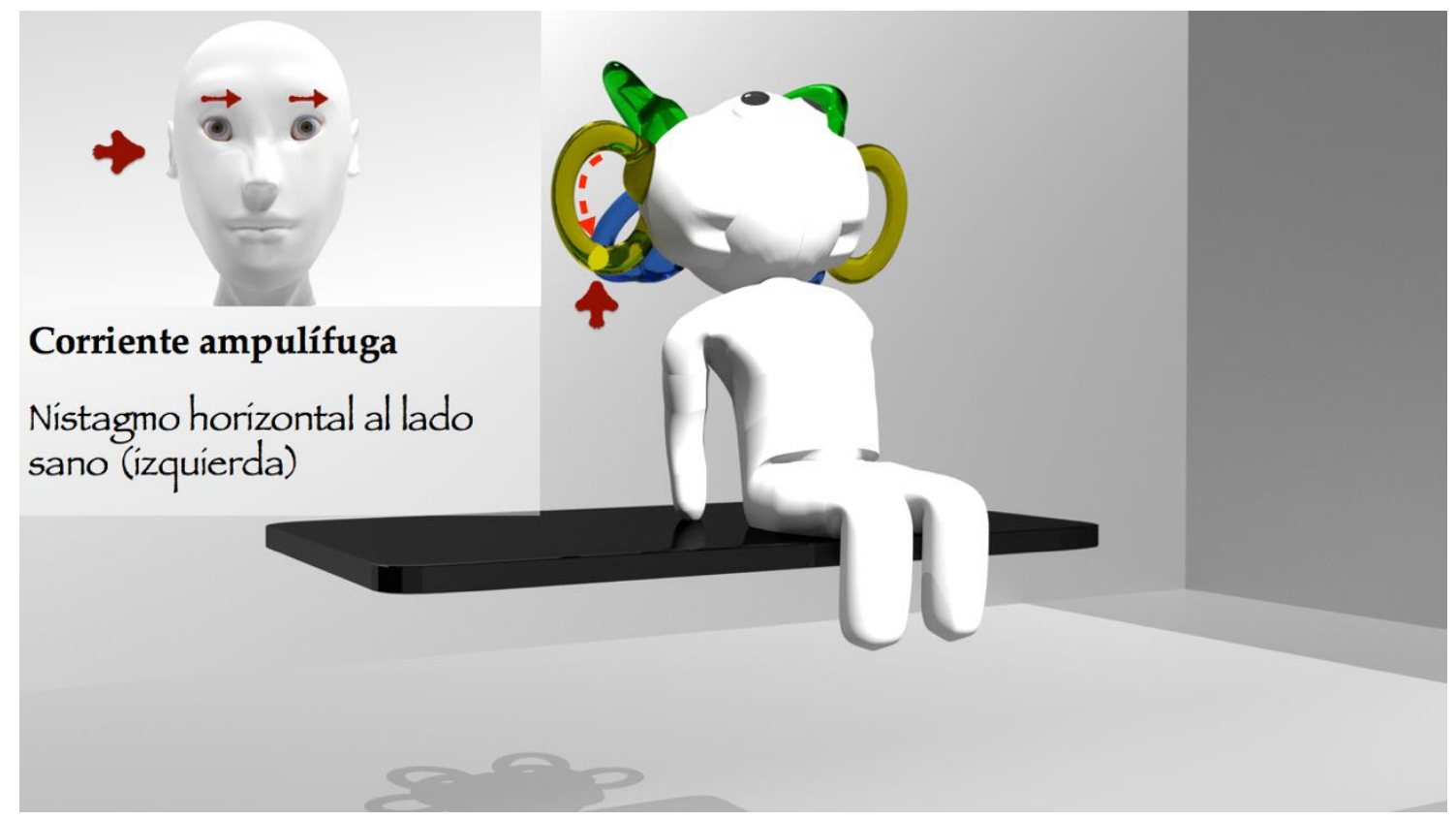

Figura 24. Maniobra de Bow and Lean para la canalitiasis del canal horizontal. Al hiperextender la cabeza hacia atrás, objetivaremos un nistagmo que bate hacia el lado sano. 


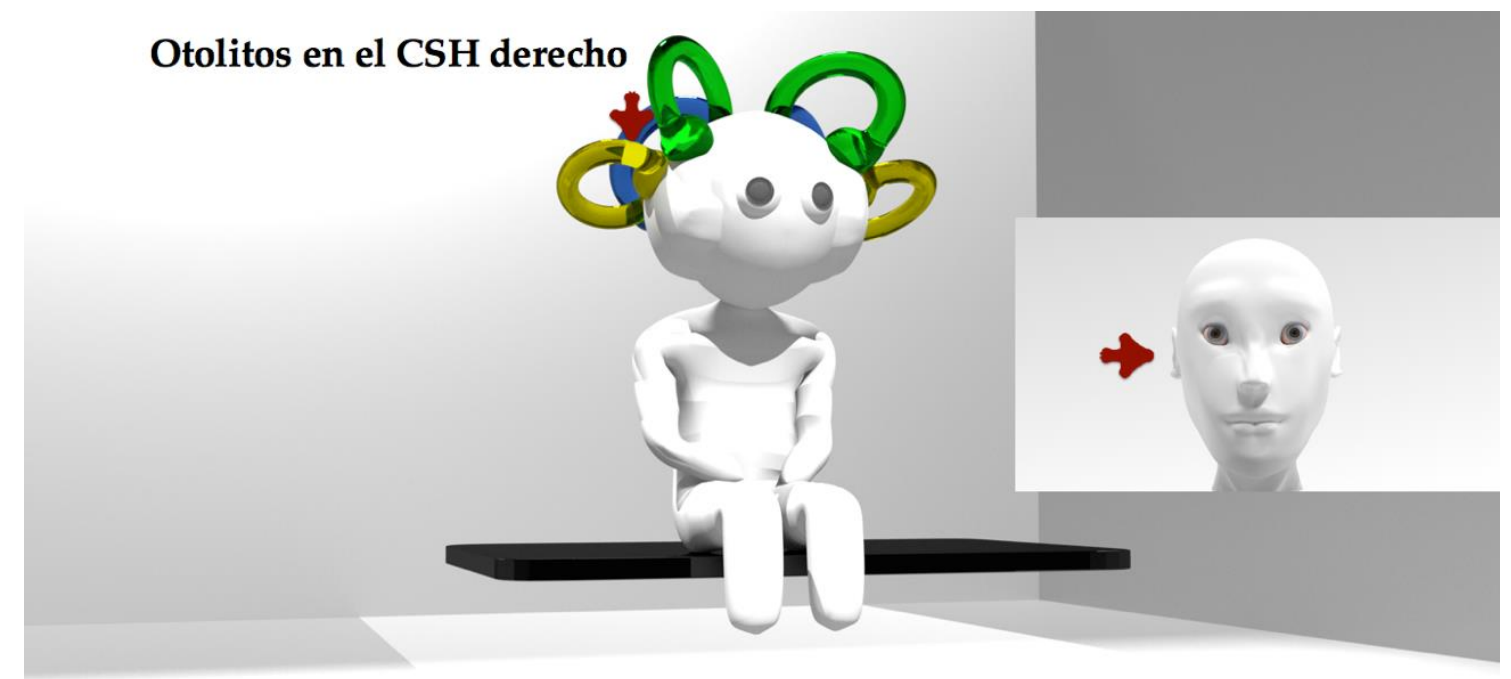

Figura 25. Maniobra de Bow and Lean para la cupulolitiasis del canal horizontal. Al igual que en el caso de la canalitiasis Se realiza cuando existen dudas sobre cuál es el lado afecto. Se inicia con el paciente en posición sentada mirando al frente.

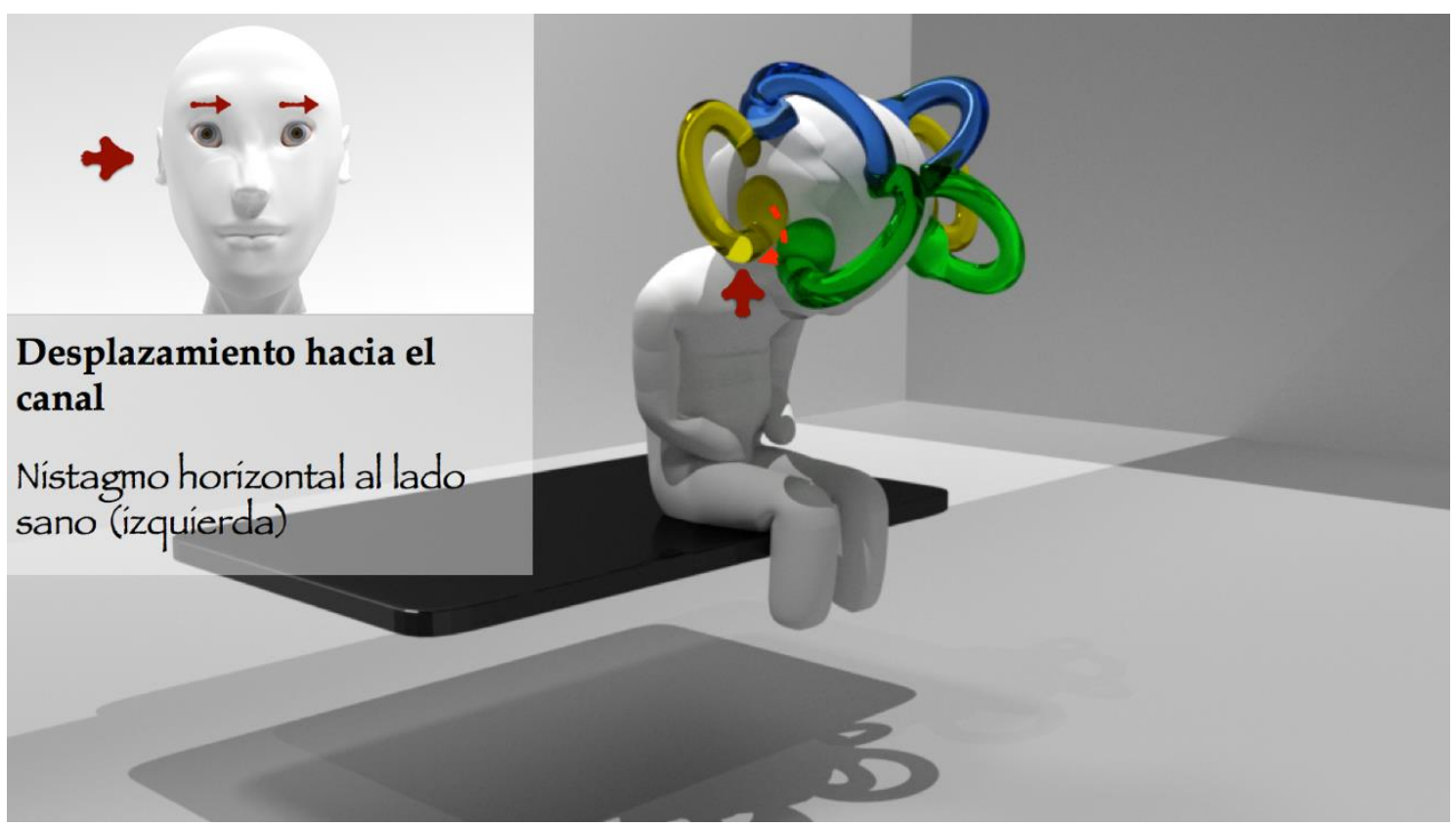

Figura 26. Maniobra de Bow and Lean para la cupulolitiasis del canal horizontal derecho. Al inclinar la cabeza hacia delante, hiperflexionando, en un paciente con una cupulolitiasis del canal horizontal derecho objetivaremos un nistagmo que bate hacia el lado sano. 


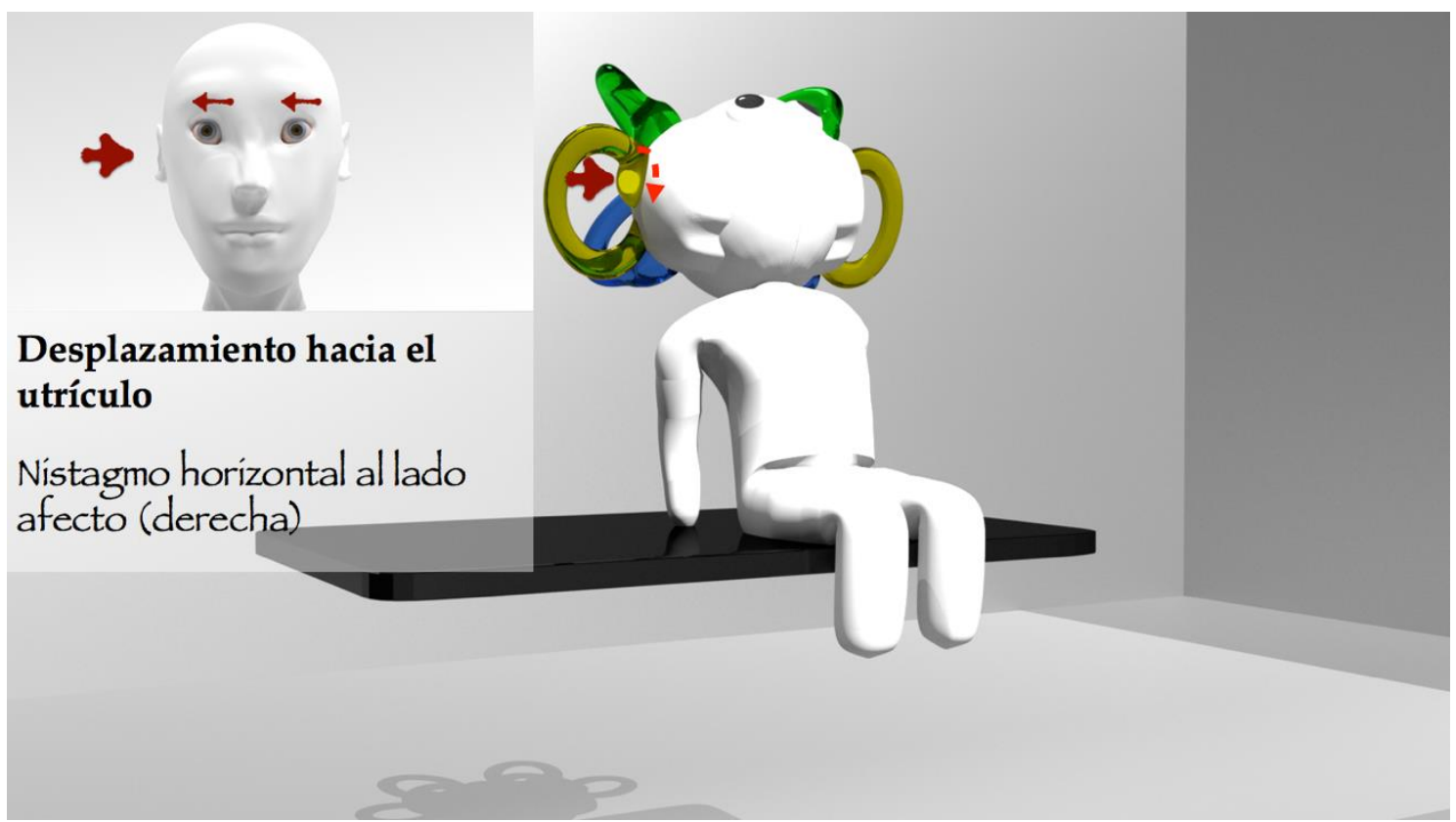

Figura 27. Maniobra de Bow and Lean para la cupulolitiasis del canal horizontal. Al hiperextender la cabeza hacia a tras, objetivaremos un nistagmo que bate hacia el lado enfermo.

En el caso de la cupulolitiasis, este test nos permite diferenciar al lado afecto ya que al inclinar la cabeza hacia delante el nistagmo se dirige al lado sano y al extender la cabeza hacia atrás el nistagmo se dirige al lado enfermo (Figuras 25, 26 y 27 )

Sería conveniente realizar una maniobra de agitación cefálica a todos los pacientes con una sospecha de VPPB de CSH puesto que podría aparecer un nistagmo que batiera hacía el lado sano en las cupulolitiasis. Además, tiene acción terapéutica por si sola y puede convertir un VPPB ageotrópico en geotrópico. Se realiza, con el paciente sentado, girando de 15 a 20 veces la cabeza de un lado a otro con una cadencia de dos giros por segundo.

La localización del lado patológico es determinante para aumentar las probabilidades de éxito en las maniobras de reposicionamiento. Se ha comprobado en varios estudios que en un alto porcentaje de casos no se orientaba correctamente el lado afecto tras la primera exploración.

Debemos ir juntando todos los resultados de la exploración para ver si son congruentes a la hora de determinar el lado causante de la sintomatología. Probablemente la forma más efectiva de decidirlo sea comparando la velocidad máxima de la fase lenta del nistagmo ho- rizontal tras los giros cefálicos laterales. Mediante videooculografía se puede establecer de un modo objetivo cual es el lado hacia el que se produce un nistagmo de mayor intensidad, que en la canalitiasis correspondería al lado afecto y en la cupulolitiasis al sano.

En caso de no disponer de esta técnica exploraremos el nistagmo del paciente en posición reverencial y de sentado a tumbado, como se ha explicado. No obstante, en aproximadamente un $10 \%$ de casos no se puede identificar el lado afecto. A veces nos indica el paciente hacia dónde tiene el vértigo más intenso y en otras puede ayudar la prueba térmica que detecta una paresia reversible del lado patológico.

\section{MANIOBRAS DE REPOSICIÓN DE PARTíCULAS}

No hay ensayos clínicos aleatorizados que proporcionen medidas fiables de efectividad ni existe suficiente evidencia científica para aconsejar una maniobra sobre otras.

Una vez establecido el diagnóstico es recomendable un tratamiento profiláctico antiemético e incluso con sedantes vestibulares antes de realizar las maniobras.

Una forma de iniciar el tratamiento, sobre todo si el paciente tiene síntomas vegetativos intensos, es anciano, obeso o con limitación de la movilidad, consiste en realizar una Maniobra de Vannucchi -forced prolonged position, 
FPP-. Localizado el lado afecto, el paciente debe acostarse sobre el lado sano (el del nistagmo menos intenso si geotrópico y el de mayor intensidad si ageotrópico) toda la noche (unas 12 horas), lo que permitiría que las otoconias salieran del canal por gravedad (con una eficacia del 75 al 90\%).

1. Si estamos ante una canalitiasis (nistagmo geotrópico más intenso hacia el lado afecto) podemos realizar la «maniobra de la barbacoa» o de Lempert. El paciente en posición supina y con la cabeza flexionada de 0 a $30^{\circ}$, la rota hacia el oído afecto (nistagmo más intenso). La cabeza va girando desde el lado afecto al lado sano con giros sucesivos de $90^{\circ}$ (boca arriba $\left(90^{\circ}\right)$, lado enfermo $\left(180^{\circ}\right)$, boca abajo (270) y de nuevo lado afecto (360), desde el que se sienta), manteniendo la cabeza al menos un minuto en cada posición. Si una posición provoca un vértigo más severo o nauseas deberemos esperar unos 4 minutos en dicha posición. El paciente completa un giro de 360 grados, terminando en la misma posición inicial. (Figuras 28, 29, 30, 31 y 32).

También podemos aplicar la Maniobra de Gufoni, en la que desde la posición sentada el paciente se tumba rápidamente hacia el lado sano (donde el nistagmo geotrópico es menos intenso). Esta maniobra debe ser rápida, golpeando la cabeza contra la camilla y al cabo de unos segundos se inclina la cabeza $45^{\circ}$ hacia abajo, permaneciendo 2 minutos antes de sentarse. La maniobra puede repetirse 3 veces. En un porcentaje de casos, la técnica provoca una conversión del VPPB del canal horizontal a otro del canal posterior, haciendo necesario el uso de maniobras de reposición específicas, tales como Epley o Semont (Figuras $33,34,35$ y 36 )

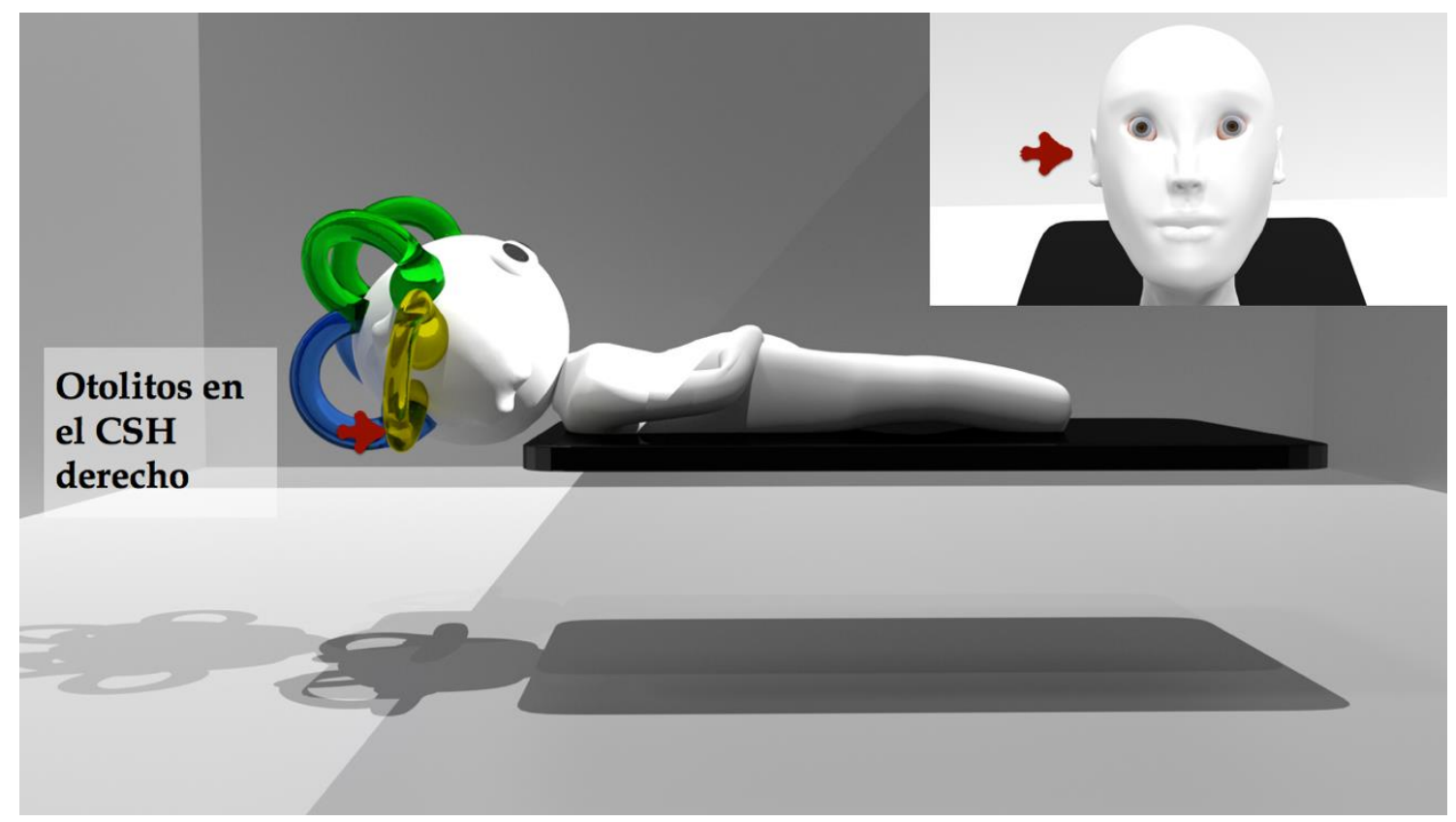

Figura 28. La maniobra de Lempert para la canalitiasis del canal horizontal (en este caso derecho) comienza con el paciente en decúbito supino. 


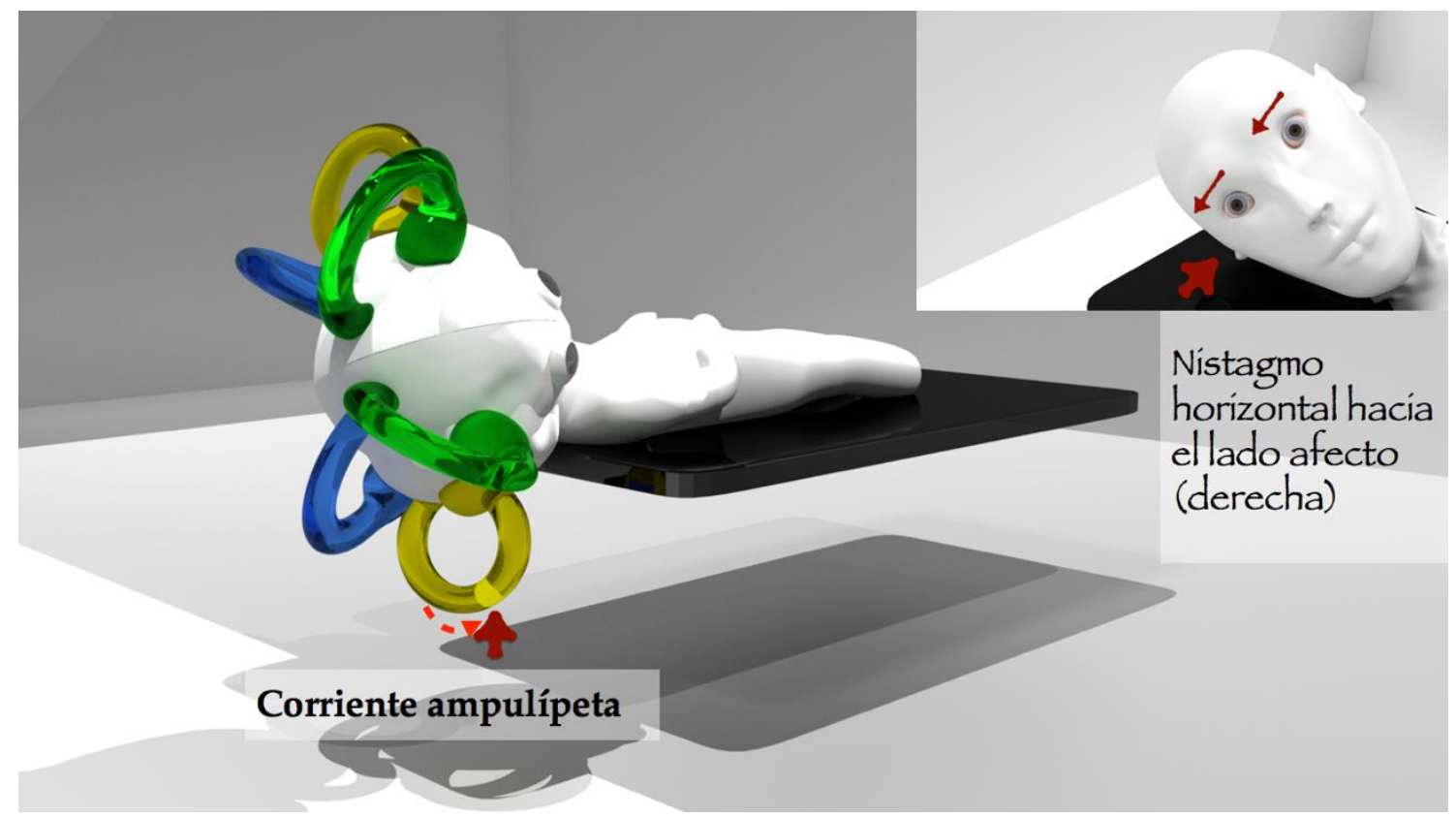

Figura 29. A continuación giramos la cabeza del paciente hacia el lado afecto. Esperaremos en cada posición al menos a que el nistagmo desaparezca. Este movimiento se realiza por la propia modificación de Lempert para tratar de "agrupar las otoconias antes de iniciar la maniobra completa.

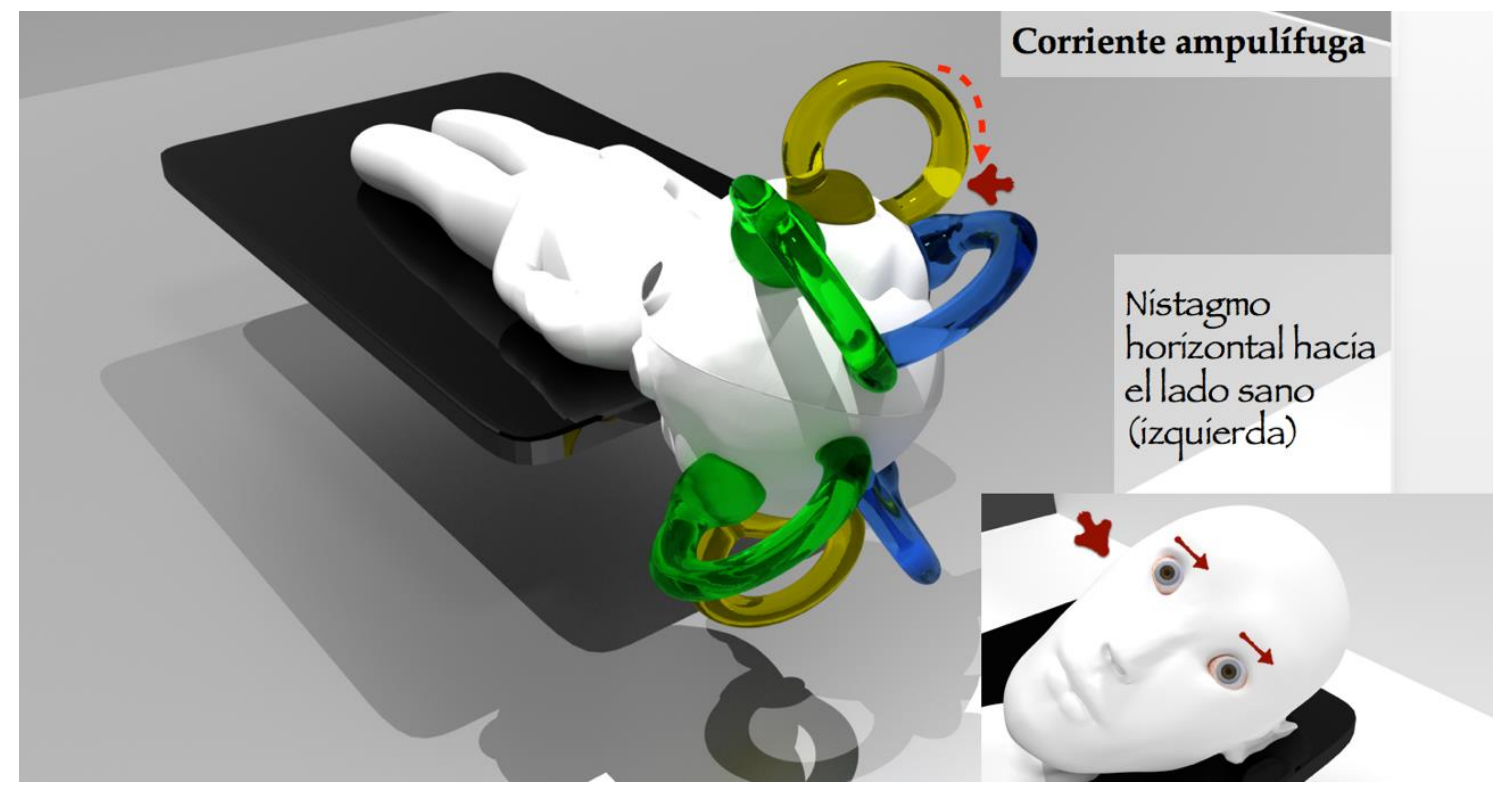

Figura 30. Seguidamente giraremos la cabeza del paciente hacia el lado sano. Objetivaremos, como es lógico, un nistagmo geotrópico. Esperaremos a que se agote. 


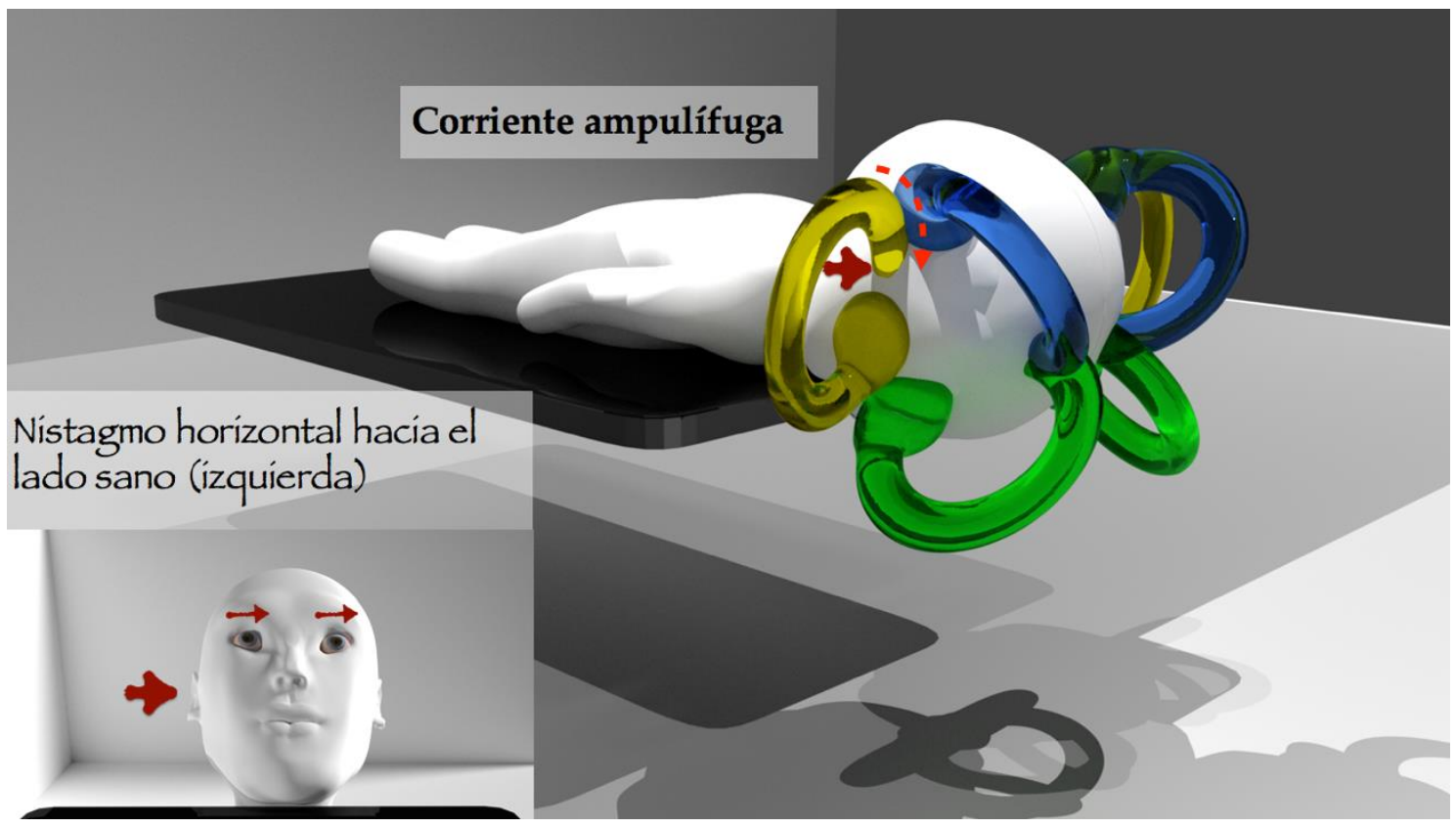

Figura 31. Una vez haya desaparecido el nistagmo, giraremos otros $90^{\circ}$ al enfermo, pasando a estar en decúbito prono, mirando al suelo.

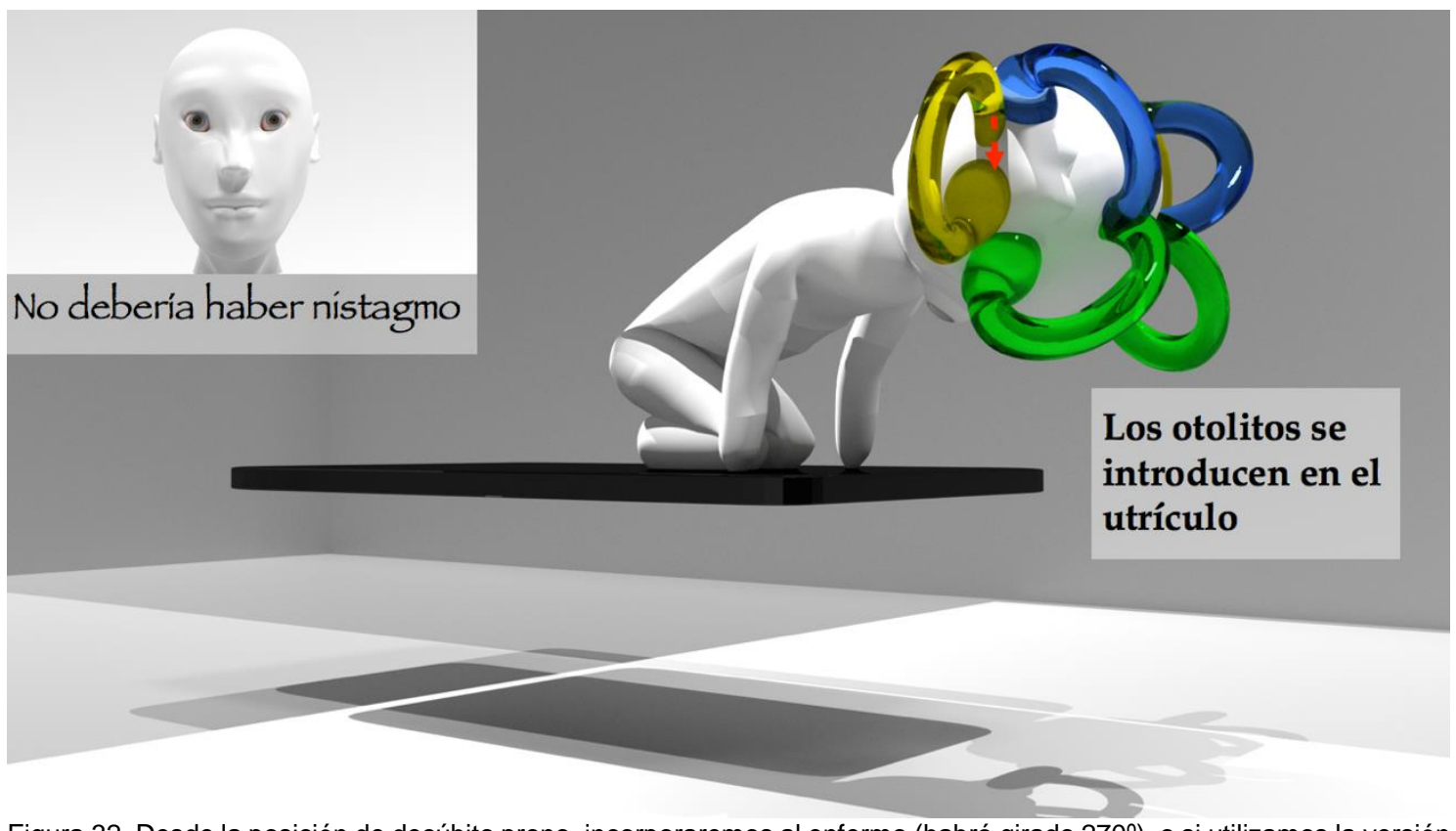

Figura 32. Desde la posición de decúbito prono, incorporaremos al enfermo (habrá girado $270^{\circ}$ ), o si utilizamos la versión modificada de esta maniobra, giraremos aún otros $90^{\circ}$ al enfermo en el sentido del giro que hemos llevado desde el inicio de la maniobra, llegando a posicionar la cabeza en la misma posición desde la que iniciamos la maniobra habrá girado $\left.360^{\circ}\right)$ 
Guía PRÁctica del VÉRTIGo Posicional PaROXístico BENIGNO BENITO-OREJAS JI ET AL.
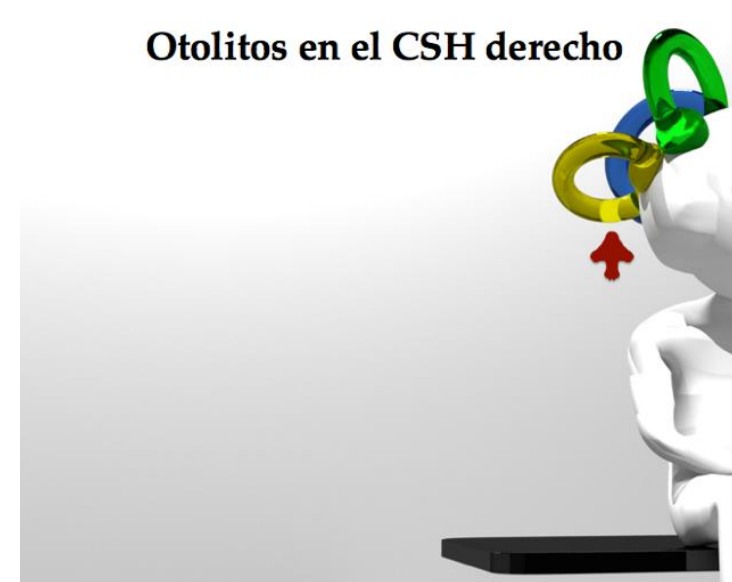
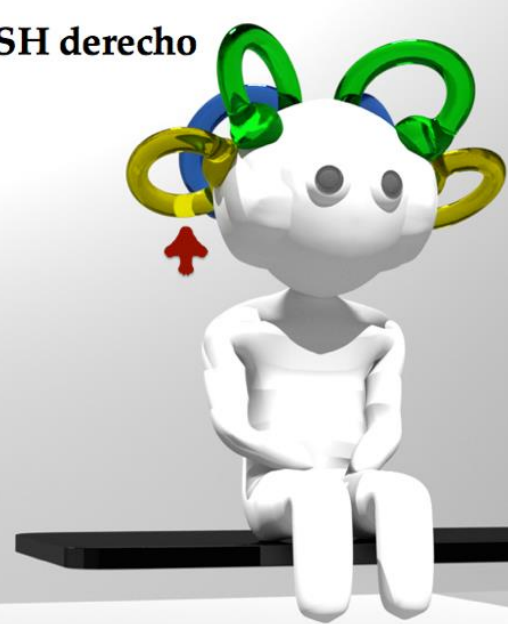

(
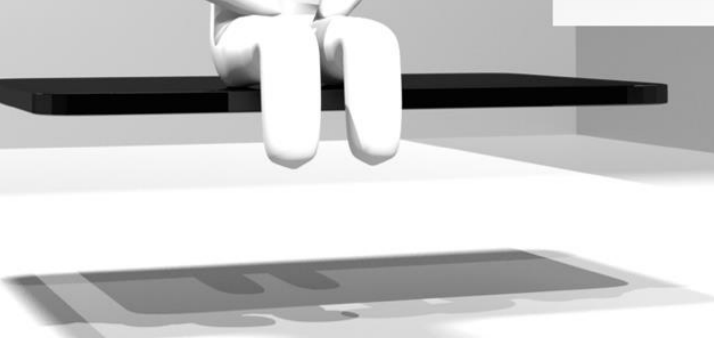

Figura 33. Maniobra de Gufoni para la canalitiasis del canal horizontal. El paciente se sitúa sentado sobre la camilla.

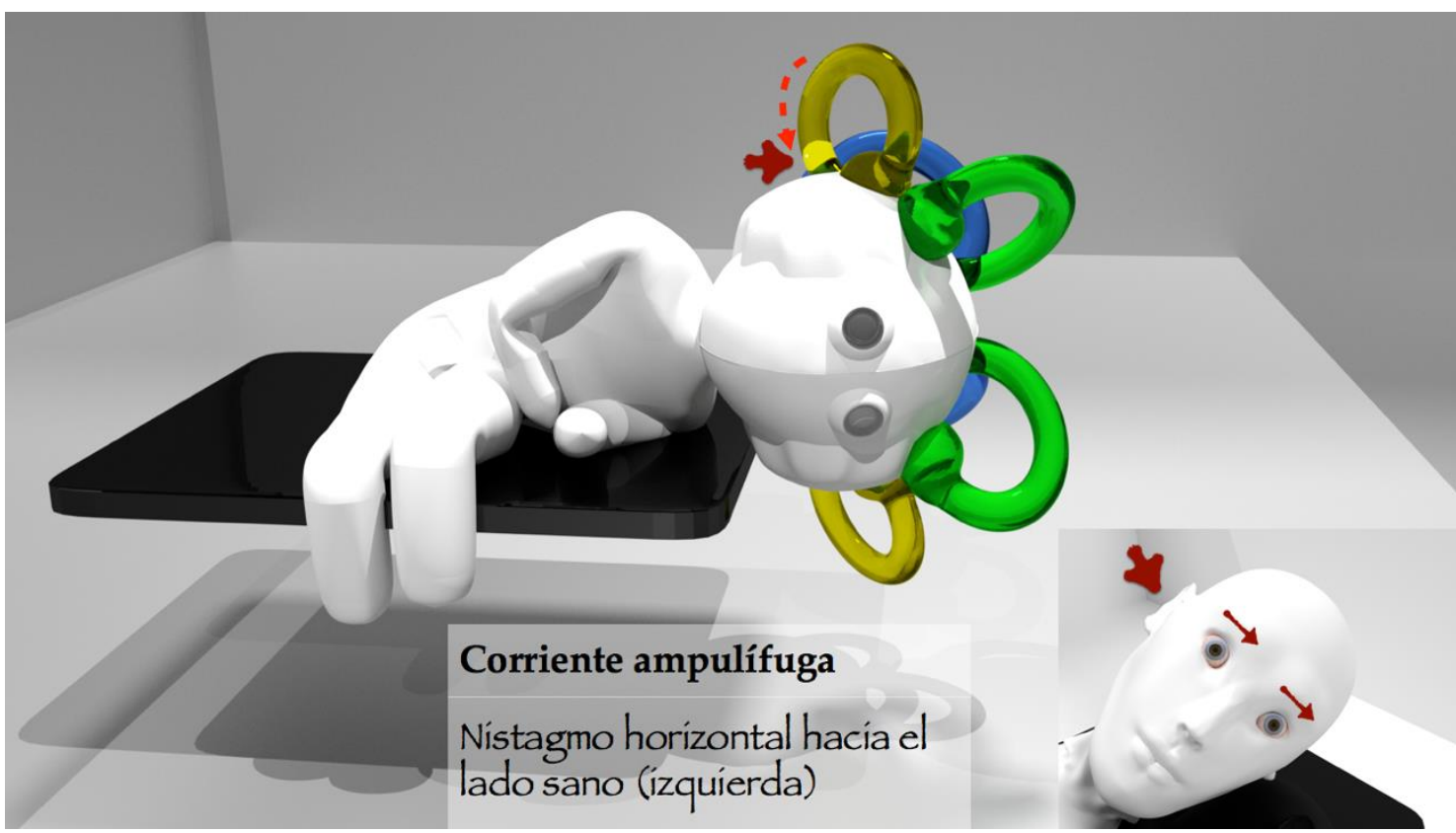

Figura 34. Maniobra de Gufoni para la canalitiasis del canal horizontal. Desde la posición de sentado el paciente se abate sobre el lado sano. 


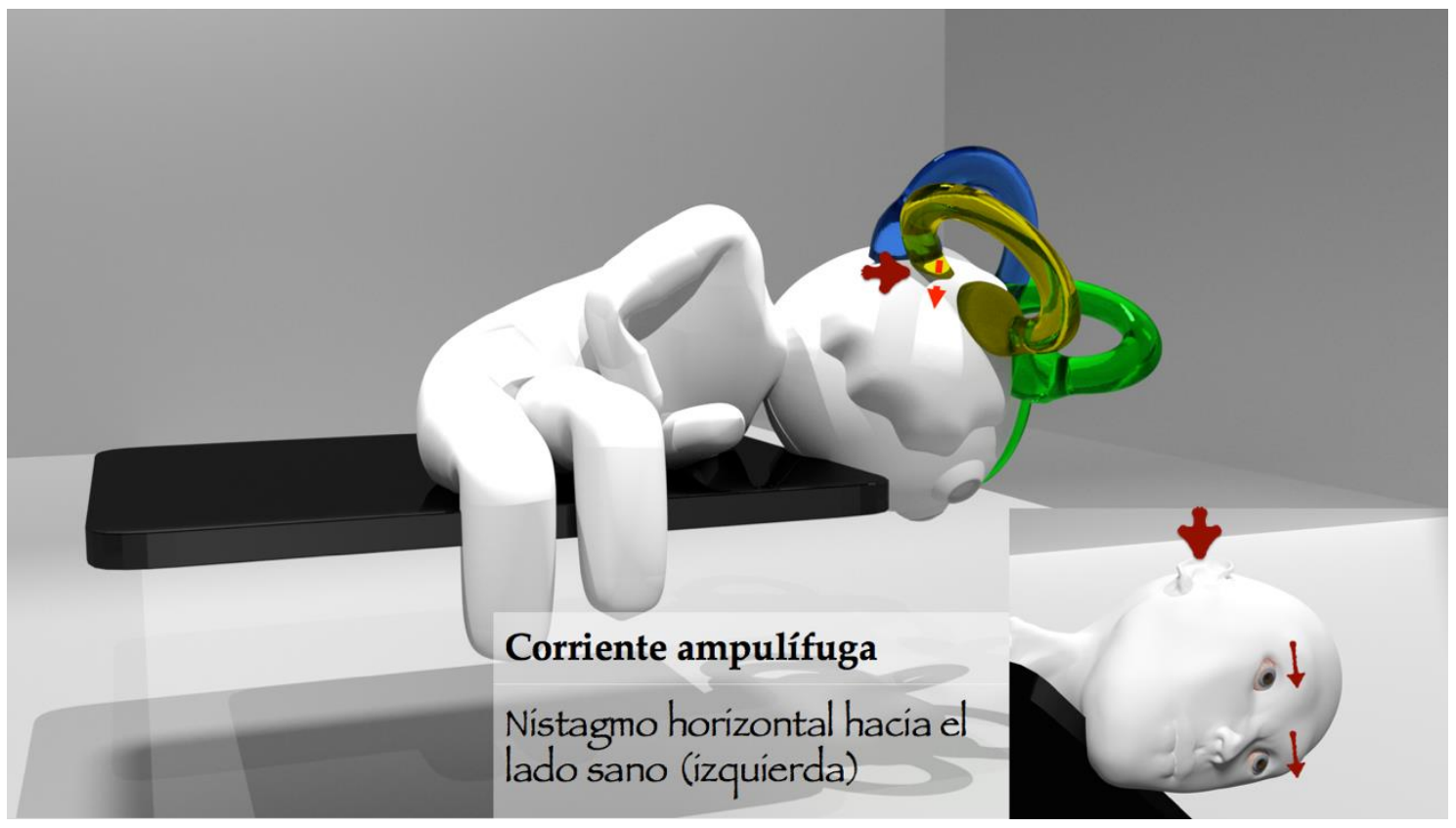

Figura 35. Maniobra de Gufoni para la canalitiasis del canal horizontal. Desde la posición previa, se gira la cabeza del enfermo $45^{\circ}$ hacia el suelo.

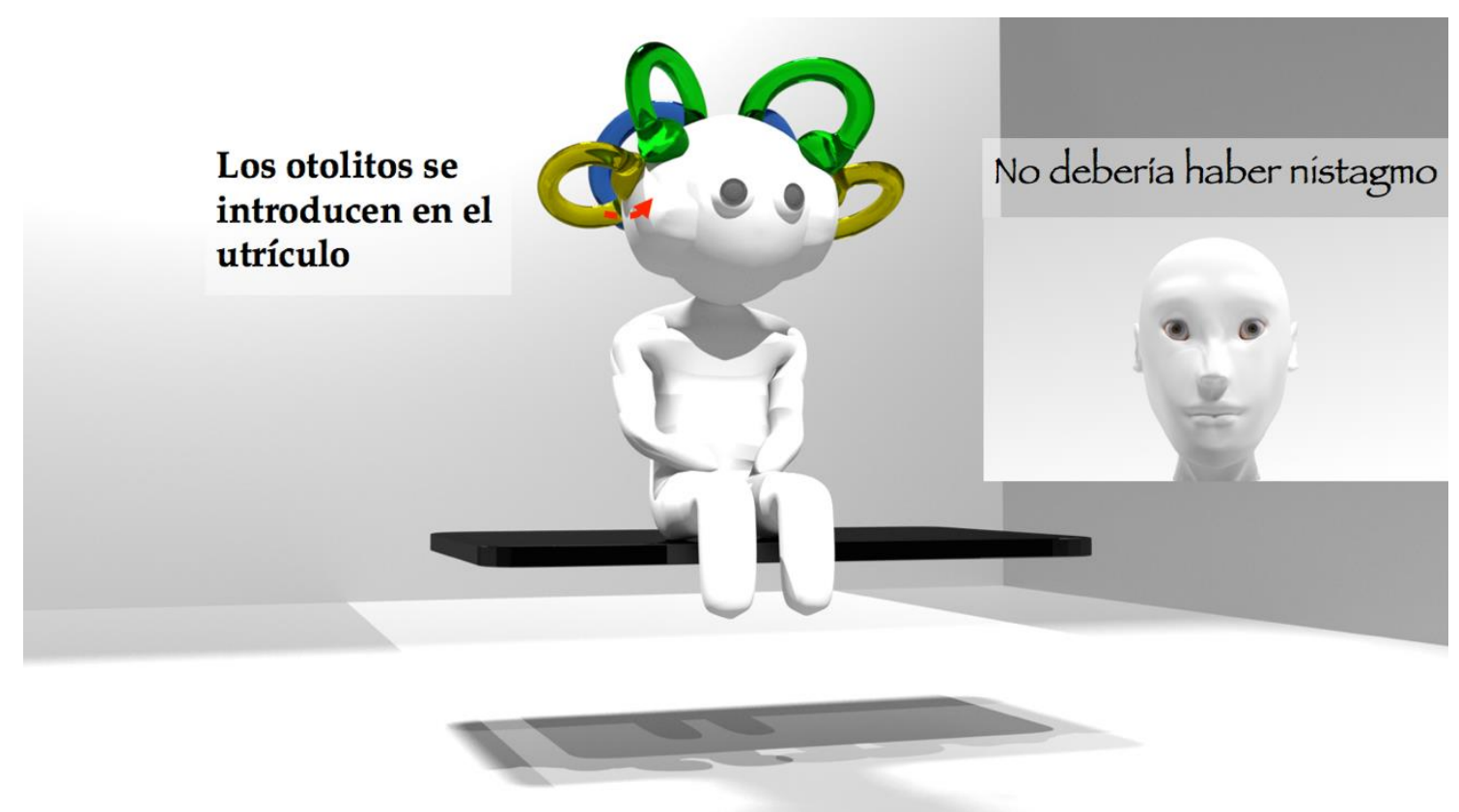

Figura 36. Maniobra de Gufoni para la canalitiasis del canal horizontal. Finalmente se incorpora al enfermo. 
2. Si se trata de una cupulolitiasis, el resultado de las maniobras es peor. Podemos empezar por una maniobra de Vannuchi de FPP sobre el lado sano (donde el nistagmo ageotrópico es más intenso, aunque a veces es difícil de reconocer). Pero también se puede intentar transformar la cupulolitiasis en canalitiasis, mediante distintas maniobras:

- En decúbito supino, se coloca la cabeza de 0 a $30^{\circ}$, hacia el oído afecto. Se gira bruscamente $90^{\circ}$ (nariz al frente) y otros $90^{\circ}$ hacia el oído sano, volviendo a continuación lentamente a la posición inicial, para repetir la maniobra.

- Maniobra de la barbacoa hacia el lado sano.

- Maniobra de Gufoni invertida. Desde la posición de sentado se tumba rápidamente sobre el lado afecto (donde el nistagmo ageotrópico es menos intenso) y tras unos segundos en esta posición se gira la cabeza $45^{\circ}$ con la nariz hacia arriba, donde se permanece unos 2 minutos antes de sentarse. Al ser una maniobra más rápida que la de Lempert y de eficacia similar, podríamos probar inicialmente con ella. (Figuras 37, 38, 39 y 40).

- Pero se pueden mezclar ambas. Comenzamos con la maniobra de Gufoni invertida: el paciente sentado, se tumba rápidamente de lado sobre el oído afecto, observando un nistagmo ageotrópico horizontal. A continuación, se le suben las piernas a la camiIla, manteniendo la cabeza girada hacia el lado enfermo y se inicia la técnica de rotación de Lempert, hacia el lado sano.
- Maniobra de Vannuchi-Asprella: se tumba rápidamente al paciente de sentado a decúbito supino, con la cabeza a 0 . Se gira bruscamente la cabeza hacia el lado sano (como en la primera maniobra). Desde esta posición se sienta al paciente (manteniendo la cabeza girada) y una vez sentado se coloca lentamente la cabeza hacia delante. Esta secuencia se debe repetir un mínimo de 5 veces.

Tras aplicar cualquiera de estas maniobras, verificamos el resultado al cabo de 30 minutos, repitiendo la maniobra de McClure-Pagnini (supine roll test). Si el nistagmo posicional ha cambiado de dirección y se ha hecho geotrópico, podemos aplicar las maniobras explicadas para la canalitiasis, si el estado del paciente lo permite, o indicarle la posición forzada de Vannucchi.

Alternativa: Si los síntomas persistieran a pesar de aplicar múltiples técnicas, le podemos indicar al paciente que realice en casa las $\mathrm{Ma}$ niobras de habituación modificadas de BrandtDaroff, en las que, comenzando en la posición sentada, se tumbaría rápidamente de cada lado, de forma alternante, comenzado por el oído afecto y con la cabeza derecha (sin rotar). Se mantiene en cada posición $30 \mathrm{~s}$. después de que el vértigo se detenga.

Aun siendo los resultados peores en la cupulolitiasis, la edad, el tiempo de evolución y la sumación de otras patologías médicas empeoraría la respuesta a las maniobras de reposición y aumentaría el número de las necesarias para resolver el proceso.

Recordar que un pequeño porcentaje de pacientes puede experimentar inestabilidad a pesar de la desaparición del vértigo posicional. En estos casos habría que valorar la posibilidad de rehabilitación vestibular. 
Guía PRÁctica del VÉRTIGo Posicional PaROXístico BENIGNO BENITO-OREJAS JI ET AL.
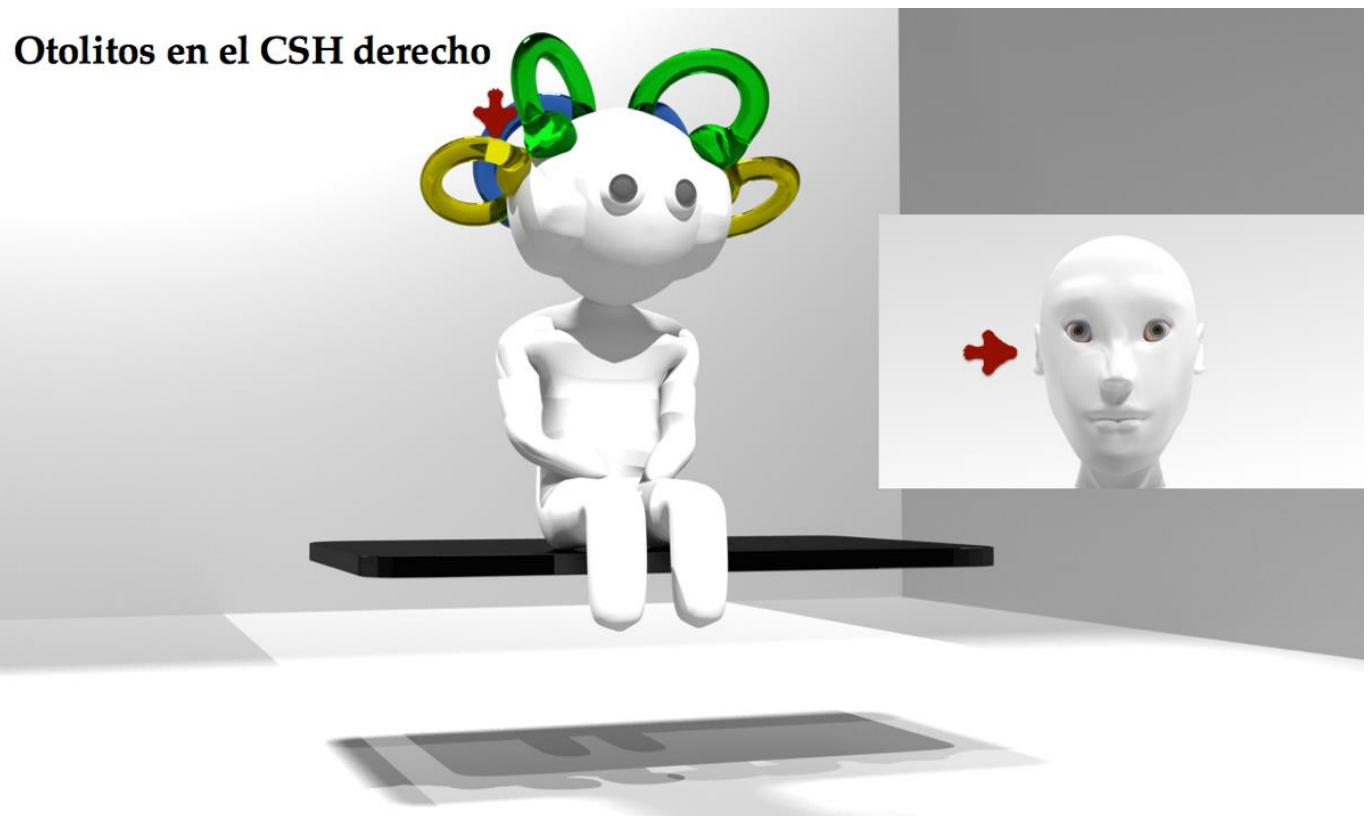

Figura 37. Maniobra de Gufoni para la cupulolitiasis del canal horizontal. El paciente se sitúa sentado sobre la camilla.

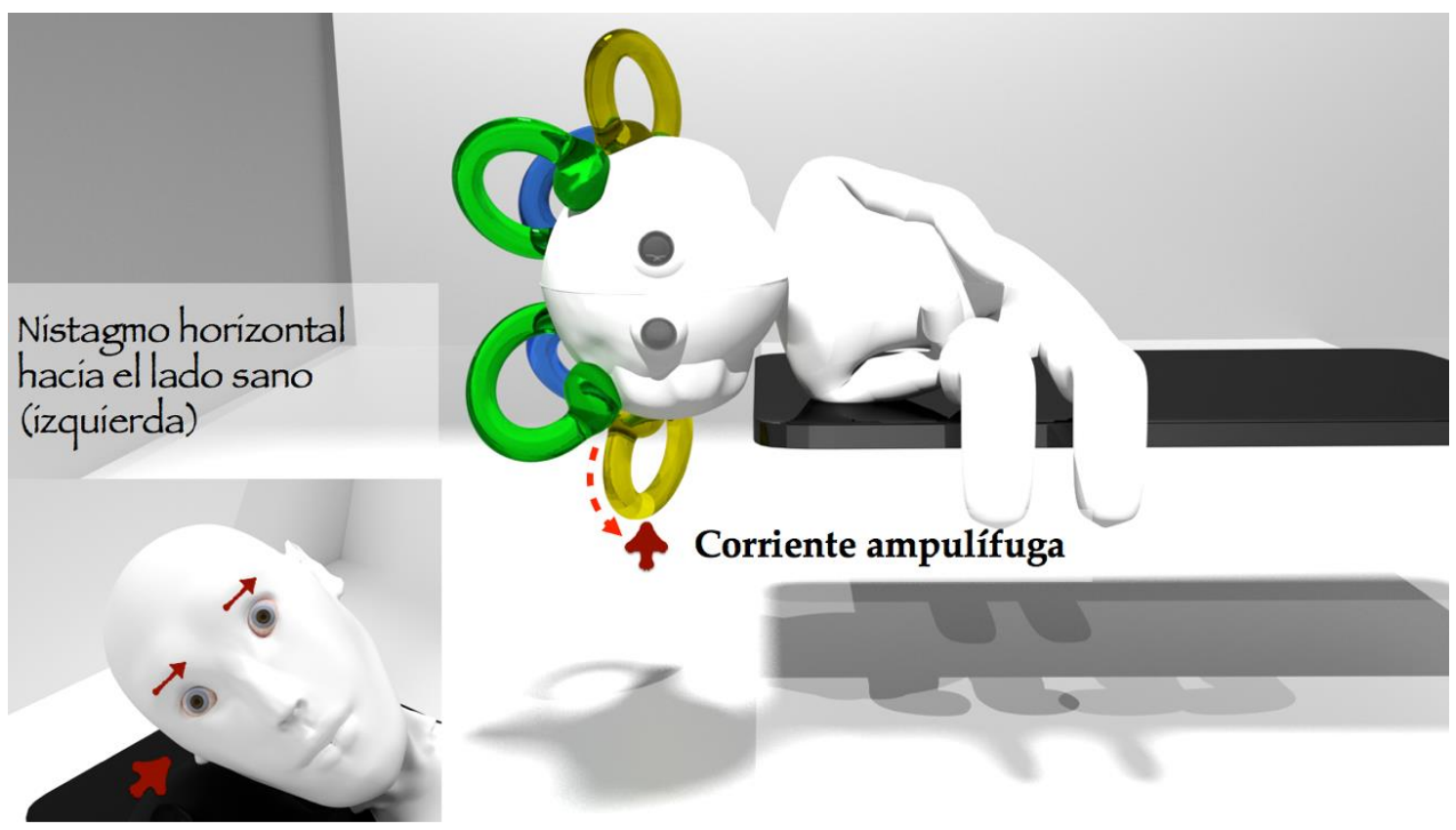

Figura 38. Maniobra de Gufoni para la cupulolitiasis del canal horizontal. Desde la posición de sentado el paciente se abate sobre el lado enfermo. 


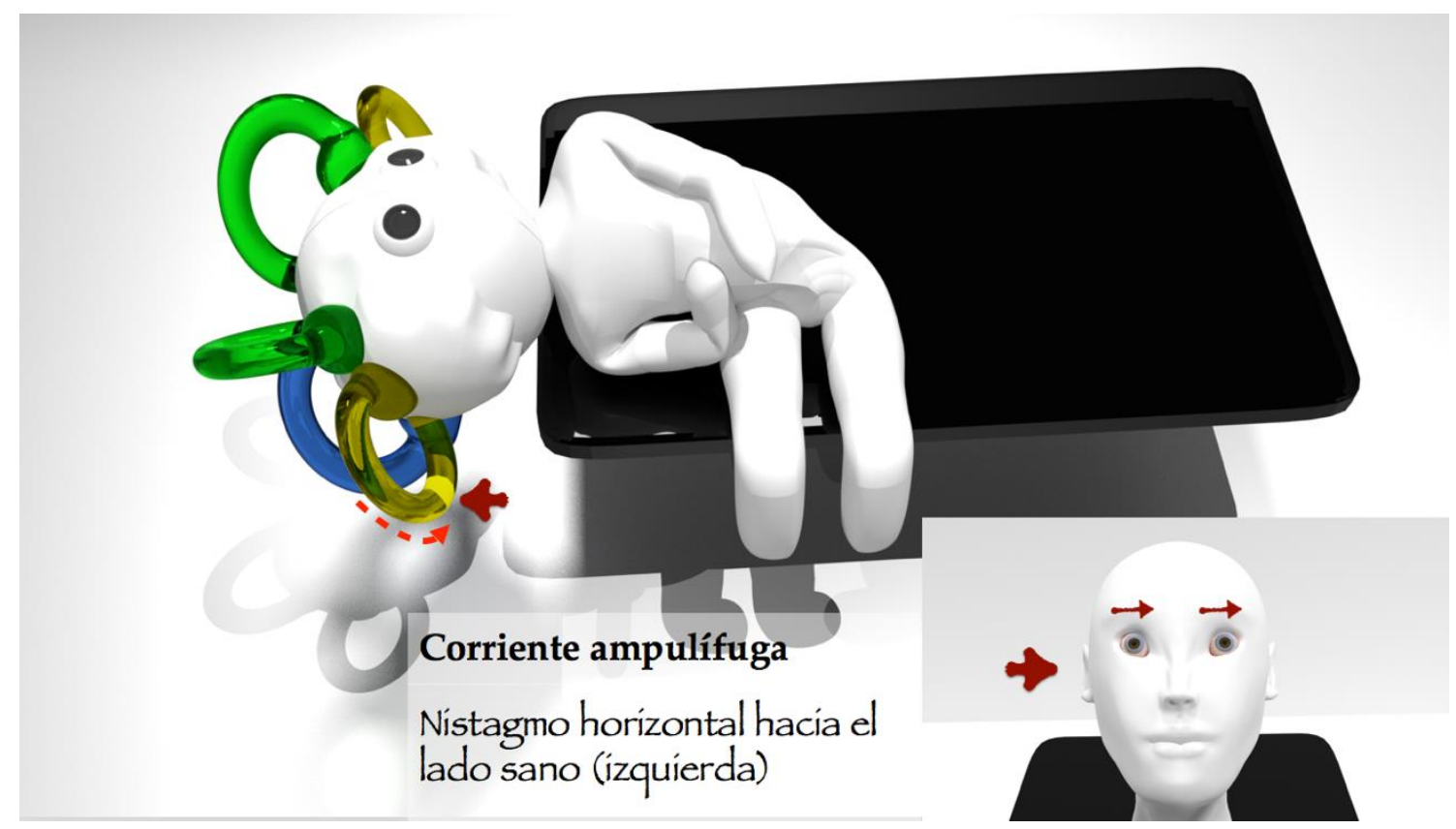

Figura 39. Maniobra de Gufoni para la canalitiasis del canal horizontal. Desde la posición previa, se gira la cabeza del enfermo $45^{\circ}$ hacia el techo.
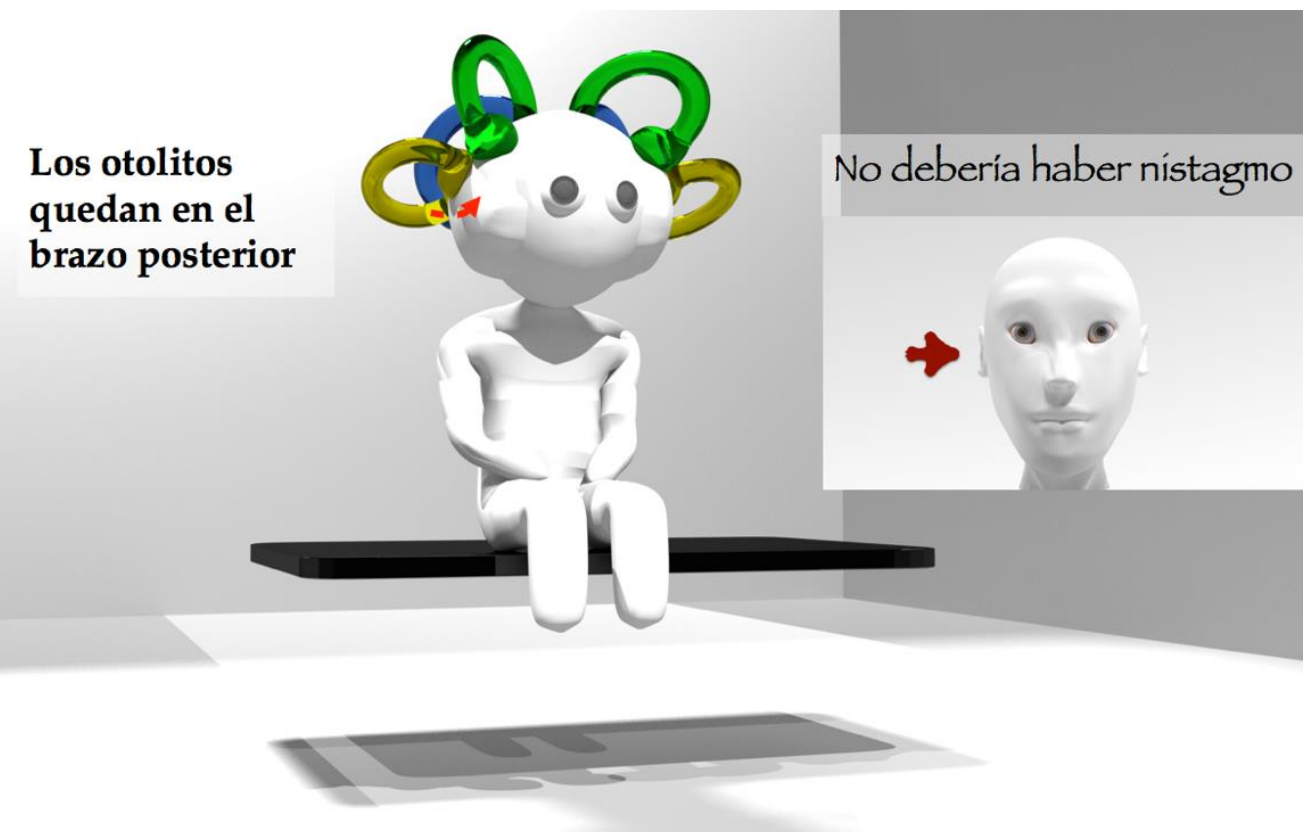

Figura 40. Maniobra de Gufoni para la canalitiasis del canal horizontal. Finalmente se incorpora al enfermo. 


\section{VPPB DEL CONDUCTO SEMICIRCULAR ANTERIOR/SUPERIOR (CSA) $[3-10,17]$}

\section{CARACTERÍSTICAS GENERALES}

La variante anterior se considera la forma menos común de VPPB, con una frecuencia de un $1 \%$ a $24 \%$. La baja incidencia de litiasis del conducto anterior se atribuye a las características anatómicas del laberinto. Las partículas del conducto anterior suelen eliminarse, debido a que el brazo posterior del canal anterior desciende hacia la cruz común y el utrículo, favoreciéndose la expulsión de otoconias.

\section{DIAGNÓSTICO}

Los criterios diagnósticos, según el Consensus Document of the Committee for the Classification of Vestibular Disorders of the Bárány Society, 2015, son:

- Ataques recurrentes de vértigo provocados al acostarse o girar en la posición de decúbito supino.

- Se desencadenan inmediatamente o tras unos segundos, con la maniobra de DixHallpike (en uno o ambos lados) o en la posición de cabeza colgando.

- La duración del vértigo no suele exceder el minuto. Los ataques más largos deben considerarse atípicos y emprender la búsqueda de diagnósticos alternativos o adicionales.

- La latencia de aparición del nistagmo tras provocar la maniobra desencadenante puede llegar a ser hasta de 30 segundos.

- El diagnóstico definitivo de un VPPB por canalitiasis del CSA se establece si se evidencia la inmediata resolución del nistagmo posicional después de una maniobra terapéutica. Pero si el nistagmo es refractario a estas maniobras, podemos dar un diagnóstico probable de VPPB por canalitiasis del CSA, siempre y cuando se haya descartado patología del SNC.
- También apoya el diagnóstico, la transición a canalitiasis del CSP y a canalitiasis o cupulolitiasis del $\mathrm{CSH}$, durante las maniobras de reposición.

\section{MANIOBRAS DE EXPLORACIÓN DEL CSA}

- Maniobra de Dix-Hallpike.

- Maniobra de cabeza colgando (en hiperextensión) en decúbito supino.

Tras dichas maniobras se desencadena un nistagmo posicional con batidas hacia abajo y con un pequeño componente torsional geotrópico o ageotrópico. La estimulación del CSA genera una respuesta oculomotriz con contracción del músculo recto superior ipsilateral y del músculo oblicuo inferior contralateral, que produce el nistagmo descrito.

MANIOBRAS DE REPOSICIÓN DE PARTÍCULAS:

- Maniobra de Epley contralateral (es decir, empezando por el lado sano).

- Pero también se han visto buenos resultados realizando la maniobra de Epley desde el lado afectado.

- Maniobra de Yacovino, que tiene la ventaja de no requerir la identificación del lado afecto. Se inicia con el paciente sentado en la camilla de exploración, haciendo que adopte con rapidez la posición de decúbito supino con la cabeza colgando por fuera de la camilla. Esperamos 30-60 segundos y flexionamos la cabeza hasta que la barbilla toque el pecho y tras esperar otros 30-60 segundos, finalizamos con la posición que el paciente tenía en un inicio -posición de sentado-(Figuras 41, 42, 43 y 44). 


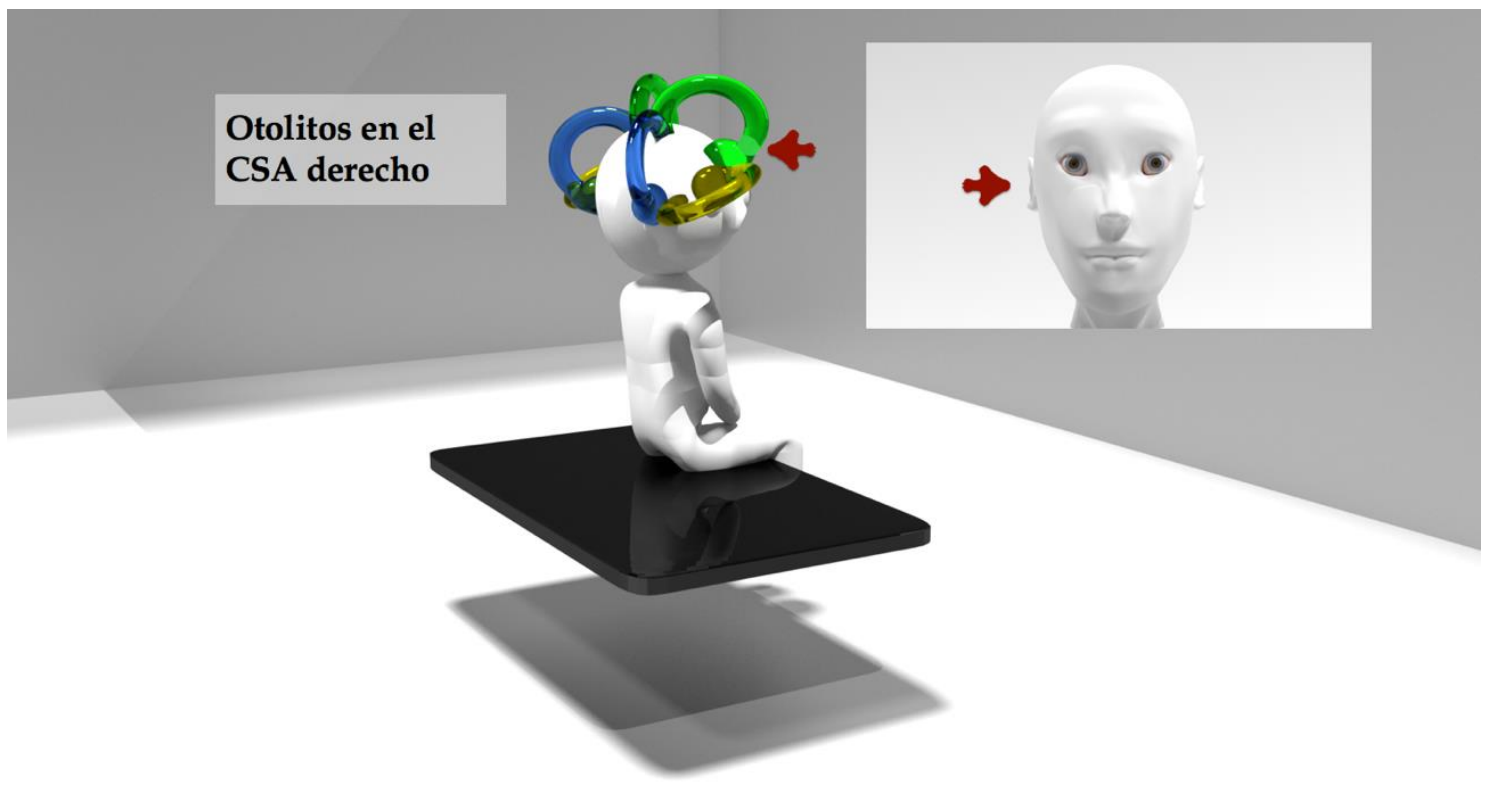

Figura 41. Maniobra de Yacovino para el canal semicircular anterior. El paciente permanece sentado, mirando al frente.

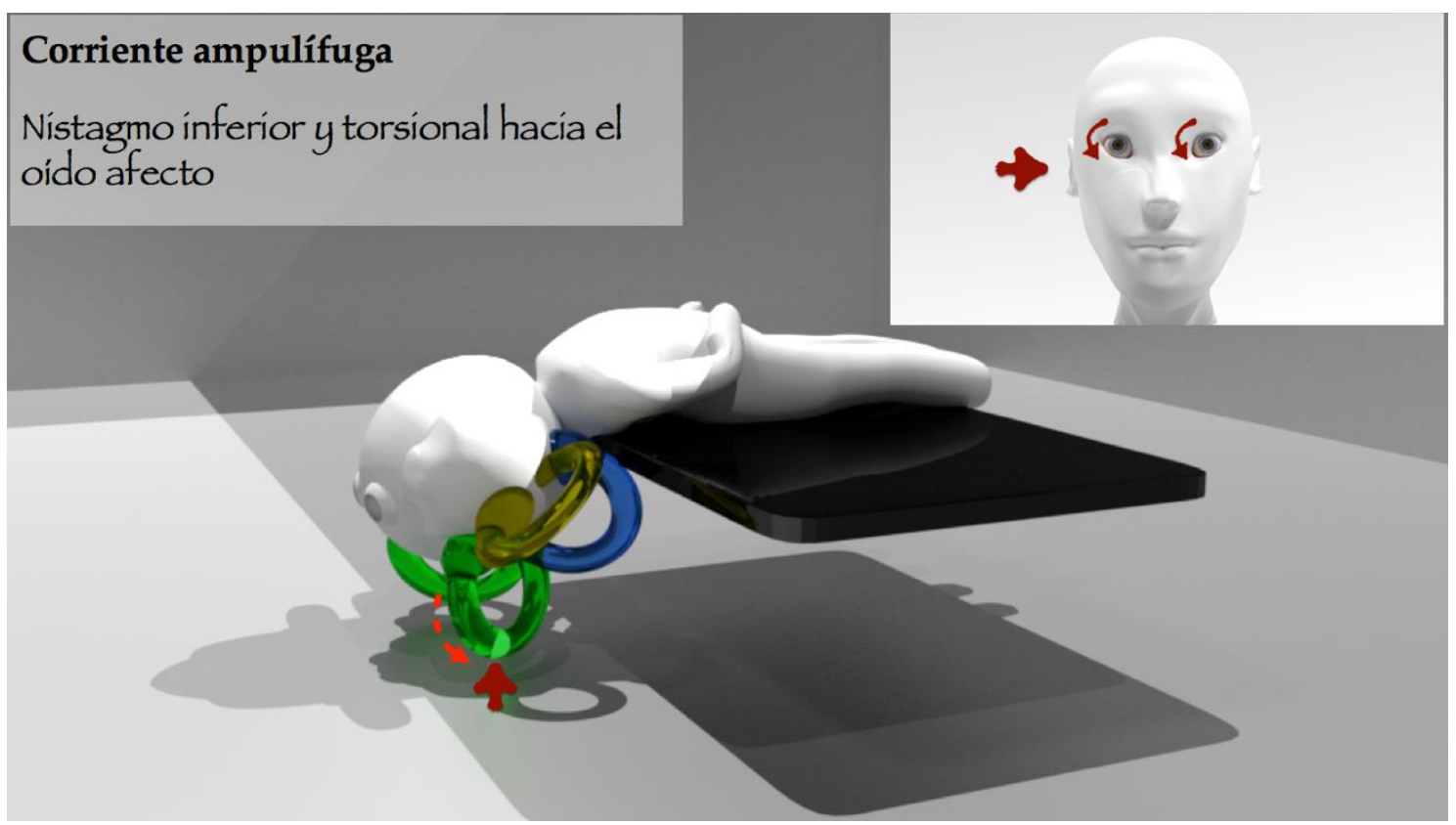

Figura 42. Maniobra de Yacovino para el canal semicircular anterior. Desde la posición de sentado, el paciente pasa a la posición de decúbito supino, con hiperextensión de la cabeza. En esa posición observaremos el nistagmo característico del VPPB de canal anterior, que es un nistagmo vertical inferior con componente rotatorio hacia el lado afecto. 


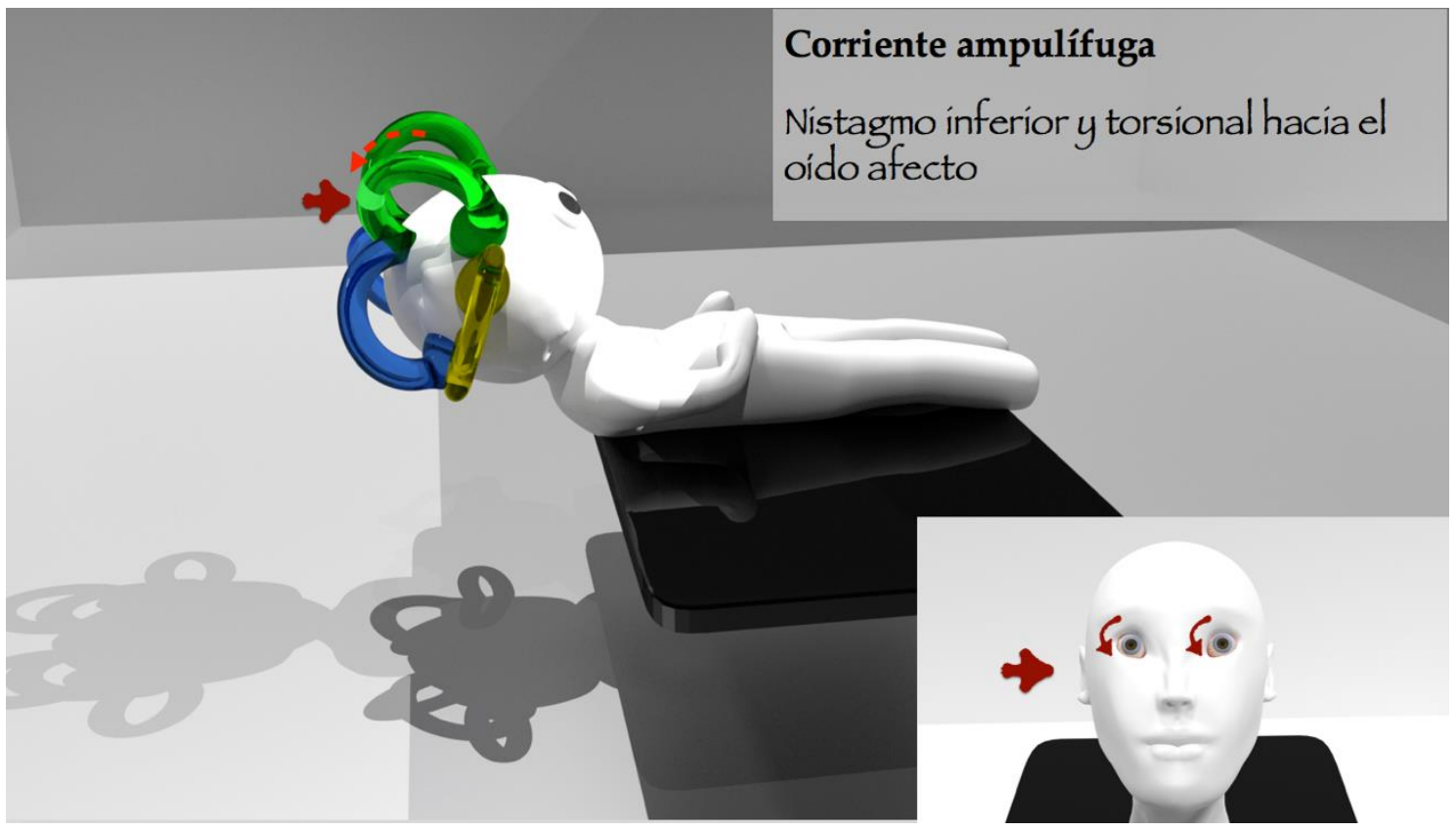

Figura 43. Maniobra de Yacovino para el canal semicircular anterior. Con el paciente en decúbito supino, se hiperflexiona la cabeza. En esta segunda posición se debe objetivar un nistagmo similar al de la posición anterior.

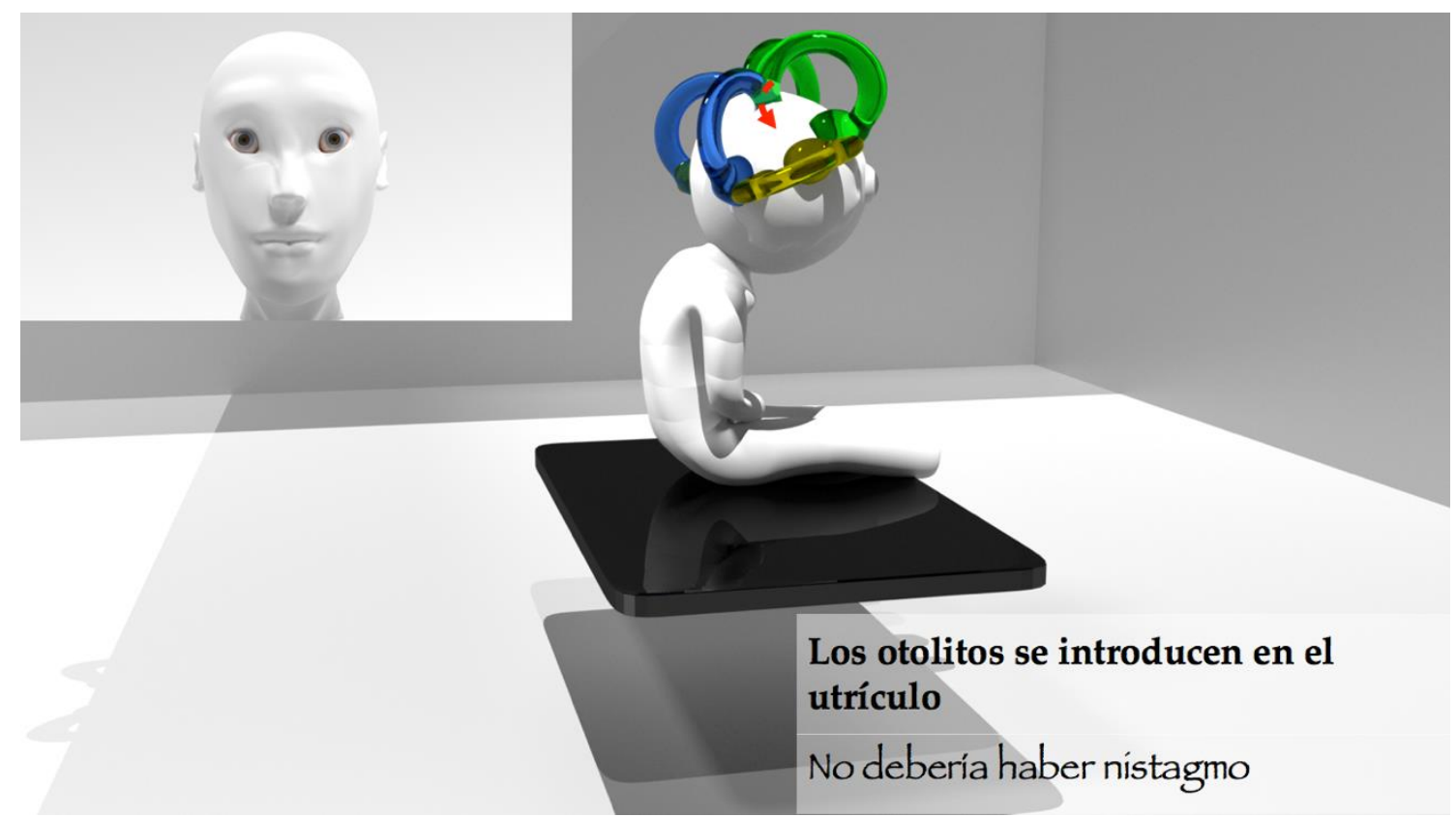

Figura 44. Maniobra de Yacovino para el canal semicircular anterior. Con la cabeza hiperflexionada se incorpora al enfermo hasta la posición de sentado. 
4. VPPB CON AFECTACIÓN MULTICANAL $[2,3,5-10]$

\section{CARACTERÍSTICAS GENERALES}

Aunque el VPPB generalmente deriva de un solo CS, la alteración de varios se describe entre un 5 y un $20 \%$ de casos. Esta afectación múltiple puede provenir de la litiasis del mismo canal en ambos lados (1ª categoría) o de diferentes canales en el mismo o en ambos lados (2 ${ }^{a}$ categoría).

En la 1a categoría destaca la afectación bilateral del CSP y en la $2^{a}$ categoría la alteración unilateral del CSH y CSP (por razones anatómicas el CSA es menos probable que se vea involucrado).

Predomina en el género femenino y la principal causa es el traumatismo craneal o cervical, aunque también se ha descrito relacionado con enfermedades otológicas, especialmente la laberintitis (paresia vestibular e hipoacusia súbita), donde la inflamación del utrículo facilitaría la liberación de otoconias. El antecedente de VPPB es relativamente frecuente en el unilateral multicanal y no sorprende el que una maniobra de reposición para el CSP provoque una litiasis en el CSH (VPPB transicional del $\mathrm{CSH})$, ¿qué podría ser asintomática durante un tiempo?

\section{DIAGNÓSTICO}

El diagnóstico del VPPB multicanal se basa en encontrar una combinación de hallazgos, según los canales afectados (presencia de nistagmo con sus características, al realizar DixHallpike para los canales anterior y posterior, maniobra de McClure-Pagnini (supine roll test) para el horizontal y la maniobra de cabeza colgando). La afectación de varios canales permite ser mejor evaluada mediante videooculografía.

En los casos de afectación bilateral del CSP, se observará en el Dix-Hallpike de cada lado, el típico nistagmo mixto.

\section{Aviso}

Debemos diferenciarlo del VPPB seudobilateral posterior, que aparece cuando al explorar el lado bueno (en una afectación unilateral del CSP) la cabeza no se coloca apropiadamente y los otolitos del CSP lesionado se mueven hacia la cúpula, generando un nistagmo inhibitorio, que se dirige hacia el oído sano, dando la impresión de bilateralidad. La diferencia se puede detectar porque el nistagmo inhibitorio tiene generalmente una menor amplitud y frecuencia que el del lado afecto y los pacientes expresan menos síntomas al explorar el oído sano. Si tumbamos al paciente con la cabeza en la línea media y colgando (por debajo del plano horizontal), la afectación bilateral, provoca la anulación del componente torsional y sólo se observa un intenso nistagmo que bate hacia arriba, mientras que, en el seudobilateral, sí aparece un componente torsional que bate hacia el oído afecto. En cualquier caso, se debe tratar inicialmente el lado más intenso, tras lo cual observaremos que desaparece completamente la sintomatología, evidenciando que se trataba de una afectación seudobilateral (sólo del lado con mayor sintomatología). Se considera que la mayor frecuencia de afectación bilateral del CSP estaría sobreestimada por inclusión de estos casos seudobilaterales.

Por lo explicado, se puede comprender que será muy difícil diagnosticar, la afectación bilateral del CSA o del CSH, cuya exploración ofrece síntomas de ambos lados. En el caso de una canalitiasis bilateral del CSA, la sumación vectorial de todos los componentes provocará un nistagmo intenso vertical inferior (con débil o ausente componente torsional) de ambos lados; lo que en ocasiones también se ve en las formas unilaterales. Al tumbar al paciente con la cabeza extendida, se anulan los componentes torsionales y aparece un nistagmo vertical de dirección inferior, que tampoco descarta la afectación unilateral. El criterio de respuesta al tratamiento no es tan claro en este caso, porque no hay una maniobra terapéutica establecida en el tratamiento del CSA y tanto la de Epley (directa o inversa) como otras, pueden ser útiles. Por su parte, la afección bilateral de ambos CSH se manifestará "teóricamente" con un nistagmo simétrico geotrópico o ageotrópico (según se trate de canalitiasis o cupulolitiasis), más intenso que la alteración unilateral (aunque la simetría no es un criterio sólido, porque también puede haber una afectación asimétrica de ambos CSH); sin embargo, no es infrecuente en estos casos que al tumbar al paciente con la cabeza colgando aparezca un nistagmo horizontal, cuya dirección marca el lado afecto (hacia donde bate si en las posiciones laterales es geotrópico o hacia el lado contrario si ageotrópico). Con frecuencia, la maniobra de reposición de la barbacoa (maniobra de Lempert) en una dirección provoca la remisión de los síntomas. 
Aún se puede complicar más el diagnóstico si se combina la canalitiasis y la cupulolitiasis en cada lado.

La perturbación de diferentes canales de ambos o del mismo lado es más fácil de diagnosticar. Se han publicado todas las combinaciones: CSP y CSA, CSP y CSH, CSA y CSH de uno y ambos lados. La combinación más frecuente es la canalitiasis del CSH y CSP. No hemos encontrado descrita la litiasis de los 3 canales semicirculares.

Diagnóstico diferencial: con varios desórdenes vestibulares centrales; destacando el vértigo posicional central, la isquemia vertebro-basilar transitoria y el vértigo posicional migrañoso.

\section{MANIOBRAS DE REPOSICIÓN DE PARTÍCULAS} Las sesiones se repiten entre 1 y 7 días, tratando 1 sólo canal durante cada sesión, o repitiendo la maniobra previa de reposición de partículas, si la remisión ha sido incompleta. Se suele iniciar el tratamiento por el canal que causa mayor sintomatología, suponiendo además que es el que lleva mayor cantidad de otolitos libres, siendo generalmente horizontal, posterior y anterior. Se considera que el tratamiento ha tenido éxito, cuando el paciente mejora los síntomas y las pruebas diagnósticas de Dix-Hallpike y supine roll test, son negativas a los 2 meses. Después de 2 años de ausencia de síntomas, se supone que la curación ha sido definitiva.

Los resultados obtenidos con el tratamiento son comparables a los que resultan de la afectación de un solo canal (porcentaje de curación superior al $90 \%$ ). Entre 2 y 4 sesiones terapéuticas suelen ser suficientes (tratamiento más prolongado, con mayor número de maniobras, pero igual de efectivo que en el unicanal). Las recurrencias son también similares en el VPPB uni o multicanal. La afectación vestibular residual y la influencia de las causas favorecedoras (isquémicas, metabólicas, posicionales...) suelen ser desconocidas.

Aviso

- Tras un traumatismo craneocervical pensar y buscar una posible afectación multicanal.

- Diferenciar con la exploración la afectación bilateral del CSP de la seudobilateral. Ante la duda, iniciar la maniobra de reposición de partículas en el lado con mayor sintomatología.
- Con la excepción comentada, la litiasis bilateral del CSP es fácil de detectar, pero resulta casi imposible si se le suma una afectación bilateral de ambos CSA o de ambos $\mathrm{CSH}$.

- El diagnóstico es bastante seguro en casos típicos de lesión combinada del CSP y CSH o del CSA y CSH, pero la combinación del CSA y CSP resulta muy difícil de descubrir. El uso de la video-oculografía facilita el diagnóstico.

- En caso de nistagmo vertical inferior, por posible afectación del CSA, realizar una RM para descartar etiología central.

\section{VPPB ATÍPICO Y CENTRAL $[18,19]$}

\section{CARACTERÍSTICAS GENERALES}

Desafortunadamente, no todos los vértigos posicionales son benignos ya que síntomas similares pueden estar causados por enfermedades que afectan al sistema nervioso central (SNC) de diversa relevancia y gravedad. Existen diversas patologías que afectan al SNC, como malformaciones, enfermedades desmielinizantes, migraña vestibular, tumores cerebelosos y pequeñas lesiones isquémicas en el vestíbulo-cerebelo especialmente en el nódulo, los pedúnculos cerebelosos o las estructuras del tronco del encéfalo próximas al IV ventrículo que pueden provocar un vértigo posicional.

La migraña vestibular debería tener una mención aparte, pues sabemos que en ella existe una frecuente asociación con el VPPB, que, además, suele tener más alta tasa de recidivas y de menor duración en el tiempo.

\section{DIAGNÓSTICO}

Existe un conjunto de signos de alarma en la exploración que pueden sugerir la presencia de un vértigo posicional paroxístico de origen central y que nos orientan a solicitar una prueba de imagen (la de elección es la RM):

1. Signos y síntomas neurológicos. Presencia de otros signos y síntomas neurológicos. De ahí la importancia de la anamnesis y la realización de una exploración neurológica minuciosa. Es importante tener en cuenta que la aparición de estos síntomas no excluye un VPPB. 
2. Nistagmo sin mareo/vértigo en las maniobras posicionales. Aparición de un nistagmo sin mareo/sensación vertiginosa en las maniobras posicionales.

3. Nistagmo de dirección atípica en las maniobras posicionales:

- Nistagmo vertical inferior. Teniendo en cuenta que:

- Puede estar presente en pacientes con migraña.

- Si tiene componente torsional, pudiera tratarse de un VPPB del CSA. Aunque la afectación de dicho canal es muy infrecuente, probablemente esté subestimada.

- Nistagmo de dirección cambiante. Nistagmo que cambia de dirección tras realizar las mismas maniobras diagnósticas en diferentes momentos. En este caso, si la prueba de imagen no muestra alteraciones, es recomendable solicitar la valoración de un neurólogo.

4. Pobre respuesta a maniobras terapéuticas. El estudio por imagen puede ser útil para detectar alteraciones anatómicas en los conductos semicirculares además de patología del SNC.

5. Alta recurrencia de los síntomas. La tasa de recurrencia esperada es aproximadamente del $27 \%$ a los 10 años, aunque dependiendo de los estudios puede variar hasta un $50 \%$ entre 5 y 10 años. Cuando se constatan 3 o más recidivas sería conveniente solicitar RM.

\section{AVISO}

Si el nistagmo cambia de dirección al colocar al paciente en la misma posición puede ser central; pero si el nistagmo cambia, al colocar al paciente en diferentes posiciones, puede ser debido a un VPPB multicanal. Además, debemos tener presente que, si hemos realizado maniobras de reposición de partículas, el cambio de la dirección del nistagmo puede estar justificado por la introducción de las otoconias en otro canal semicircular (típica conversión de una canalitiasis del CSP en canalitiasis del $\mathrm{CSH}$.

\section{6- VPPB SUBJETIVO (20)}

CARACTERÍSTICAS GENERALES

El término VPPB subjetivo fue introducido por Haynes et al. en 2002, quienes estudiaron por primera vez a un grupo de pacientes con sintomatología clara de VPPB, pero en el que no objetivaban nistagmo en las maniobras de provocación.

EI VPPB subjetivo se puede enmarcar en el item 3.4 del Consensus Document of the Committee for the Classification of Vestibular Disorders of the Bárány Society -VPPB posible-. Esta categoría acoge aquellos casos en los que falta uno de los criterios mayores de diagnóstico de VPPB, en este caso el nistagmo.

Se define VPPB subjetivo como aquel en el que aparece una historia clínica compatible y toda la sintomatología de VPPB en las maniobras de provocación, pero sin evidenciar el nistagmo característico del VPPB correspondiente.

EI VPPB subjetivo es bastante común y su porcentaje respecto al VPPB varía entre un $11.5 \%$ y un $48 \%$. Es necesario precisar que esta proporción disminuye en las grandes series estudiadas de VPPB, en la medida en la que se utilizan las gafas de Frenzel o la videonistagmoscopia en el diagnóstico.

\section{DIAGNÓSTICO}

La exploración del paciente con VPPB no difiere de la exploración típica. El diagnóstico se deriva de la ausencia de nistagmo en la maniobra de provocación en un paciente que sí presenta sintomatología cuando se realiza dicha maniobra.

Diagnóstico diferencial:

En el caso del VPPB subjetivo el diagnóstico diferencial es más importante si cabe. Las causas más frecuentes de vértigo posicional que debemos descartar son la isquemia vertebrobasilar transitoria, el vértigo posicional central y el infarto cerebeloso en cuanto a causas centrales y las fístulas perilinfáticas y la dehiscencia de canal semicircular superior entre las periféricas.

\section{MANIOBRAS DE REPOSICIÓN DE PARTÍCULAS}

Todos los trabajos publicados sobre VPPB están de acuerdo en que el VPPB subjetivo debe ser tratado con la maniobra de reposición correspondiente, siempre y cuando el canal implicado sea fácilmente identificable, esto es, 
cuando la sintomatología que presenta el paciente esté claramente relacionada con la exploración de un canal determinado.

La efectividad del tratamiento no difiere entre el grupo de pacientes con VPPB y el de VPPB subjetivo.

\section{VPPB EN EL ANCIANO [21, 22]}

\section{CARACTERÍSTICAS GENERALES}

EI VPPB es más frecuente en la edad avanzada (considerada como tal por la OMS a partir de los 60 años y de la que se calcula que en el 2030 corresponda al $20 \%$ de la población). Su prevalencia puede llegar a ser del $9 \%$ y su incidencia aumenta con la edad hasta el $10 \%$ a los 80 años.

Además de las causas examinadas en el VPPB, en la edad avanzada encontramos otros factores como la osteoporosis. La osteoporosis es más frecuente en mujeres $(2: 1)$ y difícil de evaluar de forma aislada (respecto a la edad avanzada) ya que las mujeres estudiadas son postmenopáusicas, lo que implica que son osteoporóticas en mayor o menor grado. Esto refleja la necesidad de estudios de metanálisis debido a la ausencia de ensayos controlados aleatorizados. Algunos trabajos, encuentran una incidencia de osteoporosis en pacientes con VPPB del $26,2 \%$ y una frecuencia del VPPB que se incrementa cuando las cifras de densidad mineral del hueso disminuyen. Pero no se ha encontrado relación entre la incidencia de VPPB y las cifras bajas de masa ósea por lo que no parece existir correspondencia entre el VPPB y la densidad ósea, considerándose exclusivamente un factor de riesgo en las recurrencias de VPPB, aunque sigue siendo un tema controvertido. Podemos concluir que el VPPB se puede relacionar con la osteoporosis y la osteopenia y que las preparaciones de calcio empleadas en el tratamiento de estos procesos, podrían servir como prevención del VPPB.

La explicación fisiopatológica del VPPB en el anciano no difiere del esquema utilizado para otros rangos de edad. La mayor frecuencia de traumatismos y alteraciones vasculares podrían también favorecer la liberación de otoconias a los canales, aunque esta afirmación no ha sido demostrada.

\section{DIAGNÓSTICO}

Los tipos de VPPB en el anciano no difieren de los de otras edades y tampoco existe una forma clínica más habitual. Por tanto los síntomas serán variables según el o los CS afectados. Esta afectación puede reducir la calidad de la vida, restringir las actividades diarias y aumentar el riesgo de caídas y fracturas.

Dada la frecuencia de VPPB del CSP, la prueba de Dix-Hallpike sigue siendo la base del diagnóstico, aunque ante la posible existencia de patología concomitante a nivel cervical, en ocasiones realizaremos la maniobra de Semont, si se presenta incapacidad de hiperextensión cervical.

\section{MANIOBRAS DE REPOSICIÓN}

La experiencia clínica y la bibliografía muestran la eficacia de las maniobras liberadoras (Semont) y de reposicionamiento (Epley, Lempert). Ambas tienen una eficacia comparable y provocan la desaparición de los síntomas en un $90 \%$ de los pacientes. El fallo de las mismas suele ser debido a una realización defectuosa. Esta dificultad técnica puede estar acentuada en ancianos tanto por polimedicaciones como por la dificultad de alcanzar las posiciones deseadas para la correcta ejecución de las maniobras debido a problemas osteomusculares principalmente a nivel cervical. En estos casos puede ser útil, si hay disponibilidad, de un sillón motorizado o simplemente mecánico de Richard-Vitton. De no resolverse los síntomas con los medios habituales, se indicarían los ejercicios de Brandt-Daroff.

\section{CALIDAD DE VIDA}

La disminución de la calidad de vida se asocia sobre todo a la recurrencia de la patología, que podría alcanzar a un $30 \%$ de los pacientes. El riesgo de recurrencia es mayor en el primer año después de la crisis y se mantiene elevado durante los dos primeros años. Recientes estudios sugieren que una mayor recurrencia de la patología podría estar ligada a distintas comorbilidades, al género femenino y al canal afectado, pero no a la edad. 


\section{SEGUIMIENTO Y RECURRENCIA DEL PACIENTE CON VPPB [3-10]}

A pesar de ser una patología benigna y, en ocasiones, de resolución espontánea (entre un $20 \%$ a $80 \%$ según la Guía Clínica Americana), hay un porcentaje de casos en los que el episodio vuelve a reproducirse.

La recurrencia es del $7 \%$ al $23 \%$ durante el primer año tras el tratamiento, sin embargo, a largo plazo y, dependiendo de la edad del paciente, las recurrencias aumentan hasta el $50 \%$ en 5 años.

Existen factores asociados a esta patología y otros, dependientes del individuo, que pueden influir en la recuperación y en la tasa de recidiva. Ejemplo de ello son los pacientes que han sufrido un traumatismo craneoencefálico o los que han acudido al dentista recientemente o han sido sometidos a cirugías faciales que requerían instrumental motorizado. Hay que tener en cuenta también a los pacientes (sobre todo de sexo femenino) con osteoporosis u osteopenia, dado que hay estudios que demuestran que, en ellos, la recurrencia del VPPB es mayor. La falta de actividad física parece ser un factor importante que repercute negativamente en esta entidad (sobre todo en los ancianos y las mujeres). Los trastornos del sueño también se han relacionado con la posibilidad de tener este tipo de vértigo. Las enfermedades de oído interno, incluyendo la neuritis vestibular, hipoacusia neurosensorial unilateral y enfermedad de Ménière, aumentan la tasa de recurrencia del VPPB.

La situación previa del paciente, la duración de los síntomas antes de efectuar el diagnóstico y la precisión del mismo pueden influir en la respuesta al tratamiento. Por otra parte, las restricciones posturales posteriores a la maniobra de reposicionamiento no contribuyen al éxito del tratamiento y no hay razón para someter a los pacientes a estas instrucciones.

Es necesario definir lo que consideramos un VPPB resuelto. Para evaluar la respuesta al tratamiento consultaremos al paciente sobre la desaparición de los síntomas y, además, efectuaremos una maniobra de provocación, siendo necesaria una maniobra negativa (entendiéndose: ausencia de nistagmo) para considerar al paciente curado.

Hay autores que prefieren preguntar directamente al paciente sobre su mejoría y no realizar rutinariamente la maniobra de provocación en la revisión; defienden que la ventaja de este método de evaluación es que no es necesaria una consulta con el paciente, sino que puede realizarse por teléfono o por correo, por lo que los costes para el sistema sanitario serían menores. Sin embargo, la maniobra ofrece un resultado objetivo. Además, puede ocurrir que la maniobra de provocación sea positiva y el paciente se encuentre asintomático, lo que se ha denominado VPPB subclínico.

En lo que a los síntomas se refiere, podemos encontrar una resolución completa, mejoría, ausencia de mejoría o empeoramiento. Es importante detallar si el restablecimiento es completo o se debe a la evitación consciente de ciertas posturas por parte del paciente.

Algunos autores han utilizado cuestionarios universales sobre calidad de vida para cuantificar la mejora subjetiva del paciente. En la práctica clínica consideramos que, con la anamnesis es suficiente.

En cuanto al tiempo que debe pasar desde que tratamos al paciente hasta la primera revisión, hay diferentes opiniones según los autores. Hay quienes recomiendan un plazo de 7-10 días y quienes consideran esperar 1 mes. Debemos tener en cuenta que, si espaciamos demasiado el seguimiento, podemos diagnosticar un VPPB persistente de forma errónea, ya que, puede ocurrir, que se haya resuelto el episodio tratado y estemos ante una recidiva.

Si la exploración sigue siendo positiva, debemos insistir en la realización de la maniobra de reposición correspondiente, tanto si el VPPB es del mismo canal como si es de otro canal.

Ante un VPPB que no se resuelve tras sucesivas maniobras hay que efectuar un estudio más profundo. Esto incluye la realización de una prueba calórica (va a estar afectada en torno al $25 \%$ de los enfermos y son los que más recurren), y unos VEMPs o vHIT si disponemos de ellos. Si se mantiene o es de características atípicas, sobre todo si se sospecha un origen central, se debe pedir una prueba de imagen (ver vértigo central).

Finalmente, y como hemos explicado, puede ser útil solicitar una analítica, pudiéndose encontrar depósitos bajos de ferritina o déficit de Vitamina $D$, que se han relacionado con la persistencia del VPPB.

Si se ha resuelto el VPPB y era el primer episodio que presentaba el enfermo se puede dar de alta. Deberemos revisarle en el plazo de 1 a 2 meses en el caso de que el VPPB sea recurrente, especialmente en el anciano. 
BIBLIOGRAFÍA

1. Asprella-Libonati G: Vértigo posicional paroxístico benigno. En: Carmona $\mathrm{S}$, Asprella G: Neuro-otología. Akadia. $3^{\text {a }}$ Ed. 2011. Cap 6; pp. 43-64.

2. Balatsouras DG, Koukoutsis G, Ganelis P, Korres GS, Kaberos A. Diagnosis of Singleor Multiple-Canal Benign Paroxysmal Positional Vertigo according to the Type of Nystagmus. Int J Otolaryngol. 2011;2011:483965.

3. Bhattacharyya N, Baugh RF, Orvidas L, Barrs D, Bronston LJ, Cass S, Chalian AA, Desmond AL, Earl JM, Fife TD, Fuller DC, Judge JO, Mann NR, Rosenfeld RM, Schuring LT, Steiner RW, Whitney SL, Haidari J; American Academy of Otolaryngology-Head and Neck Surgery Foundation. Clinical practice guideline: benign paroxysmal positional vertigo. Otolaryngol Head Neck Surg. 2008;139:S4781.

4. Dix MR, Hallpike CS. The pathology symptomatology and diagnosis of certain common disorders of the vestibular system. Proc R Soc Med. 1952;45:341-54.

5. Kim JS, Zee DS. Clinical practice. Benign paroxysmal positional vertigo. N Engl J Med. 2014; 370:1138-47.

6. López-Escámez JA. Abordaje práctico del vértigo posicional paroxístico benigno recurrente. Acta Otorrinolaringol Esp. 2008;59:413-9.

7. Nuti $D$, Masini $M$, Mandalà $M$. Benign paroxysmal positional vertigo and its variants. Handb Clin Neurol. 2016;137:241-56.

8. von Brevern M, Bertholon P, Brandt T, Fife T, Imai T, Nuti D, Newman-Toker D. Benign paroxysmal positional vertigo: Diagnostic criteria. Consensus document of the Committee for the Classification of Vestibular Disorders of the Bárány Society. J Vestib Res. 2015;25(3-4):105-17.

9. Bisdorff $A$, Von Brevern $M$, Lempert $T$, Newman-Toker DE. Classification of vestibular symptoms: Towards an international classification of vestibular disorders. Journal of Vestibular Research: 2009;19:1-13.
10. Fife TD, Iverson DJ, Lempert T, Furman JM, Baloh RW, Tusa RJ, et al. Practice parameter: therapies for benign paroxysmal positional vertigo (an evidence-based review): report of the Quality Standards Subcommittee of the American Academy of Neurology. Neurology. 2008;70:2067-74.

11. Baloh RW, Jacobson K, Honrubia V. Horizontal semicircular canal variant of benign positional vertigo. Neurology. 1993; 43:2542-9.

12. Nuti $D$, Vannucchi $P$, Pagnini P. Benign paroxysmal positional vertigo of the horizontal canal: a form of canalolitiasis with variable clinical features. J Vestib R 1996:6:173-84.

13. Casani A, Vannucchi G, Fattori B, Berrettini $\mathrm{S}$. The treatment of horizontal canal positional vertigo: our experience in 66 cases. Laryngoscope. 2002; 112:172-8.

14. Amor Dorado JC, Rubio Rodríguez JP, Costa Ribas C, Rossi Vargas J. Diagnóstico y tratamiento de un caso de vértigo posicional paroxístico benigno del canal horizontal. Acta Otorrinolaringol Esp 2003;54:527-30.

15. Lempert T, Tiel-Wilck K. A positional maneuver for treatment of horizontal-canal benign positional vertigo. Laryngoscope. 1996;106:476-8.

16. Ciniglio Appiani G, Catania G, Gagliardi M, Cuiuli $G$. Repositioning maneuver for the treatment of the apogeotropic variant of horizontal canal benign paroxysmal positional vertigo Otoneurotol 2005;26: 2576.

17. Yacovino DA, Hain TC, Gualtieri F. New therapeutic maneuver for anterior canal benign paroxismal positional vértigo. J Neurol. 2009;256:1851.

18. Soto-Varela A, Rossi-Izquierdo M, SanchezSellero I, Santos-Perez S. Revised criteria for suspicion of non-benign positional vértigo. $Q$ J Med. 2013;106:317-21.

19. Esteban-Sanchez J, Rueda-Marcos A, SanzFernández R, Martín-Sanz E. Nistagmo vertical inferior: ¿es obligada la resonancia magnética? Rev Neurol. 2016;62:107-12.

20. Jung JY, Kim SH. Comparison between objective and_subjective benign paroxysmal positional vertigo: clinical features and outcomes. Acta Otolaryngol. 2016;136:126772. 
21. Plodpai $\mathrm{Y}$, Atchariyasathian $\mathrm{V}$, Khaimook W. The characteristic differences of benign paroxysmal positional vertigo among the elderly and the younger patients: A 10-year retrospective review. J Med Assoc Thai. 2014;97:850-5.
22. Batuecas-Caletrio A, Trinidad-Ruiz G, Zschaeck C, Del Pozo de Dios J.C, De Toro Gil L., Martin-Sanchez V, MartinSanz E. Benign Paroxysmal Positional Vertigo in the Elderly. Gerontology. 2013;59:408-12. 